Portland State University

PDXScholar

\title{
Applying GPS and Accelerometers to the Study of African Savanna (Loxodonta africana) and Asian Elephant (Elephas maximus) Welfare in Zoos
}

Matthew Robert Holdgate

Portland State University

Follow this and additional works at: https://pdxscholar.library.pdx.edu/open_access_etds

Part of the Animal Sciences Commons

Let us know how access to this document benefits you.

\section{Recommended Citation}

Holdgate, Matthew Robert, "Applying GPS and Accelerometers to the Study of African Savanna (Loxodonta africana) and Asian Elephant (Elephas maximus) Welfare in Zoos" (2015). Dissertations and Theses. Paper 2234.

https://doi.org/10.15760/etd.2232

This Dissertation is brought to you for free and open access. It has been accepted for inclusion in Dissertations and Theses by an authorized administrator of PDXScholar. Please contact us if we can make this document more accessible: pdxscholar@pdx.edu. 
Applying GPS and Accelerometers to the Study of African Savanna (Loxodonta africana) and Asian Elephant (Elephas maximus) Welfare in Zoos

\author{
by \\ Matthew Robert Holdgate \\ A dissertation submitted in partial fulfillment of the \\ requirements for the degree of \\ Doctor of Philosophy \\ in \\ Biology
}

Dissertation Committee:

Deborah Duffield, Chair

David Shepherdson, Co-Chair

Deborah Lutterschmidt

Randy Zelick

Jiunn-Der Duh

Portland State University

2015 
(C) 2015 Matthew Robert Holdgate 


\begin{abstract}
African savanna elephants (Loxodonta africana) and Asian elephants (Elephas maximus) are a focus of welfare research in zoos due to their high intelligence, complex social structure, and sheer size. Due to these challenges, some argue that zoos are inherently incapable of providing appropriate care for elephants, while others believe that zoos can fulfill the needs of these species with improved husbandry. There is a general consensus from both within and outside of zoos, however, that zoos must improve their elephant programs or cease exhibiting these animals altogether. Now more than ever, applied research on zoo elephant welfare is needed to provide context for this debate.

Researchers are interested in how far zoo elephants walk due to the potential health and welfare benefits of walking in these highly mobile species. Zoo researchers recently adopted GPS technology to study elephant walking, and preliminary evidence suggests that African elephants in large zoo exhibits walk distances that correspond with wild elephants under non-extreme conditions. However, data are limited from Asian elephants and from elephants in more typically-sized exhibits. In Chapter Two, I discuss important methodological considerations of utilizing GPS in a zoo environment, including an introduction to the technology, sources of error and mitigation, methods to improve GPS performance, and possible effects of GPS device attachment on animal behavior. This review shows GPS performance is adequate for tracking zoo elephant walking when proper methodological techniques are applied, and should serve as a useful reference for zoo researchers considering using GPS.
\end{abstract}


In Chapter Three, I used GPS anklets to measure outdoor daily walking distance in 56 adult female African $(n=33)$ and Asian $(n=23)$ elephants housed in 30 zoos. I collected 259 days of data and found that elephants walked an average of $5.34 \mathrm{~km} /$ day with no significant difference between species. Multivariate regression models predicted that elephants with more dynamic feeding regimens (more diverse feeding types and frequencies; unscheduled feeding times) will walk more. Distance walked was also predicted to be higher in elephants that spend time in a greater number of different social groups. Distance walked was predicted to decline with age. Finally, I found a significant negative correlation between distance walked and nighttime space experience. The results of the analysis suggest that zoos that want to increase walking in their elephants need not rely solely on larger exhibits, but can increase walking by adding quality and complexity to exhibits. However, my results failed to establish a definitive link between walking distance and other validated measures of elephant welfare. Thus, the direct health and welfare benefits of walking in zoo elephants remain unresolved.

Resting behaviors are an essential component of animal welfare, but have received little attention in zoological research. In Chapter Four, I used accelerometers in anklets to complete the first large-scale multi-species investigation of zoo elephant recumbence. I collected 344 days of data from 72 adult female African $(n=44)$ and Asian $(n=28)$ elephants at 40 zoos. I found that African elephants are recumbent an average of 2.14 hours/day, which is significantly less than Asian elephants at 3.22 hours/day. Multivariate regression models predicted that African elephant recumbence increases when they experience more space at night, and Asian elephant recumbence increases when they spend time housed alone. Both species showed a similar response to 
substrate, such that African elephants spending time on all-hard substrates are predicted to be recumbent less, while Asian elephants spending time on all-soft substrates are predicted to be recumbent more. The discovery that occasional non-recumbence is a common behavior in zoo elephants also introduces a new area of research that may have important animal welfare consequences. Finally, this study established that zoos should continue their efforts to replace hard substrate with soft substrate in order to provide zoo elephants with environments that facilitate recumbence.

Overall, this work assessed walking and recumbence in zoo elephants, which will allow zoos to gauge the prevalence of these behaviors in their elephants as compared to the sub-population studied here. A variety of factors that are associated with these behaviors were also identified. With this information, zoos can prioritize modifications to their facilities and animal management programs to create an environment that encourages zoo elephants to express walking and recumbence behavior, should they choose to do so.

This work is one component of the Elephant Welfare Project, the largest zoo animal welfare project ever undertaken, and is unprecedented in both scope and scale. The project was funded by the Institute of Museum and Library Services (IMLS), an independent, U.S., federal, grant-making agency that supports libraries, museums, and zoos. At the time of this writing, the first manuscripts from this project are being submitted to academic journals. These papers will describe the prevalence and distribution of a variety of elephant behaviors and welfare indicators, serve as a benchmark for future elephant welfare studies, and aid in decision making with regard to best practices in elephant management. 
DEDICATION

For Molly. 


\section{ACKNOWLEDGMENTS}

Sincere thanks are due to the people - and elephants - at the participating zoos. It is worth noting that each of the 49 zoos listed below invested staff time and resources to a project managed by an unknown graduate student; this is truly a testament to their commitment to elephant welfare. Thank you: Africam Safari, Audubon Institute, BREC'S Baton Rouge Zoo, Buffalo Zoological Gardens, Buttonwood Park Zoo, Caldwell Zoo, Calgary Zoo, Cameron Park Zoo, Cheyenne Mountain Zoological Park, Cleveland Metroparks Zoo, Dallas Zoo, Denver Zoo, Dickerson Park Zoo, Disney's Animal Kingdom, El Paso Zoo, Fresno Chaffee Zoo, Honolulu Zoo, Houston Zoological Gardens, Indianapolis Zoological Society, Inc., Knoxville Zoological Gardens, Lee Richardson Zoo, Little Rock Zoological Gardens, Los Angeles Zoo and Botanical Gardens, Lowry Park Zoological Garden, Maryland Zoo, Nashville Zoo, North Carolina Zoological Park, Oakland Zoo, Oklahoma City Zoological Park, Oregon Zoo, Phoenix Zoo, Reid Park Zoo, Riverbanks Zoological Park, Roger Williams Park Zoo, Rosamond Gifford Zoo at Burnet Park, San Antonio Zoological Gardens \& Aquarium, San Diego Safari Park, Santa Barbara Zoological Gardens, Sedgwick County Zoo, Seneca Park Zoo, The Kansas City Zoo, Toledo Zoo, Tulsa Zoological Park, Utah's Hogle Zoo, Virginia Zoo, Wildlife Conservation Society - Bronx Zoo, Zoo Atlanta, Zoo de Granby, and Zoo Miami.

This project would not have happened without Kathy Carlstead, whose dogged pursuit of funding from the IMLS led to the largest zoo animal welfare study ever conducted. For that, Kathy, we are all in your debt. Thanks also to the other Elephant 
Welfare Project principal investigators: Anne Baker, Janine Brown, Candice Dorsey, Mike Keele, Jill Mellen, Joy Mench, David Shepherdson, and Nadja Wielebnowski. Additional collaborators who helped develop the project proposal include Jeff Rushen, Anne Marie de Passillé, Georgia Mason, Lance Miller, Jeff Andrews, Michele Miller, Joseph Soltis, Katherine Leighty, Christy Alligood, Harry Peachy, John Lehnhardt, Karen Lewis, Beth Stark-Posta, Deborah Colbert, Kari Morfeld, and Jeff Bolling. Partners on the IMLS grant included the Honolulu Zoo, Oregon Zoo, Toledo Zoo, Chicago Zoological Society, Smithsonian's National Zoo, Association of Zoos and Aquariums, and the Center for Animal Welfare at the University of California Davis. Jean-Philippe Parent, now Ph.D. candidate at Université de Montréal, provided advice and expertise in accelerometer use.

In addition to the funding provided by the IMLS, I received support from the Pittsburgh Zoo Conservation Fund Grant, the PSU Marie Brown Award and the PSU Student Education Travel Grant. Funding was also provided by the Forbes-Lea Research Grant, with special thanks to contributors and alums Marcia Schulmerich and John Salmon, who I knew would unfailingly ask for an update on my progress during our annual visits.

Cheryl Meehan of the AWARE Institute was my sword and my shield during project disputes; a fiercely loyal friend and mentor whose candid opinions on all things zoos and elephants are forever appreciated. Brian Greco and Jen Hogan received an unfair number of emails from me, and I thank them profusely for contributing so much to my research when I had so little to give in return. Kari Morfeld completed our dream 
team of young zoo professionals and was a source of joy during otherwise taxing work sessions.

At the Oregon Zoo, thanks are due to Grant Spickelmier for mercifully involving me on projects that did not involve elephants - until we began developing the Elephant Lands iPhone app and the infamous elphy-selphy feature. Thanks also to Kayla McCurry for her steadfast encouragement and Kathayoon Khalil for accepting my dissertationcompleting challenge which I completely, hilariously, lost. Debbie Ethell deserves my thanks for her years of service as research intern, but also for her stories after trips to Africa, her insatiable curiosity, and her tireless advocacy for elephants - both zoo and wild.

At Portland State University I will join others before me in thanking Roxanne Treece and the PSU Office of Graduate Studies for their proactive stewardship of the deadlines and paperwork that make these things happen. Meghan Martin, Catherine Dayger, and Kessina Lee have taught me about friendship and dissecting cadavers, and I hope to use one of those lessons in the future.

I came to Portland specifically to work under the tutelage of David Shepherdson, and he is owed many thanks for making his daunting breadth of knowledge available to me; any remaining gaps in my understanding of zoo animal welfare are my own. Deborah Duffield is the most devoted of advisors and has earned my thanks for opening up her lab to me: the improvements in zoo elephant welfare from this dissertation belong in part to you. Thank you to Deborah Lutterschmidt for being unfailingly on the side of the graduate students, Randy Zelick for teaching me to consider the sensorial world of 
zoo animals, and Jiunn-Der Duh for the improvements in my dissertation that came from his expertise.

Finally, thank you to my mother and father, and to Gina Tarbill for reminding me that animal welfare is, above all, about individual and unique living beings - each elephant, bear and badger. 
TABLE OF CONTENTS

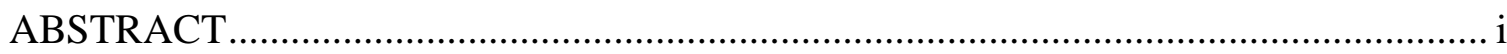

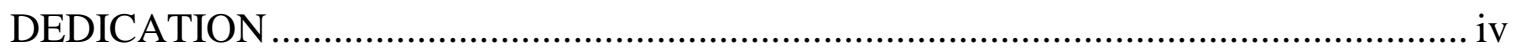

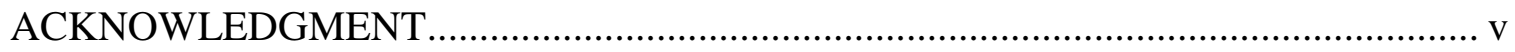

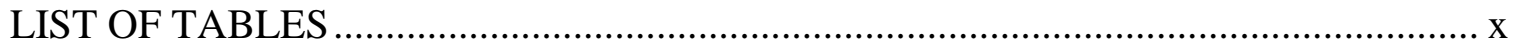

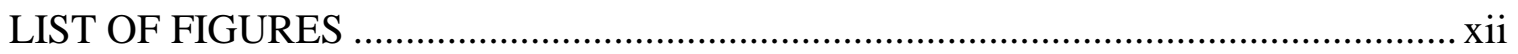

\section{CHAPTER ONE}

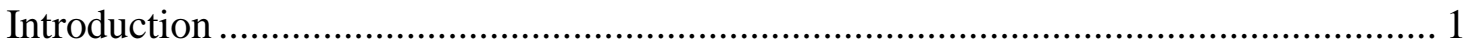

\section{CHAPTER TWO}

Measuring zoo animal location and movement with GPS: methodological concerns.. 15

\section{CHAPTER THREE}

Using GPS to determine factors affecting walking rate in African savanna elephants

(Loxodonta africana) and Asian elephants (Elephas maximus) in zoos ....................... 52

\section{CHAPTER FOUR}

Using accelerometers to determine factors affecting walking rate in African savanna elephants (Loxodonta africana) and Asian elephants (Elephas maximus) in zoos ....... 78

\section{CHAPTER FIVE}

Conclusions

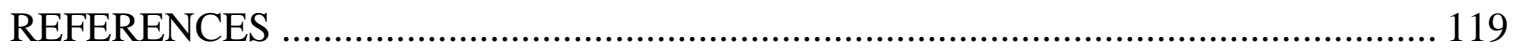




\section{LIST OF TABLES}

Table 2.1 Mean Daily Walking Distance $(\mathrm{km})$ of five randomly selected elephants from

the Elephant Welfare Project. 33

Table 2.2 Frequency and distribution of GPS fixes collected and screened during the Elephant Welfare Project.

Table 3.1: Definitions of independent variables tested for correlation with distance walked.

Table 3.2: Summary of walking data for African and Asian zoo elephants. 63

Table 3.3: Univariate correlations between mean daily walking distance and independent variables 65

Table 3.4: Independent variables that had a significant univariate correlation with mean daily walking distance.

Table 3.5: Mean daily walking distance multivariate model. 70

Table 4.1: Definitions of independent variables tested for correlation with recumbence. 85

Table 4.2: Summary of recumbence data for African and Asian zoo elephants. 89

Table 4.3: Univariate correlations between mean daily recumbence and independent variables in African zoo elephants. 93

Table 4.4: Univariate correlations between mean daily recumbence and independent variables in Asian zoo elephants.

Table 4.5: Independent variables that had a significant univariate correlation with recumbence in African and Asian zoo elephants 
Table 4.6: African zoo elephant multivariate mean daily recumbence model.

99

Table 4.7: Asian zoo elephant multivariate mean daily recumbence model. ................ 100 


\section{LIST OF FIGURES}

Figure 2.1 The basics of GPS positioning via trilateration using measured distances from

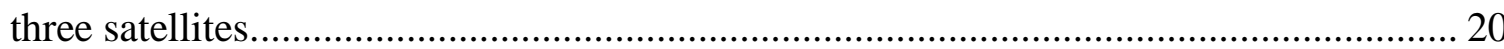

Figure 2.2 The multipath effect is the result of satellite signals reaching the receiver via more than one path.

Figure 2.3 A simplified depiction of location accuracy with a few satellites and many

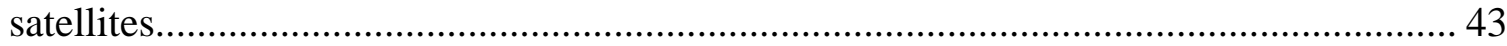

Figure 2.4 A simplified depiction of location accuracy with low DOP and high DOP.... 45

Figure 3.1: Asian zoo elephant wearing an anklet. 57

Figure 3.2: Mean daily walking distance in African and Asian zoo elephants. 62

Figure 4.1: Recumbent Asian zoo elephant wearing an anklet. 82

Figure 4.2: Recumbence in African and Asian zoo elephants.

Figure 4.3: Standing and recumbence patterns of representative African and Asian zoo elephants.

Figure 4.4: Recumbence profile showing daily distributions of recumbence in zoo elephants.

Figure 4.5: Recumbence of elephants in two categories based on their exposure to allhard and all-soft substrate. 
Chapter One: Introduction

\section{$\underline{\text { I: Defining animal welfare }}$}

Animal welfare has been defined as “the animal's state of being well or 'faring' well” (Broom \& Johnson, 1993) and includes both physical and psychological components; some definitions include emotion as well (AZA, 2014; Kagan \& Veasey, 2010). Coming to a more precise definition is challenging, but the one essential component of animal welfare is that it is a subjective state experienced by an individual. In other words, while the concepts and philosophies of animal welfare may change, the welfare of an individual stays the same. Hosey et al. (2013) sum things up well when they say "animal welfare is the subjective state of an animal, which is independent of us and our societal views about welfare."

Of course, the exact definition of animal welfare is likely to continue evolving with changes in society and advancements in science. For example, the Animal Welfare Committee of the Association of Zoos and Aquariums (AZA) has rewritten its definition of animal welfare in the last few years from one that emphasizes "(coping) with challenges in its environment" to one that focuses on "an animal's collective physical, mental, and emotional states" (AZA, 2014). How welfare is defined does not change the subjective experience of an animal, but it may help guide zoo researchers towards a more holistic approach to animal welfare research.

One of the earliest and most pivotal scientific approaches to animal welfare was the five freedoms. The five freedoms encompass the basic needs of animals, and were proposed as the minimum set of requirements necessary to attain an adequate level of 
welfare (Hosey et al., 2013). The five freedoms can be briefly described as freedom from hunger or thirst; freedom from discomfort; freedom from pain, injury or disease; freedom to express normal behaviors; and freedom from fear and distress (FAWC, 1992). This general concept was a good starting point, but researchers have since pointed out that these minimum requirements may cause a lack of incentive to push beyond these standards; more important is the idea that good welfare is not merely freedom from negative experiences, but the presence of positive experiences such as pleasure (Boissy et al., 2007; Hosey et al., 2013; Yeates \& Main, 2008). With that understanding, concepts of animal welfare are now much more complex, and researchers are making efforts to identify, validate, and refine both negative and positive measures of animal welfare that include both physical and psychological states.

As a subjective state, animal welfare can be inferred but not directly measured, and so indicators of welfare must be measured as a proxy (Mason \& Veasey, 2010). Though a number of potential welfare indicators exist, selecting a technique for measuring these indicators is a daunting task (Maple \& Perdue, 2013). Behaviors can be difficult to read or quantify, physiology can be affected by handling or sampling stress, and interpretation without anthropomorphism may pose the greatest challenge of all (Mason \& Veasey, 2010). However, researchers continue to seek out "gold standard" welfare indicators (Carlstead et al., 2013); these should be validated, evaluated for strengths and weaknesses, well-suited for the specific research question, and, when possible, used in conjunction with other welfare measures, as no single measure is perfect (Mason \& Veasey, 2010). 
The identification and refinement of appropriate animal welfare measures is a critical aspect for ensuring acceptable welfare standards in zoos (Maple \& Perdue, 2013). For now, zoos have relatively few established indicators of welfare, but researchers continue to propose and investigate new possibilities. This is especially true in species that are susceptible to poor welfare in captivity, such as African and Asian elephants (Carlstead et al., 2014; Mason \& Veasey, 2010).

\section{Indicators of zoo elephant welfare}

Promoting good welfare in African savanna elephants (Loxodonta africana, the species of African elephant found in North American zoos, hereafter referred to as "African elephants") and Asian elephants (Elephas maximus) in zoos is particularly challenging due to their high intelligence, specialized dietary requirements, complex social structures, mobile nature, and sheer size. Zoo professionals have maintained that zoos can fulfill the needs of these species by improving husbandry capabilities (Hutchins, 2003), while others have argued that zoos are inherently incapable of providing appropriate care for elephants (Hutchins, 2006; Stroud, 2007). There is a general consensus, however, that zoos must improve their elephant programs or cease exhibiting these animals altogether (Hancocks, 2008; Hutchins, 2006). Applied research on zoo elephant welfare is necessary to provide context for this discussion.

One of the best validated and most used welfare indicators is stereotypical behavior (Mason \& Veasey, 2010). Stereotypies are "unvarying and repetitive behaviors with no apparent goal or function” (Mason \& Veasey 2010). Research into stereotypy has been driven in part by its prevalence in a number of mammalian species (Swaisgood 
\& Shepherdson, 2005), including elephants. Clubb and Mason (2002) estimated that approximately $40 \%$ of zoo elephants exhibit stereotypies, while Harris et al. (2008) found that almost $25 \%$ of African and $50 \%$ of Asian elephants showed stereotypies during the daytime. Asian elephants also stereotyped for almost three times as long as African elephants. Despite recent findings on the possible causes of stereotypies, abolishing these behaviors in zoos remains a difficult task (Mason et al., 2007). For example, these behaviors may reflect historical welfare challenges (i.e., they represent a welfare "scar"), so stereotypies may not be an accurate reflection of current welfare (Mason, 1991). In addition, stereotypical behaviors may help animals cope with sub-optimal environments by providing beneficial sensorial feedback akin to that provided by natural behavior patterns; alternately, the rhythmicity of stereotypies may be calming in some way (Mason et al., 2007). Thus, it is theoretically possible that in some cases, the welfare of animals performing stereotypies is better than those that do not (Swaisgood \& Shepherdson, 2005). Fortunately, our understanding of the potential underlying motivations and neurological causes of stereotypy continues to expand (Mason \& Rushen, 2006), and in the meantime, environmental enrichment has been shown to at least partially reduce its occurrence (Swaisgood \& Shepherdson, 2005).

Zoo elephants are particularly prone to foot and joint (musculoskeletal) problems, including arthritis, cracks, and fissures (Clubb \& Mason, 2002); abscesses (Roocroft \& Oosterhuis, 2001); degenerative joint disease (Hittmair \& Vielgrader, 2000); and osteomyelitis (Gage, 2001). Foot-related conditions and arthritis are reportedly the primary cause of euthanasia in captive elephants in the United States (West, 2001), and in response, zoos have organized conferences and books devoted to the topic (Csuti et al., 
2001). A number of studies have evaluated foot and joint problems in zoo elephants. Lewis et al. (2010) found that $33 \%$ of zoos had at least one foot pathology, while Harris et al. (2008) found nearly $20 \%$ of elephants in the U.K. have major problems on their forefeet, and $8 \%$ on their hind feet. In addition, $23 \%$ had an obvious limp or were severely lame. Factors predisposing zoo elephants to foot and joint problems include a lack of exercise, excess weight, improper or unhygienic substrates, climate, stress leading to infection, physically taxing trained behaviors, and stereotypies (Clubb \& Mason, 2002; Clubb \& Mason, 2003; Fowler, 2001).

One factor that may predispose elephants to foot and joint problems is obesity (Veasey, 2006). Body condition in zoo elephants is a major concern and poor body condition is likely the result of a combination of a lack of exercise, overfeeding, and qualitatively inadequate diets (Clubb \& Mason, 2002; Hatt \& Clauss, 2006). Harris et al. (2008) found that $75 \%$ of elephants in the U.K. are categorized as "overweight" or "very overweight." In a recent study, Morfeld et al. (2014a) validated a visual body condition score index for female African elephants using ultrasound measures of subcutaneous fat. When applied to 50 zoo elephants and 57 wild elephants, they found that on a scale of one (thinnest) to five (fattest), wild elephants had a median score of three, while zoos had a median score of four. Perhaps more disconcerting, only $4 \%$ of wild elephants were obese, compared to $40 \%$ of zoo elephants. Finally, obesity may predispose zoo elephants to uterine (Hatt \& Clauss, 2006) or ovarian tumors (Clubb \& Mason, 2002) and ovarian acyclicity (Morfeld \& Brown, 2014).

Zoo elephant populations are said to be in serious demographic peril due, in part, to low conception rates (Hutchins \& Keele, 2006). Much of the research in this area has 
focused on irregular ovarian cycles or ovarian acyclicity (lack of an ovarian cycle in female elephants of reproductive age) (Brown et al., 2004a, 2004b; Dow \& Brown, 2012; Freeman et al., 2004; Freeman et al., 2009; Morfeld et al., 2014a; Morfeld et al., 2014b; Morfeld \& Brown, 2014; Schulte et al., 2000). Historically, studies have had difficulty identifying the causes of acylicity (e.g., Brown et al., 2004a), but some recent evidence suggests that noncycling in African elephants is associated with high body condition scores (overweight or obese elephants) (Morfeld \& Brown, 2014) and hyperprolactinaemia (high circulating prolactin concentrations) (Dow \& Brown, 2012). Prolactin is a hormone secreted by the pituitary gland that is involved in a number of biological processes, and is linked to infertility in humans (Jones, 1989). However, the results of endocrine analyses are sometimes difficult to interpret; for example, in African zoo elephants, some acyclic females have shown prolactin concentrations that are significantly higher than normal, some have shown levels significantly lower than normal, and in general, prolactin secretion patterns are temporally altered in acyclic zoo elephants (Dow \& Brown, 2012). Unfortunately, rates of acylicity have remained frustratingly steady in recent years; worse, rates of irregular cycling continue to rise (Brown et al., 2004; Dow et al., 2011; Proctor et al., 2010).

Glucocorticoid outputs are considered to be one of the best validated and most widely applied measures of welfare, along with stereotypies (Mason \& Veasey, 2006). Briefly, glucocorticoids are a type of hormone secreted by the adrenal gland in response to a stressor (Nelson, 2005). In elephants, cortisol is the primary glucocorticoid of interest, and cortisol or its metabolites can be measured using saliva, feces, urine, and, potentially, hair (Mason \& Veasey, 2006). Fecal samples in particular can be obtained 
relatively noninvasively, and studies of wild African elephants recorded elevations in cortisol metabolites in relation to presumed stressful circumstances. Foley et al. (2001) reported that metabolite concentrations were correlated with dominance in the largest herd (of three being monitored), such that concentrations in the most subordinate individuals were almost double those in the highest ranking individuals. Anthropogenic effects may also be stressful for wild African elephants, as cortisol metabolites increased in the feces of elephants after the translocation of a family group (Viljoen et al., 2008) and after (legal) hunting events - both in bulls present at the hunt, and bulls and breeding herds distributed throughout the park (Burke et al., 2008). Despite these findings, careful interpretation is required when glucocorticoid outputs are used to determine if an animal is suffering a stress-related decrease in welfare. For example, chronic stress can in some cases lead to decreased renal activity (false negative), while a positive stressor (e.g., excitement or exertion) can also elevate glucocorticoid levels (false positive).

In addition to the fairly well-established elephant welfare measures, researchers have proposed dozens more for further investigation (Mason \& Veasey, 2006). Candidates that have already been validated to some extent include vocal and postural signals, measures of preference-avoidance, and cardiovascular disease. Non-validated (in zoos) indicators include male infertility, fear-stress pheromone release, and measures of heart rate, pupil dilation, and blood pressure. The distances elephants walk has also been proposed as a biologically meaningful metric (Chapter Three; Hutchins, 2006), and resting behaviors are essential for the good health and welfare of animals (Chapter Four; Botreau et al., 2007; Broom \& Fraser, 2007). 


\section{Multi-institutional studies of zoo elephant welfare}

The earliest comprehensive zoo elephant welfare study was a review of European zoo elephant welfare (Clubb \& Mason, 2002). The report compiled published literature, secondary source materials, and interviews, and concluded that elephants generally experience poor welfare due primarily to stress and/or poor physical health. The authors also identified several potential causes of diminished welfare; these can be grouped generally into the categories of space, confinement (including inappropriate substrate), social factors (including early weaning), diet, and climate. In addition, the authors call attention to a general lack of opportunity to perform natural behaviors, and some risks associated with free contact management. However, the authors of this study were unable to look for statistical correlations between these risk factors and welfare issues due to a lack of access to zoo facility data. Despite this limitation, their review was a sobering call-to-action for many zoos and animal welfare advocates, prompting follow-up studies.

Multi-institutional data on zoo elephant welfare was collected in a 1997 survey of elephant foot condition and care that included 54 responding North American zoos found that $91 \%$ had elephant barns with concrete floors, and $67 \%$ considered it a low priority to change the indoor flooring substrate (Dimeo-Ediger, 2001). This is a surprising result, as medical evidence already existed for the overwhelming prevalence of foot problems in captive elephants in North America (Mikota et al., 1994), as acknowledged in the same volume in which the survey results were published (Csuti et al., 2001). In 2006, a similar survey was sent to all 80 AZA facilities exhibiting elephants, and received 78 responses (Lewis et al., 2010). Although the results were not directly comparable to the earlier 
study, the Lewis et al. survey shows a clear trend towards more natural substrate use, despite the fact that concrete continues to be the largest single flooring type inside barns. In addition to facility characteristics, Lewis et al. collected data on husbandry and foot health attributes, and found that $33 \%$ of zoos had at least one foot pathology in the previous year; pathologies included onychitis (infected nails), perionychia (lesion/sore between the nails), penetrating erosions, and sloughed pads (complete separation of the sole of the foot). The authors also found that zoos with younger herds that were provided more exercise were significantly less likely to encounter foot pathologies. More specifically, when holding herd age constant, the odds of a zoo experiencing foot pathology in their elephants decrease by $37 \%$ for each additional $10 \mathrm{~min}$ of exercise provided per day.

Another comprehensive study combined survey information with physiological and behavioral data collected from all 77 elephants in the United Kingdom's 13 elephantholding zoos (Harris et al., 2008). The elephants showed a high prevalence of foot pathology, stereotypy, poor body condition score, and abnormal gait. However, some evidence indicates that elephants with more outdoor space may have improved gait and reduced stereotypy. The small sample size and statistical methods used in this study limited analyses; a number of potentially confounding variables could not be discounted and the relative contribution of different risk factors to welfare outcomes could not be assessed.

A few other studies with large sample sizes have taken a more focused approach to elucidate the causes and effects of specific health and welfare factors (e.g., reproductive health [Dow et al., 2011], fecundity [Clubb et al., 2009], and mortality 
[Clubb et al., 2008] or more deeply explore specific environmental variables (e.g., flooring [Haspeslagh et al., 2013]). Overall, these larger studies of zoo elephant welfare provided additional insight and helped researchers improve data collection and analysis techniques. However, attempting to draw sweeping conclusions from individual studies on sub-populations of elephants was difficult, as subjects, sample sizes, and data collection periods varied over time, and different outcomes were measured using a wide range of methodologies that were unique to each project. Thus, there existed a desire for a comprehensive study characterizing a full suite of welfare indicators in a large population of zoo elephants.

\section{The Elephant Welfare Project}

In response to the notable lack of integrated elephant welfare data, especially in North American zoos, a group of researchers from AZA-accredited zoos applied for, and was awarded, a grant from the Institute of Museum and Library Services (IMLS) to fund their project entitled "Using Science to Understand Zoo Elephant Welfare" (Elephant Welfare Project for brevity). This project is the largest scale animal welfare study ever undertaken by the zoo community and is unprecedented in both size and scope. Of the 73 accredited elephant-holding zoos in North America, 72 committed to the study; these zoos collectively care for 166 African and 125 Asian elephants. My research on the use of Geographic Positioning System (GPS) in zoos (Chapter Two), daily walking distances in zoo elephants (Chapter Three), and recumbent rest behavior in zoo elephants (Chapter Four) is one component of the Elephant Welfare Project. We gathered a wide range of zoo-level and elephant-level data from all participating zoos in four categories: 
management, social, housing, and demographics. In some cases, researchers developed novel variables that better reflect the perspective and experience of zoo elephants, capturing the complexity and variability within the zoo population. For example, shorthand discussions of zoo exhibits commonly refer to the exhibit size as the area (e.g., $\mathrm{ft}^{2}$ or $\mathrm{ft}^{3}$ ) accessible and utilizable by a zoo animal, yet this approach may not accurately reflect the experience of some species. Zoo elephants rarely remain within a single enclosure throughout a 24-hour period, but instead are shifted between different yards, viewing areas, and stalls, which can themselves be combined or split apart to form an increasingly complex number of possible spaces that elephants inhabit for varying amounts of time. Thus, the Elephant Welfare Project included a new space variable proposed for use in animal welfare research: space experience, which considers the area the elephant occupies as a function of time. Similarly, zoo elephants have complex social arrangements that require additional considerations of how researchers can best measure the sociality from an elephant-centric point of view. Herd size, the total number of elephants at the zoo, could easily be presumed to be the most informative number to measure the social opportunities for an individual zoo elephant. However, some zoo elephants never share physical space with some other members of the herd (Meehan et al., 2015). Complicating matters further, these elephants may still be in tactile, visual, olfactory, and acoustic communication with other elephants at the zoo, so the inability to share the same physical space may only seem isolating from an anthropomorphic viewpoint. Because of this complexity, the Elephant Welfare Project includes a variety of social variables, including herd size, animal contact (maximum number of unique elephants focal animal is in contact with), social group contact (maximum number of 
unique social groups focal animal is part of), and social experience, a variable similar to space experience, which takes into account both the number of elephants a focal animal shares space with, and the time spent in that social group (for a more detailed review, see Meehan et al., 2015). We also collected data on a wide range of welfare outcomes to investigate associations with management, social, housing, and demographic variables. Seven outcomes thought to be associated with welfare were available for the first round of study and analysis: foot health, musculoskeletal health, stereotypy, body condition score, ovarian cyclicity, distance walked (Chapter Three) and recumbence rest (Chapter Four).

\section{$\underline{\text { V. Dissertation organization }}$}

The two themes of this dissertation are, broadly, GPS technology as applied to tracking zoo animals - including techniques zoo researchers can use to minimize error and bias in their studies; and walking and recumbence in zoo elephants, two behaviors of which we have little baseline knowledge and an incomplete understanding of what they may indicate about animal welfare.

In Chapter Two, I will review the methodological constraints of using GPS in animal research applications, beginning with a brief history of wild, farm, and zoo animal tracking. Next, I will discuss the overall operation of GPS, including sources of error and mitigation, to provide some context for the challenges associated with these methodologies. Researchers can overcome GPS limitations in many cases by applying specific data processing and screening techniques; some of these I will discuss using GPS data from the Elephant Welfare Project as a case study. 
In Chapter Three, I aimed to 1) quantify and describe distance walked in zoo elephants using GPS anklets, 2) determine the potential effects of a variety of housing, social, management, and demographic factors on distance walked, and 3) test for associations between distance walked and two accepted welfare metrics: foot health and joint health. Elephants are highly mobile species, although their motivations for traveling are not always clear; walking may primarily be used to access the sometimes widely distributed resources they require, or, it may be expressed as part of their need or desire to explore and gather information about their environment. In zoos, resources are more readily accessible and their spatial environment is reduced, which may lead to elephants walking less. This lack of exercise could have health and welfare consequences for zoo elephants, although no studies have looked for direct associations between walking and welfare in zoo elephants. This study will provide the first multi-institutional dataset on zoo elephant walking, and will identify the factors in the zoo environment that are most strongly associated with walking. I will also make a first attempt at establishing a correlation between walking and established welfare measures.

In Chapter Four, I aimed to1) quantify and describe zoo elephant recumbence to better understand its timing, patterns, and prevalence, and 2) determine the potential effects of a variety of social, housing, management, and demographic factors on recumbence. Recumbence is a natural resting posture exhibited by elephants in the wild and in captivity. Studies in cattle have shown these animals are highly motivated to lie down, and limiting their opportunities to do so is associated with a deleterious health and welfare effects, including stress, lameness, and hoof problems, among others. Additionally, species that naturally exhibit recumbent rest may suffer from sleep 
disturbance of deprivation if they are unable to adequately attain or remain in this posture; this can cause a host of disruptions in vital biological processes. Again, no multi-institutional studies have examined this behavior Chapter Five discusses the general conclusion and implications of my research, some of the challenges associated with studying zoo animal welfare indicators, and areas for possible future work. 
Chapter Two: Measuring zoo animal location and movement with GPS: methodological concerns

\section{GPS applications in biological studies: a brief history}

The advent of the global positioning system (GPS) provided a major advance in spatiotemporal data acquisition for animal tracking. Biologists first used GPS to track wild animals in 1993 (Rodgers, 2001); early research used bulky collars on large terrestrial animals, including moose (Alces alces) (Moen et al., 1996; Moen et al., 1997; Rempel et al., 1995; Rodgers \& Anson, 1994) deer (Cervus and Odocoileu spp.) (Blanc \& Brelurut 1997; Bowman et al., 2000; Merrill et al., 1998), wolves (Canis lupus) (Merrill et al., 1998), and elephants (Loxodonta spp.) (Blake et al., 2001; DouglasHamilton, 1998). At first, researchers focused on validating GPS as a research tool in different habitats (Edenius, 1997; Merrill et al., 1998; Moen et al., 1997) and experimenting with data processing techniques (Dussault et al., 2001). As GPS technology advanced and researchers became more familiar with the technology, they began answering specific questions using spatiotemporal data. For example, researchers used GPS to identify optimal locations for wildlife corridors across highways to minimize risk to cougars (Puma concolor) (Maletzke et al., 2005). GPS tracking showed that Bewick's swans (Cygnus columbianus bewickii) with low-pathogenic flu infections had altered migratory patterns, suggesting that more virulent strains (e.g., H5N1) could have serious impacts on bird health and ecology (van Gils et al., 2007). GPS has also been used in marine applications, including a study of loggerhead sea turtles (Caretta caretta) that showed they have complex pre-nesting habitat preferences, and protected areas 
should not focus only on the location of the nesting beach as has historically occurred (Schofield et al., 2007).

Livestock researchers also took early advantage of GPS technology (Hulbert et al., 1998; Rutter et al., 1997; Turner et al., 2000). In one study, researchers tested whether the relocation of salt or water sources would more effectively shift cattle distribution to prevent overgrazing in large ranges (Ganskopp, 2001). When water sources were moved, GPS collared cattle would shift their location and remain near water, however, manipulation of salting stations only temporarily affected cattle distribution. More recently, livestock researchers have created "virtual fences" by which cattle wearing GPS collars are trained to remain within a virtual boundary via an audio cue (conditioned using a mild electric shock) (Lee et al., 2009). These fences allow livestock managers to optimize the "nutritional landscape" by moving cattle across the range in a spatially and temporally efficient manner (Anderson, 2007).

The first applications of GPS within zoos were conducted by wildlife biologists using zoo animals as a proxy for wild animals to validate their methodologies. In a 2006 study, six captive-bred Oriental Pied Hornbills (Anthracoceros albirostris) in a zoo were outfitted with GPS receivers. After five months of behavioral observations, researchers concluded that the behavior of the GPS-outfitted individuals was not significantly different than individuals not wearing GPS equipment (Chaiyarat et al., 2012). The study animals were then released into the wild and their GPS data were used to estimate home range sizes to better design conservation areas. In a second study, researchers outfitted red deer (Cervus elaphus) in a zoo with different GPS devices to compare their 
performance; they also tested whether deer movement or collar orientation affected GPS location error, and found there was no effect (Uno et al., 2002).

Researchers at zoos were relatively late adopters of GPS technology, perhaps due to the small spatial scales of zoo environments, and thus, the higher required GPS performance standards. The first study conducted by zoo researchers included five adult female African savanna elephants (Loxodonta africana) at Disney’s Animal Kingdom (Leighty et al., 2008). The researchers used unique digital audio and GPS recording collars to determine if elephants use rumble vocalizations to mediate animal proximity between and within social groupings. Their findings supported previous research in wild elephants that found rumbles are important for spatial cohesion among group members; in addition, they discovered that post-rumble elephant movements were affected by the social affiliation of the individuals. The researchers followed up with a GPS collar study that looked specifically at walking behavior in the same herd of African elephants (Leighty et al., 2009). They found that the elephants walked at rates within the range observed in the wild; they also found some evidence that the elephants had higher walking rates when housed in more complex social groups in larger enclosures. In the third and final study from this research group, a subset of elephants wore GPS collars to document their use of exhibit space and resources as a function of their position within the dominance hierarchy (Leighty et al., 2010). Dominance was not correlated with the use of mud wallows or permanent shade areas, but it was correlated with overall space usage, the use of watering holes, and the use of restricted flow areas. This pioneering work had clear animal welfare and exhibit design implications, and the zoological research community soon completed a number of studies of zoo elephant movement and 
GPS methodologies (Horback et al., 2012; Miller et al., 2012; Rothwell et al., 2011), including the work of a number of university students (Chapter Three; K. L. Ficken, personal communication, October 15, 2013; Soulsby, 2013).

GPS provides researchers with more data of a higher quality while optimizing research effort, and is being applied to species with smaller and more nuanced patterns of movement, in zoos and in the wild. As GPS technology becomes more advanced and ubiquitous, the tendency will be to make assumptions about the reliability and autonomy of the system. On the contrary, GPS remains a complex and error-prone system, and over-expectation of system functionality and performance can lead to inadequate study design or researcher frustration, which may ultimately compromise the study results (Goodyear, 2007). Before a zoological researcher undertakes a project utilizing GPS, an understanding of the basic principles of the system - including sources of error and how to mitigate them - is essential.

\section{$\underline{\text { II. GPS Operation, Sources of Error, and System Improvements }}$}

\section{GPS Operation}

The United States was the first country to deploy a Global Navigation Satellite System (GNSS). Today, the Department of Defense NAVSTAR Global Positioning System (GPS) remains the most widely used GNSS in the world (Bolstad, 2012), but GNSS's also exist or are being developed in Russia (GLONASS), the E.U. (Galileo), and China (BeiDou) (Kaplan, 2006). Due to the many similarities between these systems, the term GPS is often broadly applied to describe any GNSS. However, some differences exist, so in this document the term GPS is best considered as specific to the NAVSTAR 
program. Readers interested in the history of GPS program development or other GNSS's are directed to Kaplan (2006), Misra \& Enge (2006), and El-Rabbany (2006).

GPS has three main components: control, satellite, and user. The control segment is a network of ground stations that are responsible for monitoring and maintaining satellite and system integrity. The satellite segment consists of a constellation of 24-32 satellites in six orbital planes (USNO, 2015); this allows for four to eight satellites to be typically available from any unobstructed location on Earth (Bolstad, 2012). The user segment includes any receiver that accesses the GPS satellite data to calculate its location.

GPS positioning works using two basic mathematical concepts. The first concept, trilateration, is used to estimate an unknown position based on measurement of distances (Misra \& Enge, 2006). More specifically, GPS uses trilateration to estimate receiver position based on measurement of distances between the receiver and the satellites. But how do we measure these distances? The answer lies in the second mathematical concept used in GPS, the equation distance = rate $x$ time. GPS satellites are continuously transmitting radio signals that, in general, travel at the speed of light. GPS signals are also embedded with timing information, which enables the receiver to calculate when the signal left the satellite. The product of the satellite-to-receiver propagation time, and the speed of light, is the distance between the receiver and the satellite (Kaplan \& Leva, 2006). Theoretically, a receiver needs to simultaneously track only three satellites to estimate its location (Fig. 2.1). From a practical point of view, however, a minimum of four satellites is preferred for optimal GPS operation, and additional satellites can improve location accuracy even further. 
The basic idea behind GPS is rather simple, yet the intricacies of the system become rapidly complex. Some of these will be explored in the following sections. For additional details introductory GPS users are directed to Bolstad (2012) and El-Rabbany (2006); advanced users may wish to consult Kaplan \& Hegarty (2006) and Misra \& Enge (2006).

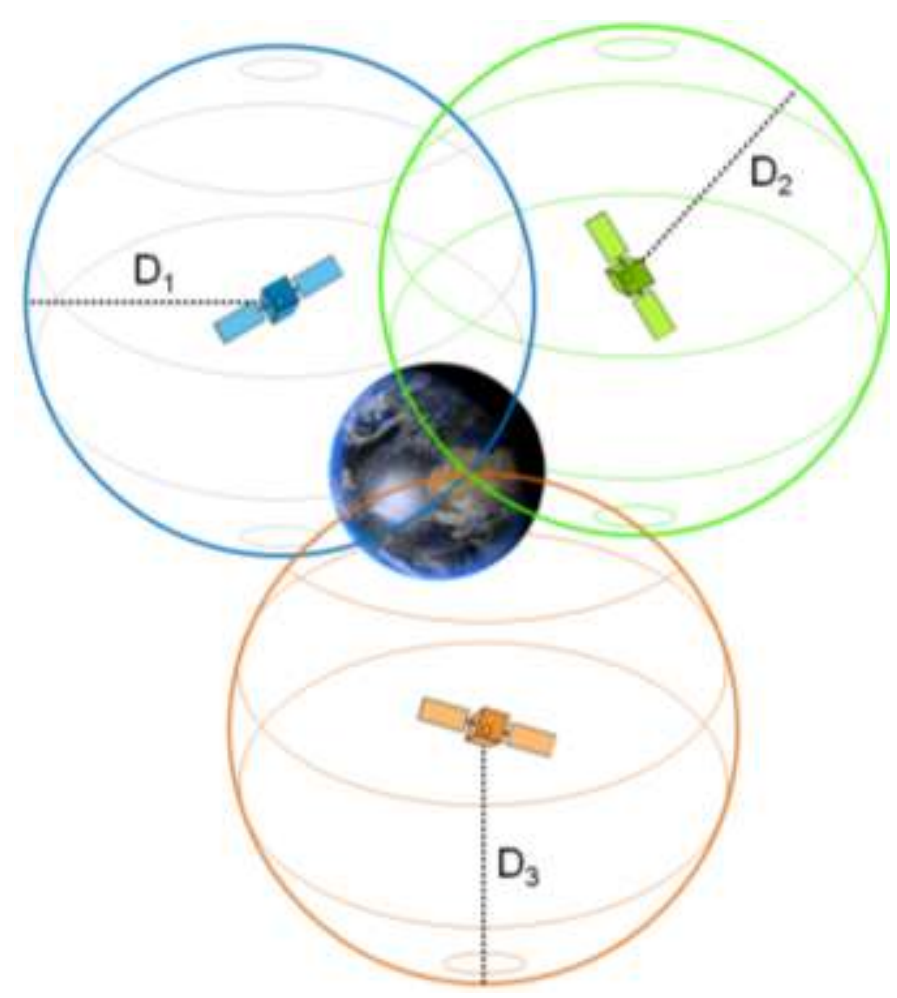

Figure 2.1: The basics of GPS positioning via trilateration using measured distances from three satellites. In most practical applications, a minimum of four satellites is used to calculate an accurate fix.

\section{Universal error sources}

Many sources of GPS error are due to limitations inherent to the technology. These errors universally affect all GPS users, whether they are military, aviation, or civilian. These errors primarily relate to the space and control segments, thus, there is 
little that the end user can do about them. Regardless, briefly reflecting on these universal error sources will provide a better understanding of GPS operation and limitations.

One of the smallest error sources in GPS is ephemeris error, also known as orbital error, which relates to the position of the satellite in orbit (Misra \& Enge, 2006). GPS relies on highly accurate estimates of satellite locations to function correctly, but sometimes the control segment miscalculates satellite position, speed, or trajectory, which is then relayed to the user. Ephemeris error, although small, is also difficult to control, as satellites are subject to forces (e.g., solar radiation pressure) which cannot be easily measured from the ground (Colombo, 1986).

GPS positional accuracy can also be diminished due to clock error. Each satellite is equipped with multiple atomic clocks that keep time based on the natural atomic oscillations of rubidium and cesium gases; these clocks are stable to within a few nanoseconds per day, and are monitored and corrected by the control segment (ElRabbany, 2006). Receiver clocks, on the other hand, are inexpensive crystal clocks and are much more prone to error (El-Rabbany, 2006; Kleusberg \& Langley, 1990). Despite this limitation, clock error can be mathematically estimated and nearly eliminated by combining GPS signal information, and is generally the smallest error source in the system (Misra \& Enge, 2006).

The most challenging source of error faced by all users of GPS is the Earth's atmosphere. GPS satellites orbit the Earth at an altitude of approximately $20,000 \mathrm{~km}$, and the radio signals they emit complete $95 \%$ of their journey travelling at the speed of light through the vacuum of space (Misra \& Enge, 2006). However, these signals must 
eventually pass through the Earth's atmosphere on their way to receivers on the surface of the Earth. The atmosphere contains charged particles, neutral atoms, and molecules that interact with radio signals and can change the speed and direction of the signals via refraction (Langley, 2000). Of primary consequence for GPS performance is the change in the signal propagation speed which affects the signal transit time, and, thus, the apparent range to a satellite will appear shorter or longer than reality (El-Rabbany, 2006; Misra \& Enge, 2006). The two atmospheric regions in which refraction can occur are the ionosphere and troposphere.

The ionosphere is a portion of the upper atmosphere in which radiation from the sun interacts with gas molecules and atoms, resulting in charged particles that can affect GPS performance (El-Rabbany, 2000). It is the electrons that have the greatest impact on radio signals, and the density of these electrons varies greatly both temporally (time of day, season) and spatially (user location) (Langley, 2000). This unpredictability poses a challenge to operators of the control segment, who must model the effects of the ionosphere as best they can and send correction data to the satellites. Ionospheric unpredictability is further compounded by the effects of space weather and the 11-year solar cycle. An increase in solar flares and coronal mass ejections during the sun's solar peak can degrade range measurements, and in severe circumstances, completely sever communication between the satellite and receiver (Cerruti et al., 2008; Doherty et al., 2004).

The troposphere is the lowest portion of the Earth's atmosphere and is electrically neutral; however, the troposphere is composed of dry gases and water vapor that can refract GPS signals (Misra \& Enge, 2006). At higher altitudes, refraction of signals is 
easily predicted and modeled, while at lower altitudes, water vapor is unpredictably distributed due to local weather patterns (El-Rabbany, 2006). Thus, although all GPS users may experience tropospheric error, the actual effect on location accuracy will depend on atmospheric weather. At a more applied level this means bad weather could lead to poor GPS study results; indeed evidence for this exists in a study of zoo elephant movement (Miller et al., 2012); however, surface meteorological conditions are not strongly correlated with tropospheric water vapor (El-Rabbany, 2006), so weather alone cannot predict GPS system performance.

\section{Error sources unique to the user}

While all Earth-bound GPS users are subject to similar effects from ephemeris error, clock error, and the atmosphere, other error sources are unique to the location and environment at the moment the GPS signal arrives at the user's receiver. Errors sources unique to individual users include canopy conditions, available sky, animal activity and antenna orientation, and multipath effects.

The effect of forest canopy on GPS performance was evaluated in the first published study of animal-tracking using GPS (Rempel et al., 1995). Canopy and other vegetation were known to obstruct communication between satellites and receivers, so researchers tested GPS collar performance in relation to tree spacing, height, basal diameter, and canopy closure. At about the same time, researchers also studied the effects of topographic obstructions (i.e., terrain) (Rodgers et al., 1997). They used the term "available sky" to refer to the proportion of sky available to a receiver through direct line of sight in all directions and at all angles (D'Eon et al., 2002). The result of 
these early studies was that canopy cover and available sky could both have detrimental effects on GPS performance. More specifically, GPS was likely to perform poorly if an animal was in a valley bottom or on a steep slope with dense vertical vegetation, and GPS was likely to perform best on an animal in a topographically flat area with an open canopy.

Canopy and available sky conditions can degrade GPS performance two ways. First, they can completely sever the connection between the receiver and all satellites, or nearly all satellites, such that the receiver is unable to calculate its location (Belant, 2009; D’Eon et al., 2002; Hansen \& Riggs, 2008; Phillips et al., 1998; Rempel et al., 1995; Sager-Fradkin et al., 2007; but see: Bowman et al., 2000; Lewis et al., 2007). Second, they can introduce error into position estimates by blocking some satellite signals, causing poor satellite geometry and/or forcing the use of less valuable signals to make a fix (Bettinger \& Fei, 2010; Deckert \& Bolstad, 1996; Dussault et al., 1999; Hansen \& Riggs, 2008; Moen et al., 1996; Moen et al., 1997). Both of these scenarios are of concern to researchers studying animal location and movement, however, the latter scenario introduces a new potential source of error. If the receivers worn by study animals are acquiring more coordinate fixes in some habitats, and less in others, those obstructed habitats will be missing data, which is arguably the largest source of potential error and bias in GPS data (D'Eon, 2003). In this case, the rate of fixes would not be randomly distributed, but instead would be the result of a directional bias caused by habitat; this bias could potentially translate into wrongful research conclusions (D'Eon \& Delparte, 2005). 
Animal activity can also affect GPS performance. First, animals being tracked with GPS have the ability to move across the landscape and select microhabitat that may compound problems with satellite communication; for example, animals resting at the base of large trees (Sager-Fradkin et al., 2007). This is a potential concern for zoo researchers, as animal exhibits often include microhabitats such as shade structures, shelters, holding pens, walls, and vegetation, all of which may introduce fix rate bias into the dataset. Second, animal activity can change the orientation of the antenna in the GPS receiver. Vendors stress that consumers maintain the GPS antenna orientation as close to $90^{\circ}$ from horizontal as possible (Belant, 2009). Indeed, collars tested in an open area showed that the percent of successful locations decreased as antenna orientation moved away from the vertical position (Belant, 2009); other researchers found antenna orientation affects positional accuracy in a forest area, but not in an open area (Jiang et al., 2008). In the most comprehensive study to date, GPS collars were rotated through different orientations, with antenna pointing from 0 degrees to 180 degrees. There was a consistent downward trend in both fix rate error and location error as the collars angled away from vertical, but a threshold effect appeared at 90 degrees, such that large affects on GPS performance appear only when the orientation approaches or exceeds horizontal (D’Eon \& Delparte, 2005).

A final source of local error for GPS receivers comes from multipath signals. The term multipath derives from the fact that a signal transmitted from a GPS satellite can follow a "multiple" number of propagation "paths" to the receiver (Townsend \& Fenton, 1994). The ideal path will run directly from the satellite to the receiver (i.e., "line-ofsight”), but multipath signals are reflected back to the receiver off surrounding objects, 
thereby increasing the travel time of the signal (Fig. 2.2). Receivers will then attempt to correlate with both signals, creating a composite signal that reduces location accuracy. Vegetative obstructions can also play a significant role in introducing error into position estimates through the use of multipath signals (Bettinger \& Fei, 2010). In fact in forested areas, multipath error can account for over half of the positional error in static receivers (Danskin et al., 2009). The ability of a GPS receiver to reject multipath signals may be one of the main causes in differences in positional accuracy between types of receiver (Bolstad et al., 2005). Unfortunately, these effects are difficult to measure, as they exist in a dynamic environment, constantly in flux as the animal moves. They are also impossible to avoid in many cases, as multipath can arise due to reflections off environmental surfaces such as rock faces and smooth bark (Rempel et al., 1997), but also (and more commonly) off urban structures with an abundance of corner reflectors, such as the sides of buildings and streets (Bolstad, 2012). Zoo exhibits often contain a combination of both these natural and artificial reflective surfaces, so zoo researchers must be wary of the degrading of GPS performance by multipath signals. 


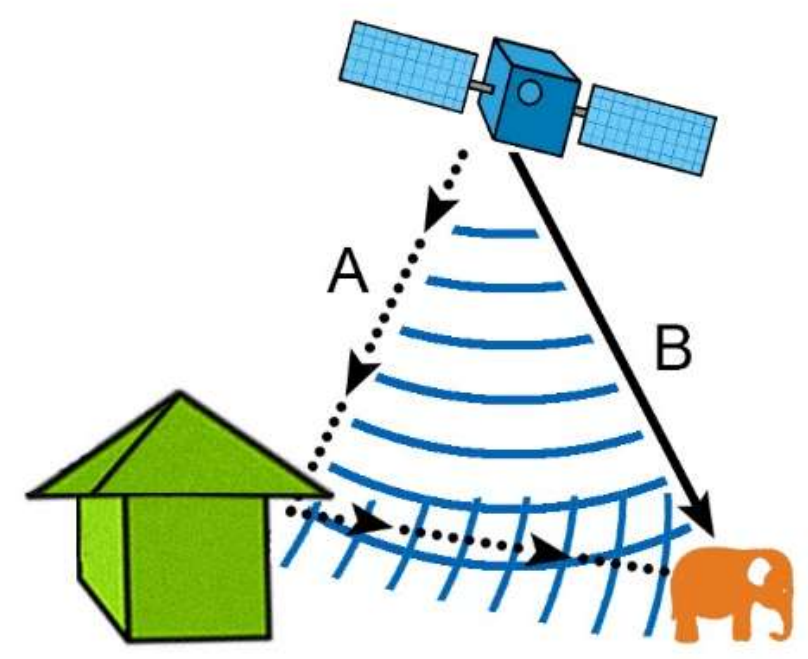

Figure 2.2: The multipath effect is the result of satellite signals reaching the receiver via more than one path. If a physical structure on one pathway causes a signal refraction, it can introduce positional error because multipath (A) and direct signals (B) create a composite signal.

\section{Improving GPS performance}

\section{System Improvements}

Soon after GPS became operational, civilian users began lobbying hard for system design and policy changes to further expand GPS applications. Since that time, GPS has become nearly ubiquitous due to its use in location and navigation, but also in its less visible role as the source of precise time for telecommunications, banking, power, and the internet. In response, the U.S. government announced a new GPS modernization initiative in 1999, which included a reassessment of the entire GPS architecture (Misra \& Enge, 2006). System improvements from this modernization initiative are ongoing, and as better clocks, satellites, and mathematical models, are introduced by the government, so too are manufacturers unveiling improved receivers. Thus, before we consider the 
techniques that a GPS user can use to improve GPS performance, let us first review these ongoing modernization efforts.

A larger satellite constellation is the key to mitigating many common GPS error sources, and the number of satellites available will improve drastically over the next ten years. One increase in satellites will be due to the association between the U.S. and the E.U., which have worked together since 2004 to ensure that the Galileo satellites will be interoperable with the newer GPS satellites scheduled to launch in 2016 (becoming available around 2026) (GPS.gov, 2014a). Meanwhile, the GPS modernization program has been continuously launching satellites over the last few years; four new satellites were launched in 2014 alone (GPS.gov, 2014a). The additional satellite coverage will improve satellite availability in a variety of situations, including urban areas where buildings can reduce available sky (EC, 2013). In addition, the newer satellites are far more advanced than previous models. The satellite upgrade with perhaps the largest effect on GPS applications is the inclusion of a second civilian signal, dubbed L2C. The L2C signal operates at a higher power than the current L1 C/A signal, improving its ability to operate indoors or under obstructions like canopy cover (GPS.gov, 2014b). More importantly, than the new L2C signal is the potential for integration of the L2C signal and the L1 signal. Dual-frequency receivers will be able to simultaneously use and compare the two signals to realize faster signal acquisition, enhanced reliability, and essentially eliminate ionospheric errors (Misra \& Enge, 2006) - down to millimeter level accuracy (Hoque \& Jakowski, 2008). Currently, dual frequency receivers are considerably more expensive than single frequency receivers, although prices are likely to reduce as demand increases. Demand will likely be tied to the success of the GPS 
IIR(M) satellites carrying the L2C signal, and although the full constellation is not expected to be available until 2018, some are already in orbit and broadcasting (although as of writing they are consider to be officially in a "pre-operational state" for testing) (DOD, 2014). The IIR(M) satellites will significantly improve GPS performance, but the modernization program is not ending there, and newer models will integrate additional upgrades. GPS IIF satellites, available in 2021, will use advanced atomic clocks to keep time within 8 billionths of a second, and GPS III satellites in 2026 will incorporate another channel (L1C) to allow for international interoperability.

In addition to satellite segment improvement, the control segment is undergoing modernization. One key upgrade is the expansion of the number of monitoring stations from six to sixteen; the increase in orbital data being monitored led to a $10 \%$ to $15 \%$ improvement in system accuracy (GPS.gov, 2014c). Improved IT and other upgrades also enhance the accuracy of mathematical models, such as those used to predict clock error and the forces acting on satellites. Finally, while tropospheric effects remain an error source that, frustratingly cannot be corrected via dual frequency receivers (ElRabbany, 2006), improved models that estimate the "standard atmosphere" at the user's location based on latitude and longitude, average pressure, temperature, and humidity have reduced location errors to the order of 5-10cm (Misra \& Enge, 2006).

Receiver design and software also continue to improve, with one primary goal being the reduction of multipath signal effects. Receiver manufacturers have applied a flurry of cutting-edge technologies towards the mitigation of multipath through both antenna design and receiver processing methods (Weill, 1997). For example, some new receivers can be programmed to ignore signals with a high noise relative to signal 
strength, which is often indicative of multipath (Bolstad, 2012). Despite these efforts, multipath remains a dominant source of error in GPS (Weill, 2002), most notably in urban settings (Bolstad, 2012).

\section{Differential GPS}

In addition to general system improvements, GPS users can take an active role in system performance through the use of differential GPS (dGPS). This system uses base station receivers of known location to correct for error and provide significant increases in positional accuracy. Fortunately, most modern GPS receivers come equipped with the ability to automatically utilize some dGPS corrections in real time, making dGPS a simple and convenient way to improve GPS performance. DGPS systems vary widely, but perhaps the simplest and most widely applied in the U.S. is the wide area augmentation system (WAAS) (Chapter Two). WAAS was developed by the Federal Aviation Administration to enhance the GPS system for use in civil aviation (ElRabbany, 2006). The core of the system is a network of 25 widely distributed base stations, whose locations are known to a very high degree of accuracy. Because the locations of the base station are known, and the locations of the GPS satellites are (fairly accurately) known, the "true" distance from a given satellite to the base station can be calculated. This known "true" distance can then be compared to the measured distance as determined by a receiver at the base station; the difference between these values are due to error (DOT \& FAA, 2012). WAAS then uses a pair of geostationary satellites to broadcast corrections based on these measurements, which any WAAS-enabled receiver can receive and apply. Currently, WAAS capabilities are built in to most modern GPS 
receivers, including the cheapest recreational handheld receivers (MELP, 2008).

However, the WAAS correction signals are relatively weak, and do not reliably penetrate canopy, therefore they may not reach their full potential in some applications (MELP, 2008).

For GPS users requiring additional accuracy, other dGPS options are available. For example, the National Geodetic Survey (NGS) manages the Continuously Operating Reference Stations (CORS) network, a multi-purpose cooperative endeavor involving government, academic, and private organizations that as of January, 2014, contains more than 1,900 stations designed to improve GPS accuracy in surveying, mapping, engineering and related fields (Ali, 2012; NOAA, 2014). NGS makes the data collected by CORS available for public use; researchers can then use software to apply corrections from their nearest reference station via a technique called post-processing. In general, post-processing is considered slightly more accurate than the alternative real-time processing (e.g., WAAS) (Bolstad, 2012). A final option for users in remote locations not covered by WAAS or reference stations is to establish their own base station within their study area using highly accurate surveying equipment; this was also essential in early GPS studies before the development of alternate dGPS techniques (e.g., Rempel \& Rodgers, 1997).

\section{Sampling interval}

Improving GPS system performance requires advance consideration by researchers, beginning in the early stages of study design. For example, one of the most difficult methodological decisions a GPS researcher will make is selecting the sampling 
interval - the amount of time that elapses between consecutive location fixes. This decision is especially important for researchers who are interested in quantifying the movement of their subjects (e.g., distance walked), as sampling frequency can lead to vast over- or underestimations of travel distance. Ryan et al. (2004) explains it this way: "Just as the length of a coastline varies depending on the scale at which you map it, so the track length of [an animal] is influenced by the frequency with which it is 'sampled."” Clearly, an infrequent sampling interval (e.g., once per hour) will miss the intricacies inherent to the movement of most species, and an underestimation of travel will occur. On the other hand, a very frequent sampling interval (e.g., once per second) may cause a rapid accumulation of small inaccuracies, especially when the animal is not moving. Put simply, if intervals are too long, they undersample the details of movement paths, and if too short, they oversample sites of rest and inactivity (Brown et al., 2012).

As an example of how sampling interval may affect movement data, I will reference data from the Elephant Welfare Project, a large-scale study of elephant welfare in North American zoos funded by the Institute of Museum and Library Services (Carlstead et al., 2013). This project included a study of African savanna elephant (Loxodonta africana) and Asian elephant (Elephas maximus) walking distance using GPS and accelerometer equipped anklets (Chapter Four). For our investigation of sampling interval, I have randomly selected mean daily walking distance $(\mathrm{km})$ data from five elephants (Table 2.1). These data were collected at 5 second intervals; reanalyzing the dataset at $10 \mathrm{~s}$ and $30 \mathrm{~s}$ intervals allows us to see how severely sampling interval does, or does not, affect the outcome of our research question. In this case, elephants are estimated to walk either $5.7 \mathrm{~km} /$ day ( $5 \mathrm{~s}$ intervals), $5.2 \mathrm{~km} /$ day (10 s intervals), or 4.2 
$\mathrm{km} /$ day (30 s intervals). Thus, a change in sampling interval may change an elephant's reported distance walked by as little as a few hundred meters (subject C), or as much as several kilometers (subject D).

Table 2.1: Mean Daily Walking Distance $(\mathrm{km})$ of five randomly selected elephants from the Elephant Welfare Project. Calculated distance walked is reduced as sampling intervals increase from 5 seconds to 10 seconds, and 5 seconds to 30 seconds.

\begin{tabular}{cccc} 
& \multicolumn{3}{c}{ Mean Daily Walking Distance $(\mathbf{k m})$} \\
\cline { 2 - 4 } Subject & 5 Seconds & 10 seconds & 30 seconds \\
\hline A & 5.9 & $5.6(0.3)$ & $4.9(1.0)$ \\
B & 6.1 & $5.6(0.5)$ & $4.4(1.7)$ \\
C & 4.1 & $3.9(0.2)$ & $3.5(0.6)$ \\
D & 6.7 & $5.7(1.0)$ & $3.8(2.9)$ \\
E & 5.4 & $5.1(0.3)$ & $4.4(1.0)$ \\
Mean & 5.7 & $5.2(0.5)$ & $4.2(1.4)$ \\
\hline
\end{tabular}

Researchers have a number of options when selecting the sampling interval. Ideally, researchers would strategically set the sampling interval a priori, based on existing knowledge of species behavior and movement patterns, the specific research questions being addressed, study limitations, and the accuracy and precision of the GPS device (Frair et al., 2010). Alternately, GPS devices can be set to collect data at the highest possible frequency, thereby allowing researchers to evaluate alternate sampling intervals. Some researchers will, of course, find the latter option impossible due to battery or memory constraints. Overall, the evolving technology, and the intricacies of GPS data collection in diverse applications, means there is no established or agreed upon sampling interval. Thus, intervals range widely, even in studies of elephant movement. 
Not surprisingly, the least frequent intervals are used in studies of wild elephants, e.g., 13 records/day (Leggett, 2006). Zoo studies have used intervals of 1 and 2 seconds (Soulsby, 2013), 5 seconds (Chapter Three; Miller et al., 2012), 10 seconds (Leighty et al., 2008, 2010), and 30 seconds (Leighty et al., 2009). These values show a fairly consistent trend towards shorter sampling intervals in more recent studies, which may reflect improvements in GPS system and device performance.

\section{Data Screening}

Armed with an adequate knowledge of GPS operation, error sources, and system improvements, researchers can strategically apply a variety of data filters to further improve the accuracy of their final dataset. At the same time, researchers must be aware that the data screening process could lead to significant reductions of data and a subsequent introduction of bias into the dataset (Lewis et al., 2007). Thus, with each data screen, researchers must evaluate the trade-offs between eliminating inaccurate locations and retaining the maximum amount of location data (Lewis et al., 2007).

\section{Roving and stationary error}

Despite the benefits of system updates, dGPS, and thoughtful study design, researchers will still encounter error in their GPS data. This residual error can be categorized as either roving error (occurs when an animal is moving) or stationary error (occurs when an animal is inactive). For researchers interested in measuring animal travel distances, roving error is of much less concern. This is because estimations of distance traveled are most sensitive to the cumulative errors between observations, and 
less sensitive to the measured error of any single observation (Palmer, 2008). For example, if an animal walks along a straight wall for 100 meters, and multipath effects cause the receiver to record a string of data point as $2 \mathrm{~m}$ East of the true location, the cumulative distance walked will remain accurate at $100 \mathrm{~m}$, despite the location error. Of course, if the errors are random in their distribution, error could accumulate. However, roving errors lead to both overestimations and underestimations of actual travel distances (Ganskopp \& Johnson, 2007). Thus, in the long run, these series of errors will likely approximate zero, as long as movements exceed normal position error (Ganskopp \& Johnson, 2007).

On the other hand, stationary error can be quite problematic for researchers interested in quantifying distance traveled. If a stationary GPS device has even a small amount of randomly distributed error, any fix containing error will only ever overestimate travel distance, without the opportunity to average out over time. These errors can accumulate rapidly, especially if the location errors are large, and/or or the sampling interval is high. In response, researchers have found a number of ways to screen their data to minimize the effects of stationary error.

One technique researchers use to screen stationary error begins with identifying species-specific (or individual-specific) bouts of rest. Once identified, resting bouts might be excluded, or treated differently, during subsequent data analyses (Frair et al., 2010). This is especially important for researchers studying species with long, sustained rest periods, especially those that rest in locations with satellite interference (as this will further compromise location accuracy). Perhaps the simplest application of this screening technique is to deactivate the GPS receiver during assumed resting hours. This 
method was used successfully in a study of the common brushtail possum (Trichosurus vulpecula) (Dennis \& Shah, 2012). The authors knew that the possums usually emerge from den shortly after sunset, remain outside throughout the night - depending on weather - and cease activity just before dawn. The authors also had information on differences in active hours based on sex and season. Applying this data screening technique not only helped minimize stationary bias, it also conserved battery life, which allowed for a prolonged period of collar attachment (Dennis \& Shah, 2012).

A more advanced solution for avoiding stationary error requires the integration of GPS devices and accelerometers. Accelerometers measure g-force and degree of tilt; they are widely-used to measure animal behavior, including the resting postures of cattle (Ito et al., 2009) and zoo elephants (Chapter Four). Brown et al. (2012) created a custom system to track northern tamanduas anteaters (Tamandua mexicana) and fisher (Martes pennanti) on a dynamic GPS schedule that was linked to the activity level of the animal as reported by the accelerometer. This allowed them to remove not only data that was collected during prolonged rest periods, but any periods of inactivity. When compared to traditional GPS receivers, their "accelerometer-informed" receivers achieved higher fix rates, spent less time searching for satellites, and had fewer redundant location attempts during inactivity, all while preserving battery life. On the other hand, this method has the potential to confuse inactivity with fine-scale foraging behavior, depending on typical species movement patterns and device accuracy (Frair et al., 2010). Despite these limitations, a variety of devices that allow joint recording and integration of position and activity are now on the market (Moreau et al., 2009). 
There are two other methods - unique to zoos and other captive environments - by which researchers may be able to mitigate roving and stationary error. First, screening data points that occur while animals are indoors or in obstructed errors will remove fixes that are susceptible to multipath signals. This is especially beneficial for animals that are rotated between indoor and outdoor areas, such as elephants. During the Elephant Welfare Project, we requested that animal care staff record the times during which GPSoutfitted elephants were confined indoors; we then eliminated any fixes during this period from the dataset. In addition, we mapped the data using AcrMap software (v. 10.1, Environmental Systems Research Institute, California, USA) and used the clip function to remove any remaining data from indoor areas. By combining these two steps, we ensured that we removed all indoor data points, including those that occurred when elephants with mixed indoor/outdoor access chose to go inside. Building off the spatial review using ArcMap, the second unique data screening process zoo researchers may wish to undertake is an evaluation of points that fall outside of the exhibit boundaries. Regardless of whether the animal was stationary or roving, these points are clearly inaccurate; however, there are advantages and disadvantages to screening these points. Consider, for example, that these fixes may simply be the result of elephants standing near the exhibit border, or walking along the exhibit wall, and as such, the points falling outside of the exhibit boundary are not inherently any different than points falling further inside of the exhibit boundary. By removing only the out of exhibit points, distance traveled may be underestimated, and the researcher may be introducing bias by removing the opportunity for roving errors to average out, as discussed previously. On the other hand, failing to screen fixes that are clearly inaccurate makes little intuitive sense. Zoo 
researchers faced with this dilemma may gain some insight by evaluating the effect of keeping or removing the points before making a decision. In the Elephant Welfare Project we elected to remove these points from the dataset after an analysis suggested that distance walked would only decrease a few percentage points. This decision also aligned with our efforts to be conservative and make choices that would underestimate, rather than overestimate, distance walked.

\section{Upper and lower fences}

Upper and lower fences remove travel distances that are impossibly large or small based on pre-existing knowledge of species-specific behavior. Removing impossibly large travel distances, that is, distances that exceed the possible range of a study animal, has historically been a highly recommended screening procedure (D'Eon et al., 2002). However, improvements to GPS system performance and the relatively open nature of some zoo exhibits may make this process less relevant for zoo researchers. During the Elephant Welfare Project, we decided to apply an upper fence so that large and unexpected errors caused by multipath signals or available sky constraints would not lead to a gross overestimation of distance walked. Applying the upper fence required that we know how far an elephant could travel in five seconds (the time between two consecutive fixes). According to Hutchinson et al. (2006), elephants have near-maximal speeds of 6.8 $\mathrm{m} / \mathrm{s}$; however, anecdotal evidence indicated they elephants can move at much higher speeds. We then executed a series of tests using a radar gun and found that zoo elephants do, in fact, travel at speeds of nearly $10 \mathrm{~m} / \mathrm{s}$ in specific contexts, such as when they are given access to a yard full of scattered food. Thus, we set an upper fence to remove any 
distance over $50 \mathrm{~m}$ that occurred between two consecutive fixes. Surprisingly, we found no values that reached that limit. This may be because the test elephants moved at the upper range of zoo elephant speed, or it may reflect improvements in GPS performance such that sudden, abnormally large errors are rare.

Researchers can also remove distances that are impossibly small, although the application of this data screening process is less clear. A lower fence was considered during the Elephant Welfare Project, based on the results of an elephant kinematic study by Hutchinson et al. (2006) that evaluated over 2400 elephant strides and found that stride length ranges from 0.67 to 4.4 meters. This conclusion could support the argument a lower fence of $0.67 \mathrm{~m}$, with the assumption that an elephant is either stationary or has taken at least one stride; anything in-between $0 \mathrm{~m}$ and $0.67 \mathrm{~m}$ would therefore have to be attributed to GPS location error. However, a distance in-between $0 \mathrm{~m}$ and $0.67 \mathrm{~m}$ could arise if the device recorded a new fix at the beginning or completion of a stride. To avoid this complication, researchers can establish a lower fence using a stationary test. Miller et al. (2012) collected data from a stationary GPS device at 5 second intervals for 24 hours, and calculated a mean location error of $0.0087 \mathrm{~m}$ (range $0-0.4657 \mathrm{~m}$ ) across all data points. In this case, a value of $0.0087 \mathrm{~m}$ could then be used as a lower fence, but $0.0087 \mathrm{~m}$ is likely below the precision of the GPS device. Instead, it could be argued that because the lower fence would only apply to non-zero (erroneous) values, the mean location error should have been calculated using only non-zero values, leading to a higher and perhaps more useful lower fence value. 


\section{Fix information}

By far the most straightforward data screening process is to filter data points based on information provided with each coordinate fix. Fix information includes not only the latitude/longitude and timestamp, but also the number of satellites used in the fix, the geometry of those satellites, and whether differential correction was applied to the data (devices can be programmed to record additional data). In this section we will address how this fix information can be applied to improve GPS data accuracy. For illustrative purposes, data from the Elephant Welfare Project's GPS study will be presented. The study included 100 elephants at 50 zoos, and after removing indoor and out of exhibit data points, resulted in 4,038,196 fixes available for data screening based on fix information (Table 2.2). A summary of the data screening results is imperative for researchers seeking to better understand their data and the performance of their GPS device. 
Table 2.2: Frequency and distribution of GPS fixes collected and screened during the Elephant Welfare Project.

\begin{tabular}{|c|c|c|c|}
\hline & & Frequency & $\%$ Screened \\
\hline Total & All Fixes & 4038196 & \\
\hline \multirow{2}{*}{ WAAS } & Enabled & 4025240 & \multirow{2}{*}{$0.32 \%$} \\
\hline & Unavailable & $12956^{\mathrm{a}}$ & \\
\hline \multirow{15}{*}{ NSAT } & 0 & $126^{\mathrm{b}}$ & \multirow{15}{*}{$0.10 \%$} \\
\hline & 1 & $87^{\mathrm{b}}$ & \\
\hline & 2 & $274^{\mathrm{b}}$ & \\
\hline & 3 & $3533^{b}$ & \\
\hline & 4 & 11889 & \\
\hline & 5 & 29399 & \\
\hline & 6 & 97966 & \\
\hline & 7 & 401539 & \\
\hline & 8 & 1374666 & \\
\hline & 9 & 1154811 & \\
\hline & 10 & 674099 & \\
\hline & 11 & 240099 & \\
\hline & 12 & 46310 & \\
\hline & 13 & 3290 & \\
\hline & 14 & 108 & \\
\hline \multirow{11}{*}{ HDOP } & $<1$ & 2381055 & \multirow{11}{*}{$1.05 \%$} \\
\hline & 1 to $<2$ & 1614920 & \\
\hline & 2 to $<3$ & $28696^{\mathrm{c}}$ & \\
\hline & 3 to $<4$ & $6351^{\mathrm{c}}$ & \\
\hline & 4 to $<5$ & $2122^{c}$ & \\
\hline & 5 to $<3$ & $909^{c}$ & \\
\hline & 6 to $<3$ & $721^{\mathrm{c}}$ & \\
\hline & 7 to $<3$ & $629^{c}$ & \\
\hline & 8 to $<3$ & $347^{\mathrm{c}}$ & \\
\hline & 9 to $<3$ & $307^{\mathrm{c}}$ & \\
\hline & $10+$ & $2139^{\mathrm{c}}$ & \\
\hline Total & Screened Fixes & 59197 & $1.47 \%$ \\
\hline
\end{tabular}


${ }^{\text {a }}$ Removed due to screening of points with unavailable WAAS

${ }^{\mathrm{b}}$ Removed due to screening of points with NSAT $<4$

${ }^{\mathrm{c}}$ Removed due to screening of points with HDOP $\geq 2$

The accuracy of a GPS dataset can be easily improved by removing fixes that were unable to apply differential correction via WAAS or another dGPS system. As stated previously, most consumer GPS receivers on the market today are able to receive and apply correctional data from WAAS in real time, however, WAAS signals are low power and may have difficulty penetrating canopy. In our experience, WAAS signals are readily available in zoo elephant exhibits, perhaps due to the minimal canopy cover found in these exhibits. Of the four million coordinate fixes we analyzed, less than thirteen thousand were screened due to WAAS unavailability (Table 2.2).

The number of satellites (abbreviated NSAT or SV [space vehicles]) used to make a fix is also important, as more satellites usually improves accuracy (Bolstad, 2012) (Fig. 2.3). The proper functioning of a GPS receiver requires signals from at least four satellites (Kleusberg \& Langley, 1990) (although three satellites are technically sufficient to calculate latitude, longitude, and altitude, a fourth satellite is needed to correct for the unsynchronized time between the satellite clock and receiver clock [Kaplan, 2006]). Early animal tracking studies in forests were severely impacted by low satellite availability, which necessitated labor-intensive techniques to preserve as much data as possible. During a study of moose movement using GPS, $25 \%$ of fixes used only three satellites (Moen et al., 1997). The authors were able to "save" this data by estimating the altitude of their field site and using that to replace one of the unknown variables in their location calculations, thereby determining an accurate fix with only three satellites. 
However, this introduced a new potential error source: as the moose traveled across the habitat and changed altitudes, the accuracy of the fixes decreased accordingly (Moen et al., 1997). In addition, the maximum observed NSAT was six, although it is unknown whether this was due to forest canopy, satellite orbits, or the number of channels on the device able to simultaneously track satellites. In the Elephant Welfare Project, NSAT values ranged from 0 to 14 (Table 2.2); our overall mean NSAT was 8.66. We screened 4,020 fixes that did not meet our requirement of NSAT $\geq 4$. Previous studies of zoo elephant movement have not reported any screening via NSAT (Leighty et al., 2008, 2009, 2010; Rothwell et al., 2011; Soulsby, 2013), except Miller et al. (2012) which required $\mathrm{NSAT} \geq 6$.

A)

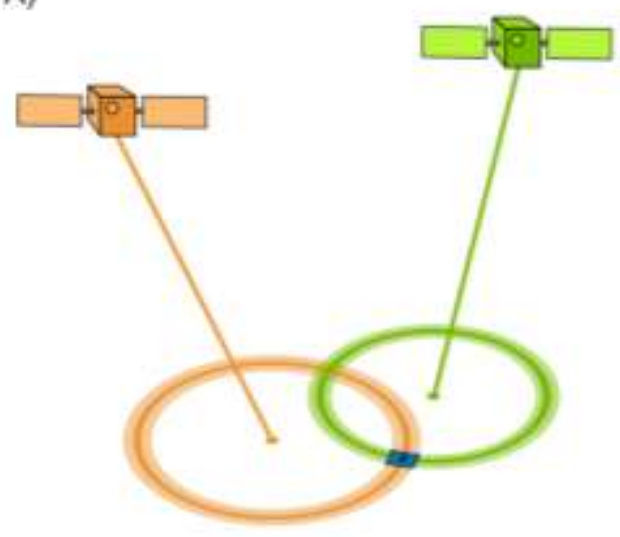

B)

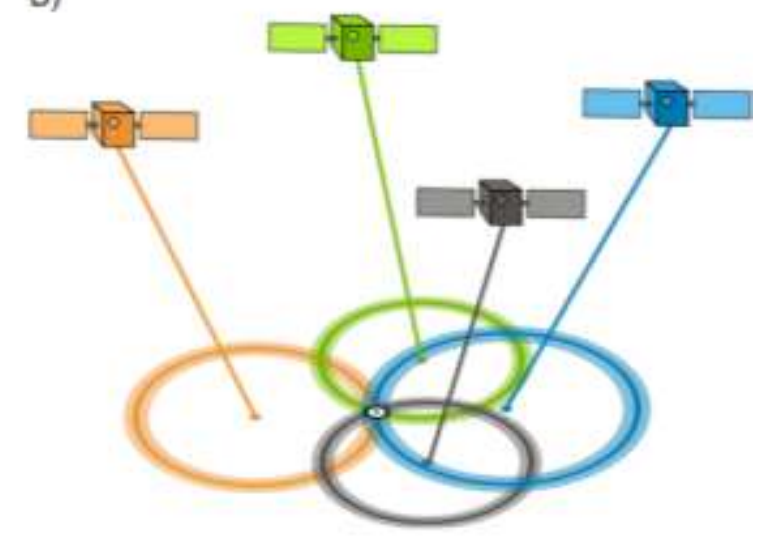

Figure 2.3: A simplified depiction of location accuracy with a few satellites (A) and many satellites (B). The blue square in (A) depicts location uncertainty; the additional satellites in (B) have reduced this uncertainty to the black dot. In practice, fixes require a minimum of four satellites, and may use as many as fourteen satellites (or more), with accuracy increasing as more satellites are available.

Intimately linked with NSAT values are dilution of precision (DOP) values, which measure the geometrical arrangement of the satellites observed by the receiver 
(Milbert, 2009). DOP is so named because an otherwise precisely operating system can be "diluted" by poor satellite geometry. When satellites are widely spaced in the sky, the sharp angles at which their signals intersect create a smaller area of uncertainty and a more accurate position fix; these fixes are assigned a low DOP value. When satellites are clustered more closely together - due to reduced available sky, for example - their signals overlap over broad areas, increasing uncertainty and resulting in fixes with a high DOP value (Bolstad, 2012) (Fig. 2.4). In general, field tests have verified this relationship between increasing spatial precision and decreasing DOP values (Langley, 1999; Lewis et al., 2007; Moen et al., 1996). As a side note, readers should know that there are different types of DOP values, the most commonly used being positional (PDOP), horizontal (HDOP), and vertical (VDOP) (Bolstad, 2012). In general, researchers tracking animal movement will only be interested in the horizontal plane, although a study involving measures of elevation or altitude would also need to include considerations of VDOP or PDOP (which is computed using both HDOP and VDOP). 
A)

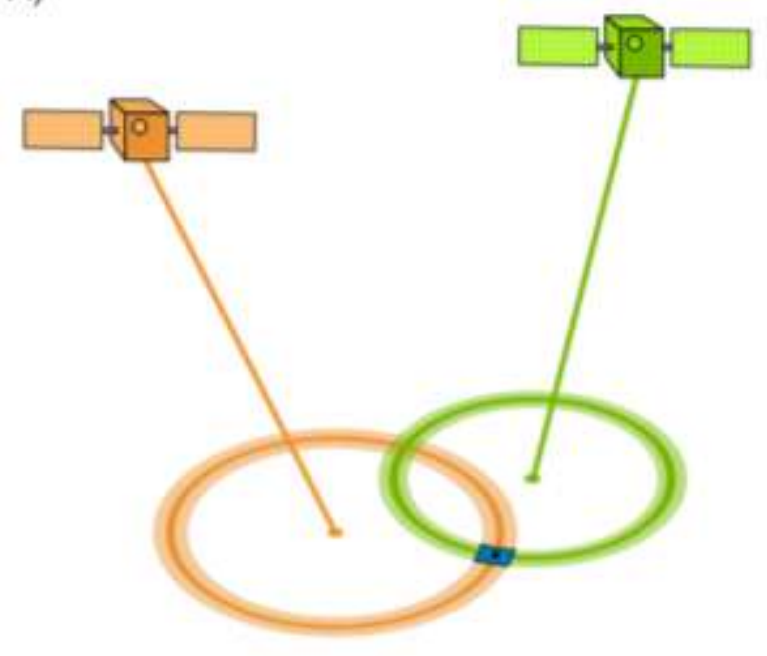

B)

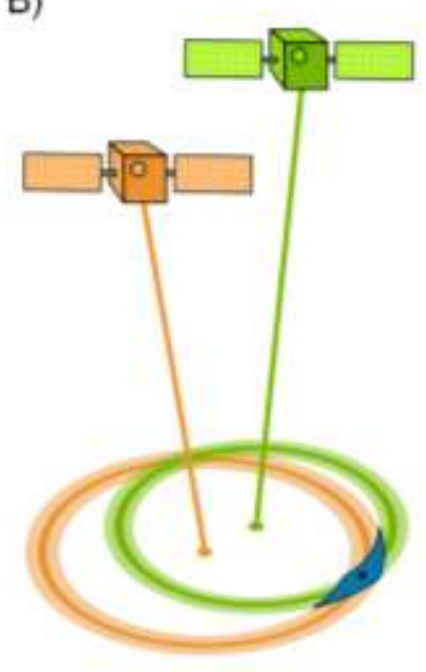

Figure 2.4: A simplified depiction of location accuracy with low DOP (A) and high DOP (B). The blue square in (A) depicts location uncertainty from satellites that are spread out in the sky. The blue square in (B) is a larger area than in (A), indicating the increased location uncertainty from satellites that are clustered in the sky. In practice, fixes require a minimum of four satellites, and may use as many as fourteen satellites (or more), with accuracy increasing as more satellites are available.

As with many data screening decisions, the appropriate screening value for DOP will depend on the specific research application and limitations. A recent study using lightweight GPS tags found that location error remains low and mostly constant up to HDOP values of 4.8 (Recio et al., 2011). This value is close to those in the earliest GPS animal tracking studies, which proposed eliminating fixes with HDOP > 4 (Moen et al., 1997), >5 (Rempel \& Rodgers, 1997) or > 6 (Moen et al., 1996). On the other hand, numerous authors have warned that applying any rigorous DOP screen is risky, due to the potential loss of large amounts of data, and the inconsistent relationship between location error and DOP (D’Eon \& Delparte, 2005; Lewis et al., 2007; Recio et al., 2011). Indeed, data screening via DOP can result in the removal of accurate fixes (Recio et al., 2011), as a high DOP value does not mean that the fix is inaccurate, but merely that the current 
satellite geometry could potentially result in a low accuracy fix. Once again the decision is up to the researcher, who must examine their dataset and determine if the reduction in dataset size can be accommodated and justified by the increase in location accuracy (Recio et al., 2011). In our experience during the Elephant Welfare Project, we found that the overwhelming majority of data points had HDOP values far below the cutoffs proposed in previous studies. In fact, we found that only about 40,000 of the four million fixes we analyzed had HDOP $\geq 2$ (Table 2.2). Despite HDOP resulting in the largest removal of data during this part of the screening process, we were surprised to find that only about $1 \%$ of fixes had poor HDOP values. We assumed the GPS devices would experience severely reduced available sky and multipath signals when elephants were wallowing, lying down, and straddling walls, shade structures and rock formations. The openness of elephant exhibits may have again promoted satellite connectivity; whether or not the GPS devices would perform at the same level in other animal exhibits is currently unknown.

\section{$\underline{\text { V. Effects of device attachment }}$}

GPS studies often operate under the assumption that animal subjects will exhibit normal behavior after capture, handling, and device attachment, or, that subsequent behavioral changes are not relevant to the focus of their study (Murray \& Fowler, 2000; Northrup et al., 2014). In many cases this may be true, yet if this assumption is violated, it may lead to biased results (Dechen-Quinn et al., 2012). In some species, capture, handling, and marking can cause indirect effects on survival (e.g., predation, starvation, and disease) (Murray \& Fowler, 2000), and in the most severe cases may cause injury 
and mortality (Dechen-Quinn et al., 2012). Additionally, animal subjects may experience more subtle behavioral effects, as will be discussed below. While the zoo environment protects zoo animals from some of the more severe effects of device attachment, zoo researchers must be vigilant to the subtle behavioral effects and the potential impact on their research conclusions.

Researchers using devices to study animal behavior in zoo animals have many advantages over their counterparts studying animals in the wild. Training programs facilitate device attachment and removal, thereby improving animal and staff safety, and minimizing handling stress. The health and welfare of zoo animals are closely monitored, and intervention, if necessary, is much more easily facilitated in a captive setting than in the field. However, researchers in the zoo and in the field must both remain vigilant to subtle behavioral effects of device attachment. This is especially true when the scale of investigation is more refined, as the relative effect of instrumentation on behavior is likely to increase (Brooks et al., 2008). Few studies have evaluated the impact of device attachment on fine-scale, individual behaviors such as movement rate (Dechen-Quinn et al., 2012), yet the data available indicate that behavioral effects should be expected, at least in the short-term. For example, a study of roe deer (Odocoileus hemionus) equipped with GPS collars found pronounced differences in spatial behavior, habitat use and activity level between the first 10 days post-capture and the next 40 days (Morellett et al., 2009). White-tailed deer (Odocoileus virginianus) outfitted with collars showed reduced movement rates for 14 days postcapture (Dechen-Quinn et al., 2012). Collared common brushtail possums (Trichosurus vulpecula) had greatly diminished activity and movement rates the first night immediately post-capture; effects for some 
measures persisted for at least 4 days (Dennis \& Shah, 2012). Ursids also show effects: black bears (Ursus americanus) and grizzly bears (Ursus arctos) outfitted with collars and captured multiple times during a long-term study showed reduced movement rates for 3-6 weeks post-capture (Cattet et al., 2008), while polar bear (Ursus maritimus) capture and telemetry data from over 40 years shows their activity and movement rates were affected by capture but returned to normal more quickly, within five days postcapture (Rode et al., 2014). Taken as a whole, these results suggest animal behavior, including fine-scale measures of movement, can be affected by capture, handling, and device attachment. Although it is likely that much of these effects are due to the stress associated with capture and handling (Dennis \& Shah, 2012), researchers must also consider the possible effects of device weight, fit, and novelty.

Perhaps the most oft-discussed topic in animal device attachment is device weight. Historically, researchers have used a "rule of thumb" stating that any attachment should not exceed 3\% (or 5\%) of the body mass (Macdonald, 1978). More recently, researchers have pointed out that little evidence exists for a biological basis or objective criteria for this rule (Brooks et al., 2008; Casper, 2009), and a more species-specific and holistic approach is required. In general, researchers continue faithfully reporting the weights of their devices and attachments, and allow the reader to determine whether or not they anticipate any behavioral effects. Rarely do researchers test device weight effects on animal movement, however a study comparing the effect of two GPS collars of different weights on the rate of travel of plains zebra (Equus burchelli antiquorum) found that a slightly heavier collar $(0.6 \%$ of total body mass) reduced rate of travel by more than half when foraging, compared with a lighter collar (0.4\% of mass) (Brooks et al., 
2008). Thus, it is recommended that at a minimum, researchers attaching devices to animals reports the total weight of the attachment, as has been done even with zoo elephants (Horback et al., 2012; Leighty et al., 2008, 2009, 2010; Rothwell et al., 2011; but failed to report in Miller et al., 2012; Soulsby, 2013).

The aforementioned zebra study suggests GPS collar weight may affect movement, but the authors also pointed out that the heavier collars appeared to fit poorly (Brooks et al., 2008). Thus, researchers must also consider the shape, size, and positioning of attachments (Wilson \& Wilson, 1989). In some cases, a suitable fit may require custom-made attachments for individual animals. For example, during a radiotelemetry study of Resplendent Quetzals (Pharomachrus mocinno), researchers sewed the subjects in to custom harnesses (Powell \& Bjork 1995). In the Elephant Welfare Project, we used a standard protocol to collect ankle-measurements from each elephant that was to be outfitted with a GPS anklet. Using this data, we ordered custom built anklets which were cut to different lengths to match the sizes and frequencies of anklets in our population. We also provided zoos with two sizes of shackles to add or remove anklet length as needed for proper fit. This allowed us to minimize costs (anklets were shared between elephants over the course of the study) while still providing flexibility in the fit. Finally, attachments must be properly shaped and positioned to reduce changes of entanglement, irritation, or constriction (Murray \& Fowler, 2000). In previous studies, attachments have become snagged in vegetation, animals have become entangled in loose collars and harnesses, and poorly-fitting devices have resulted in chafing and feather loss (for a review, see Mech \& Barber, 2002). 
Zoo researchers have a distinct advantage over wild animal researchers in that they can desensitize their subjects to novel device attachments before beginning data collection. Zoos regularly use this approach to minimize potential behavioral effects. For example, a study of African zoo elephants wearing GPS collars included a structured desensitization of the collars using positive reinforcement over several months before data collection began (Horback et al., 2012). During the Elephant Welfare Project, we provided each zoo with training protocols months in advance - to accustom their elephants to the postures needed for device attachment, and we shipped anklets to the zoos weeks in advance - to accustom their elephants to the novel smell and feel of wearing the anklets. We also elected to use an anklet-based system for our study, rather than a collar-based system as has been used in previous GPS studies of zoo elephants (Leighty et al., 2008, 2009, 2010; Rothwell et al., 2011). Anklets require less desensitization time, and are also safer for animal care staff to attach and remove (Miller et al., 2012). A final possible benefit of a comprehensive desensitization process is the opportunity for non-focal animals to become accustomed to the focal animal's device. Social partners have been seen to manipulate the devices being worn by other animals in some species (Glander, 1993; Horback et al., 2012). This type of interaction does not necessarily indicate a significant change in social behaviors, however. A researcher observing African zoo elephant behavior saw twelve instances of an elephant overtly touching or grasping the GPS collar of another with its trunk, however, the rate of "social body touch" was not significantly different from the average rate when the collars were not worn (Horback et al., 2012). This study illustrates the importance of careful testing and consideration of the behavioral effects of device attachment. 
Quantitative behavioral measurements should be used whenever possible to ensure that no bias is introduced when attaching a research device to an animal (Murray $\&$ Fowler, 2000). In a zoo setting, this would most likely be a comparison of pre- and post-instrumentation behavior of focal individuals. For example, within a few years of the first published report of GPS collar use on zoo elephants (Leighty et al., 2008), researchers at one zoo had followed up with a study evaluating possible behavioral effects, finding none (Horback et al., 2012). In some cases, a researcher may justify the use of a given device by citing previous studies that have failed to detect effects in a similar application. Locating evidence from previous studies can be difficult, however, as ecological research articles have historically tended to overlook or fail to acknowledge potential effects; this may also be a consequence of peer-reviewed journals being less likely to publish research identifying a non-effect (Murray \& Fowler, 2000). At the very least, researchers applying GPS to a new (or unrelated) species should undertake tests appropriate to the study design and outcomes (Murray \& Fowler, 2000).

Finally, zoo researchers should reflect on the ethical issues surrounding animal device attachment, including potential effects to animal health. Recently there has been a call for scientists to better present the case for their research, and measure and report how these activities affect animal health and welfare (McMahon et al., 2012). A number of references are available on this topic (Casper, 2009; Wilson \& McMahon, 2006). Zoos should also continue ensuring that all invasive and noninvasive research follows institutional guidelines including relevant protocols and IACUC review, where applicable. 
Chapter Three: Using GPS to determine factors affecting daily walking distance in African savanna elephants (Loxodonta africana) and Asian elephants (Elephas maximus) in zoos

\section{$\underline{\text { I. Introduction }}$}

In both the zoological community and amongst the public there is an interest in knowing the distances that zoo elephants walk. This interest is generally fueled by two assumptions. One assumption is that elephants are highly motivated to walk long distances and/or have an innate desire to express this part of their behavioral repertoire (cite) . Wild elephants are unquestionably highly mobile species, walking between 5 and $10 \mathrm{~km}$ per day under non-extreme environmental conditions (Leighty et al., 2009), but in some cases walking up to $27 \mathrm{~km} /$ day (Spinage, 1994) or more (Douglas-Hamilton, 1998). Yet whether elephants have any innate need or inclination for walking is not known. On the one hand, it could be argued that elephants walk only as much as is necessary to meet their biological needs. Indeed, elephant movement in the wild appears to be affected by the distribution and availability of resources. Walking may increase as elephants seek out fruiting events (Gadd, 2002), sodium (Weir, 1969, 1972), and green vegetation (Loarie et al., 2009); movement may be restricted when bulls in musth remain close to family units to maximize mating opportunities (Stokke \& du Toit, 2002) and family units congregate near permanent surface water (Stokke \& du Toit, 2002). Elephants appear to act in energetically conservative ways: they actively avoid slopes , for example (Feng \& Zhang, 2005; Wall et al., 2006). On the other hand, walking presumably facilitates exploration and information gathering. Information gathering is a 
unique behavior in that it doesn't satiate in the same way as many other behaviors do, and it could be argued that exploration occurs when all other needs are met, and is a pleasurable activity in itself (Boissy et al., 2007 ).

A second assumption maintaining the interest in zoo elephant walking is that walking is a form of exercise, and as such it affects the health and welfare of zoo elephants. If the associations between human health and physical activity (Weyerer \& Kupfer, 1994; Todd et al., 1992; Berger, 1996; Hassman et al., 2000; Motl et al., 2000; Oweis \& Spinks, 2001; Salmon, 2001; Ekelund et al., 2015) are any indication, elephants may indeed benefit from walking. However, correlations between zoo elephant welfare and walking per se are limited. In the largest multi-institutional study to date, Lewis et al. (2010) collected survey data from 78 zoos and found that zoos providing their elephants with more daily exercise have fewer incidents of foot pathology. Another study found that elephants receiving at least 14 hours of staff-directed exercise per week have a significantly reduced chance of being overweight or obese when compared to elephants receiving only one hour of exercise per week (Morfeld et al., 2015). The challenge in applying the results of these studies to the question at hand is that they only measured keeper-facilitated exercise programs, so the welfare consequences of free choice walking by zoo elephants are unknown.

Interest in zoo elephant walking has resulted in a number of scientific assessments. The first study of walking in zoo elephants occurred at Disney's Animal Kingdom, where researchers quantified African savanna elephant (Loxodonta africana) walking rates and evaluated associations between walking, social structure, and enclosure size (Leighty et al., 2009). Follow-up studies at the San Diego Safari Park measured 
African elephant walking while assessing the performance of various data collection devices (Rothwell et al., 2011; Miller et al., 2012). Walking in Asian elephants (Elephas maximus) was also measured using video analysis at the Melbourne Zoo (Rowell, 2014). While these studies provide insight into the available techniques for measuring walking, they are insufficient to draw broad conclusions about walking in zoo elephant populations due to their limited sample sizes, differing technology, and sampling periods that ranged from daytime-only to a full 24 hours.

Our goal was to build upon prior studies by quantifying distance walked within a broad population of both species of zoo elephants using a standardized methodology. A second objective was to determine the potential effects of a variety of housing, social, management, and demographic factors on distance walked. Finally, we sought to test for associations between distance walked and two established welfare metrics: foot health and joint health. We hypothesized that the factors most closely associated with walking would be the amount of space in which the elephants were housed, herd size, and enrichment program; we also hypothesized that walking would be correlated with foot health and joint health. Our study is the first large-scale multi-species investigation of zoo elephant walking and was as a component of the Using Science to Understand Zoo Elephant Welfare project, a multi-institutional collaborative effort to produce scientific data that will support decision making with regard to best practices in elephant management (Carlstead et al., 2013 ).

\section{Methods}

\section{Ethics statement}


This study was authorized by the management at each participating zoo and, where applicable, was reviewed and approved by zoo research or IACUC committees. Our study was non-invasive.

\section{Subjects and facilities}

Zoos that were accredited members of the Association of Zoos and Aquariums in 2012 were eligible for participation in this study provided that they managed only African or Asian elephants in a non-mixed species herd, and their herd included at least two adult female elephants who were not pregnant or experiencing severe illness or injury. A total of 49 zoos participated in the study; see acknowledgments for full list of participants. We used simplified random sampling to select two adult females (age $\geq 12$ years) as subjects from each zoo; however, 26 zoos only had two eligible subjects so there was no randomization. In one case there were four subjects from one zoo; this zoo housed African and Asian elephants in separate exhibits. Three subjects were removed from the dataset prior to analysis because they were transferred between zoos or died during the 2012 study year.

\section{Data collection}

All data were collected between May 2012 and November 2012. We used historical weather data (NOAA, 2011) to select a one month data collection period at each location that minimized inter-zoo variation in predicted daily maximum temperature (range: $22.3 \mathrm{C}$ to $34.1 \mathrm{C}$ ). We instructed zoos to collect five non-consecutive days of 
data (24 hours/day) from each subject within a one-month timeframe. Zoos could collect data from both subjects on the same day, or use an alternating schedule.

Leather anklets (Excelsior Leather, California, USA) were used to collect data following other successful studies (Miller et al, 2012; Rothwell et al., 2011) (Fig. 3.1). The anklets were custom-fit to elephants using measurements provided by participating zoos. The ends of the anklets had D-rings to which shackles and brummel hooks were attached. A pouch attached to each anklet contained a waterproof case (OtterBox Drybox OTR3-1000S, OtterBox, Colorado, USA) inside of which was a BT-Q1000XT GPS Travel Recorder (QStarz International Co., Taipei, Taiwan) and an accelerometer used to collect data for a related study (Chapter Four). The total weight of the unit was approximately $1.2 \mathrm{~kg}$ depending on the anklet size and number of shackles used. We shipped the anklets to the zoos and elephant care staff attached the anklets to one of the front legs of each subject; this leaves the anklet vulnerable to manipulation by the elephants' trunk, but the shape of the back ankle risks the anklet slipping off the leg. Most studies of zoo elephant movement have used collars to attach GPS devices (Leighty et al., 2008, 2009, 2010, ; Rothwell et al., 2011; Soulsby, 2013; Hacker et al., 2015); anklets were preferred for our multi-institutional study because they require less training to use and are safer for zoo staff to place on the elephants.

We programmed the GPS units to record data points at five second intervals. Each data point includes the date, time, latitude, longitude, and two estimates of location quality: the number of satellites used (NSAT) and the geometry of satellites used (HDOP: horizontal dilution of precision; Langley, 1999) in each location estimate (Chapter Two). The device also received real-time positional corrections to improve accuracy via wide 
area augmentation system (WAAS; [Chapter Two; Witte \& Wilson, 2005]). Finally, we requested that zoos place anklets in an exposed outdoor area fifteen minutes prior to data collection to provide sufficient time for the device to download satellite constellation information.

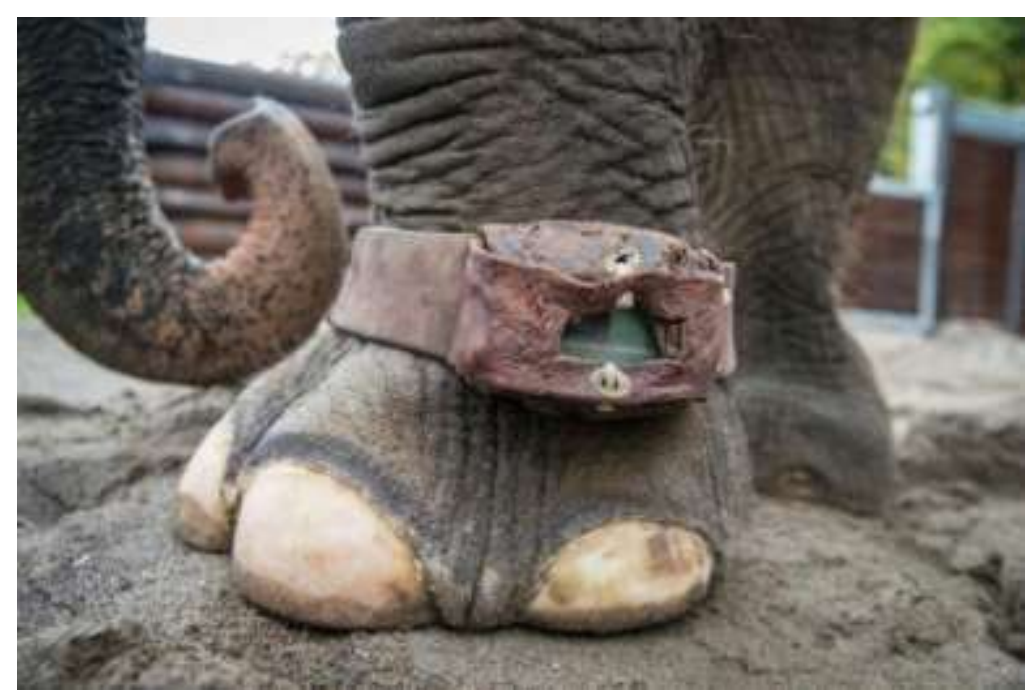

Figure 3.1: Asian zoo elephant wearing an anklet. Photo credit: Michael Durham/Oregon Zoo.

\section{Data processing}

Of the 49 original participating zoos, 40 zoos successfully collected data from 72 elephants. We downloaded the data using QTravel software (v 1.41, QStarz International Co.) and exported it into Microsoft Excel (Microsoft Corporation, Washington, USA). We removed data points that were known to have occurred while the elephant was housed indoors by using detailed reports on indoor/outdoor access provided by the zoos. We then mapped the data using ArcMap (v. 10.1, Environmental Systems Research Institute, California, USA) and used the clip function to remove any remaining data from indoor areas. We also clipped any data that fell outside of exhibit boundaries; in one test 
case we found that these data had a minimal effect (3\%) on distance traveled, but clipping the data ensures we underestimate rather than overestimate the distance. We then used a series of macros to screen out data points that failed to meet any of the following requirements: NSAT $\geq 4$, HDOP $<2$, WAAS-enabled (Chapter Two). Next, we calculated the Euclidean distance between remaining consecutive data points. Finally, we summed the distances for each day to calculate a daily distance traveled $(\mathrm{km})$, and we averaged these daily values to calculate mean daily walking distance $(\mathrm{km} /$ day $)$ for each elephant.

The amount of valid, outdoor walking data collected from the elephants in our study varied greatly. Thus, we applied additional exclusion criteria to ensure all elephants proceeding to the analysis stage met a minimum standard. First, elephants were required to have outdoor access for at least 20 hours; any 24 hour period that did not meet this criterion was excluded. This helped minimize the potential effect of long bouts of confinement indoors; post-inhibitory "rebound" behavior has caused increased locomotor activity following confinement in some species (Jones \& McGreevy, 2007). Second, elephants were required to have a total of at least 60 minutes of valid data for each one-hour period across all days of data collection (except for the 0-4 hours they did not have outdoor access). This allowed us to remove any bias due to elephants that were consistently missing data from the same time periods each day. Finally, any elephants with less than 3 days of data remaining were excluded from analysis. A total of 16 elephants were removed during data processing; our final dataset included 56 elephants from 30 zoos. 


\section{Independent variables}

Independent variables were selected based on hypotheses regarding their potential association with distance walked. Definitions for the variables selected for testing in this study are described in Table 3.1. Details on the collection and calculation of independent variables are presented by Meehan et al. (2015), Prado-Oviedo et al. (2015), Greco et al. (2015), Miller et al. (2015). Collection and calculation of recumbence variable is presented in Chapter Four.

We checked all continuous independent variables for outliers and removed any values that were greater than three standard deviations away from the mean. We adjusted some variables from continuous to binary because of zero-values for a high number of subjects within the sub-population of elephants in our study. Adjusted variables included two space variables (space experience in/out choice and percent time in/out choice), two flooring variables (percent time hard substrate and percent time soft substrate) and two social variables (percent time housed separately and percent time juveniles). 
Table 3.1: Definitions of independent variables tested for correlation with distance walked.

Variable
Age
Species
Origin
Space Experience
$\quad$ Total
$\quad$ Indoor
$\quad$ In/Out Choice
$\quad$ Outdoor
Percent Time
$\quad$ Soft Substrate
$\quad$ Hard Substrate
$\quad$ Housed Separately
$\quad$ Juveniles (<7 years old)
Social Experience
Animal Contact
Social Group Contact
Foot Physical Exam Score
Musculoskeletal Physical Exam Score
Recumbence
Herd Size
Temperature
Enrichment Program
Enrichment Diversity
Exercise Diversity
Feed Diversity
Feeding Predictability
Feed Total
Spread

\section{Description}

Age of elephant (years)

African savanna or Asian

Captive or wild born

Average size of the environment an elephant spends time in weighted by the amount of

time spent in that environment

For all environment types

For indoor environments only

For environments where there is a choice of indoors or outdoors

For outdoor environments only

Sum of monthly percent time spent in category, averaged over time period

Time spent in environment with $100 \%$ grass, sand, or rubber substrate

Time spent in environment with $100 \%$ concrete or stone aggregate substrate

Time spent housed in a social group of one

Time spent in social groups where an elephant 7 years or younger was present

Average size of a social group an elephant spends time with weighted by the amount

of time spent in that social group

Maximum number of unique elephants focal animal is in contact with

Maximum number of unique social groups focal animal is part of

Score of 0-12 indicating abnormalities on nails, pads, and interdigital space on any foot Score of 0-3 indicating range of motion or joint abnormalities from physical exam

Hours recumbent per day, averaged over all days of data collection

Total number of elephants at zoo

Average daily temperature at zoo, averaged over all days of data collection

Standardized factor score created using a polychoric PCA to examine the frequency of use of the different components of an enrichment program

Shannon diversity index score of enrichment activities types/frequencies conducted at zoo Shannon diversity index score of exercise types and frequencies conducted at zoo Shannon diversity index score of feeding types and frequencies conducted at zoo The predictability of feeding times ( $1=$ predictable, $2=$ semi-predictable, $3=$ unpredictable) Sum of the number of feedings during the day and number of feedings during the night Relative frequency of the percentage of time food was spread vs. all feeding techniques 


\section{Statistical analysis}

Univariate analyses were conducted on all independent variables of interest across all subjects. Variables with a significance level of $\mathrm{P}<0.15$ were tested for possible confounding effects of age, species, and origin, and were allowed to continue in the hierarchical model building process. Multivariate models were then fit using generalized estimating equations (GEE), which allows for repeated measurement and clustering of individual animals within zoos. At the multivariate stage, only variables with a significant level of $\mathrm{P}<0.05$ were included. Models were built by assessing individual predictors and conducting hierarchical selection based on quasi-likelihood under the independence model criterion (QIC) values and parameter estimates of explanatory variables. Models exhibiting multi-collinearity, as defined by a variance inflation factor (VIF) of greater than 10 and a Condition Index (CI) of greater than 30, were not considered for further analysis. The African elephant model used an autoregressive correlation matrix type, while the Asian elephant model specified an independent correlation structure. Statistical analyses were conducted by using SAS software, version 9.3 [PROC GENMOD, with options REPEATED, CORR=IND or AR, and DIST= NORMAL; SAS Institute, Inc., Cary, NC].

\section{Results}

\section{Summary of walking data}

Our final dataset included a total of 259 days of data, collected between May 7 , 2012 and November 1, 2012. For the majority of elephants $(n=43)$ five days of data were collected, but in some cases the data were limited to four days $(n=5)$ or three days 
$(\mathrm{n}=8)$. Our final dataset included 56 elephants at 30 zoos, including 33 African elephants (58.9\%) and 23 Asian elephants (41.1\%) (Fig. 3.2). The mean age of African elephants was 33.2 years (range $=20$ to 52); the mean age of Asian elephants was 40.39 years $($ range $=16$ to 61$)$.

Mean daily walking distance for all elephants was $5.34 \mathrm{~km} /$ day. African elephants walked an average of $5.40 \mathrm{~km} /$ day and Asian elephants walked an average of $5.26 \mathrm{~km} /$ day; there was no significant difference between the species $(\mathrm{P}=0.831)$ (Table 3.2). There was a large amount of individual variation in distance walked $(\mathrm{SD}=2.45$ km/day) (Fig. 3.2).

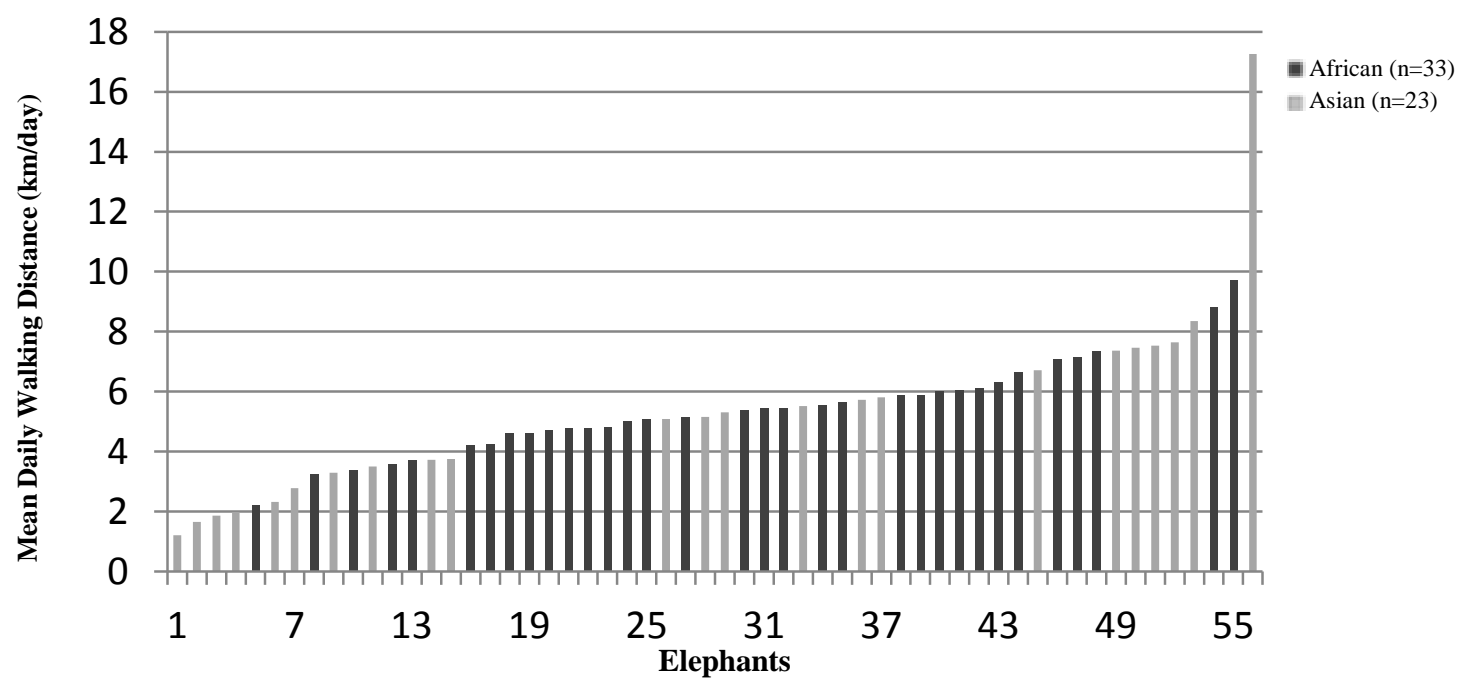

Figure 3.2: Mean daily walking distance in African and Asian zoo elephants. 
Table 3.2: Summary of walking data for African and Asian zoo elephants. A t-test was used to test for a difference in the means between species $(* \mathrm{P}<0.05)$.

\begin{tabular}{llrrrr}
\hline & & $\begin{array}{r}\text { Combined } \\
(\mathbf{n = 5 6})\end{array}$ & $\begin{array}{r}\text { African } \\
(\mathbf{n = 3 3 )}\end{array}$ & $\begin{array}{r}\text { Asian } \\
(\mathbf{n = 2 3 )}\end{array}$ & P \\
\hline & Mean & 5.34 & 5.40 & 5.26 & 0.831 \\
Mean Daily Walking & Min. & 1.21 & 2.20 & 1.21 & \\
Distance (km/day) & Max. & 17.26 & 9.71 & 17.26 & \\
& S.D. & 2.45 & 1.53 & 3.40 & \\
\hline
\end{tabular}

\section{Univariate analyses}

We evaluated a variety of demographic, housing, social, and management factors as predictors of distance walked (Table 3.1). Significant univariate correlations were observed between distance walked and a number of variables (Table 3.3). Distance walked was negatively correlated with age and percent time hard substrate overall. Distance walked was positively correlated with a number of space experience variables, including total overall and night; indoor overall, day, and night; and outdoor overall, day, and night. Distance walked was also positively correlated with herd size; animal contact overall, day, and night; social group contact; enrichment diversity; enrichment program; and feed diversity. Binary variables that were positively correlated with distance walked included space experience in/out choice day; percent time soft substrate overall and night; and percent time juveniles overall, day, and night. The categorical variable feeding predictability was significant in one category. Distance walked was correlated with origin, however, the small sample size in the significant category precluded any meaningful interpretation of the results. Finally, the variable musculoskeletal physical exam score included categories with both negative and positive 
correlations with distance walked. The population level descriptive statistics for the significant univariate analyses are shown in Table 3.4. 
Table 3.3: Univariate correlations between mean daily walking distance and independent variables $(* \mathbf{P}<0.05)$.

\begin{tabular}{|c|c|c|c|c|c|c|c|c|c|c|c|c|c|c|}
\hline \multirow[b]{2}{*}{ Variables } & \multicolumn{6}{|c|}{ Overall } & \multicolumn{4}{|c|}{ Day $^{\text {a }}$} & \multicolumn{4}{|c|}{ Night $^{a}$} \\
\hline & $+/-{ }^{b}$ & Reference & $\mathbf{n}$ & Beta & $\mathbf{P}$ & & $\mathbf{n}$ & Beta & $\mathbf{P}$ & & $\mathbf{n}$ & Beta & $\mathbf{P}$ & \\
\hline \multicolumn{15}{|l|}{ Demographics } \\
\hline Age & - & & 56 & -0.0835 & 0.037 & $*$ & & & & & & & & \\
\hline \multirow[t]{2}{*}{ Origin } & & ref=Captive & 50 & & & & & & & & & & & \\
\hline & + & Wild & 6 & 1.3249 & 0.0499 & $*$ & & & & & & & & \\
\hline \multirow[t]{2}{*}{ Species } & & ref $=$ African & 33 & & & & & & & & & & & \\
\hline & - & Asian & 23 & -0.1443 & 0.875 & & & & & & & & & \\
\hline \multicolumn{15}{|l|}{ Space } \\
\hline Space Experience Total $\left(500 \mathrm{ft}^{2}\right)$ & + & & 54 & 0.0076 & 0.128 & $*$ & 54 & 0.0045 & 0.312 & & 54 & 0.0077 & 0.093 & $*$ \\
\hline Space Experience Indoor $\left(500 \mathrm{ft}^{2}\right)$ & + & & 54 & 0.7247 & 0.008 & $*$ & 54 & 0.3896 & 0.026 & $*$ & 54 & 0.7625 & 0.005 & $*$ \\
\hline Space Experience Outdoor $\left(500 \mathrm{ft}^{2}\right)$ & + & & 54 & 0.0077 & 0.095 & $*$ & 56 & 0.0053 & 0.131 & $*$ & 54 & 0.0104 & 0.006 & $*$ \\
\hline \multirow[t]{2}{*}{ Space Experience In/Out Choice $\left(500 \mathrm{ft}^{2}\right)$} & & ref $=$ None & 19 & & & & 29 & & & & 21 & & & \\
\hline & + & Any & 37 & 0.8673 & 0.2764 & & 27 & 1.2546 & 0.1035 & $*$ & 35 & $\begin{array}{c}- \\
0.2531\end{array}$ & 0.7977 & \\
\hline \multicolumn{15}{|l|}{ Flooring } \\
\hline \multirow[t]{2}{*}{ Percent Time Hard Substrate } & & ref $=$ None & 24 & & & & 28 & & & & 27 & & & \\
\hline & - & Any & 32 & -1.3682 & 0.086 & $*$ & 28 & $\begin{array}{c}- \\
0.8872\end{array}$ & 0.240 & & 29 & $\begin{array}{c}- \\
0.5986\end{array}$ & 0.452 & \\
\hline \multirow[t]{2}{*}{ Percent Time Soft Substrate } & & ref $=$ None & 33 & & & & 36 & & & & 39 & & & \\
\hline & + & Any & 23 & 1.4220 & 0.107 & $*$ & 20 & 1.3825 & 0.165 & & 17 & 1.8114 & 0.097 & $*$ \\
\hline \multicolumn{15}{|l|}{ Social } \\
\hline Herd Size & + & & 54 & 0.4901 & 0.144 & $*$ & & & & & & & & \\
\hline Animal Contact & + & & 54 & 0.6875 & 0.086 & $*$ & 54 & 0.6875 & 0.086 & $*$ & 54 & 0.6258 & 0.135 & $*$ \\
\hline Social Experience & + & & 54 & 0.6579 & 0.208 & & 54 & 0.4097 & 0.290 & & 54 & 0.8805 & 0.176 & \\
\hline Social Group Contact & & & 54 & 0.4143 & 0.060 & $*$ & & & & & & & & \\
\hline \multirow[t]{2}{*}{ Percent Time Juveniles (age <7) } & & ref $=$ None & 47 & & & & 47 & & & & 47 & & & \\
\hline & + & Any & 9 & 3.1369 & 0.009 & $*$ & 9 & 3.1369 & 0.009 & $*$ & 9 & 3.1369 & 0.009 & $*$ \\
\hline \multirow[t]{2}{*}{ Percent Time Housed Separately } & & ref $=$ None & 28 & & & & 38 & & & & 33 & & & \\
\hline & - & Any & 28 & 0.5635 & 0.453 & & 18 & 0.8662 & 0.422 & & 23 & $\begin{array}{c}- \\
0.5888\end{array}$ & 0.443 & \\
\hline
\end{tabular}




\begin{tabular}{|c|c|c|c|c|c|}
\hline Management & & & & & \\
\hline Enrichment Diversity & + & & 50 & 3.8123 & 0.071 \\
\hline Enrichment Program & + & & 50 & 0.6860 & 0.066 \\
\hline Exercise Diversity & + & & 50 & 0.8468 & 0.250 \\
\hline Feed Diversity & + & & 50 & 3.0855 & 0.096 \\
\hline Feeding Predictability & & $\mathrm{ref}=1$ & 13 & & \\
\hline & + & 2 & 24 & 0.8879 & 0.293 \\
\hline & + & 3 & 13 & 1.8638 & 0.011 \\
\hline Spread & + & & 50 & -1.5861 & 0.535 \\
\hline Feed Total & + & & 48 & 0.1221 & 0.369 \\
\hline Other & & & & & \\
\hline Foot Physical Exam Score & - & & 51 & 0.0464 & 0.750 \\
\hline Musculoskeletal Physical Exam Score & & ref $=0$ & 29 & & \\
\hline & - & 1 & 12 & -0.8614 & 0.138 \\
\hline & - & 2 & 5 & -2.3579 & 0.001 \\
\hline & - & 3 & 1 & 1.1269 & 0.001 \\
\hline Temperature $^{\mathrm{f}}$ & - & & 56 & -0.1311 & 0.059 \\
\hline Recumbence & + & & 55 & -0.1867 & 0.413 \\
\hline
\end{tabular}

${ }^{a}$ Day and night are defined as the number of hours in a 24 hour period considered daytime or nighttime according to management schedule.

${ }^{\mathrm{b}}$ Hypothesized direction of relationship between mean daily walking distance and variable. 
Table 3.4: Independent variables that had a significant univariate correlation with mean daily walking distance. The sample size and mean age of elephants used in the correlation is provided. Variable data, where applicable, provides context for the experience of the elephants included in the analysis.

\begin{tabular}{|c|c|c|c|c|c|c|c|c|c|}
\hline \multirow[b]{2}{*}{ Variable } & \multirow[b]{2}{*}{ Mgmt. } & \multirow[b]{2}{*}{ Reference } & \multirow[b]{2}{*}{$\mathbf{n}$} & \multirow[b]{2}{*}{$\begin{array}{c}\text { Mean } \\
\text { Age }\end{array}$} & \multicolumn{5}{|c|}{ Variable } \\
\hline & & & & & Mean & SD & Min & Max & Median \\
\hline Age & & & 56 & - & 36.14 & 10.44 & 16 & 61 & 34.5 \\
\hline \multirow[t]{2}{*}{ Origin } & & ref=Wild & 50 & 37.4 & - & - & - & - & - \\
\hline & & Captive & 6 & 25.3 & - & - & - & - & - \\
\hline Space Experience Total $\left(500 \mathrm{ft}^{2}\right)$ & Overall & & 54 & 36.1 & 54.52 & 46.47 & 12 & 228.19 & 33.62 \\
\hline Space Experience Total $\left(500 \mathrm{ft}^{2}\right)$ & Night & & 54 & 36.1 & 46.48 & 47.98 & 2 & 227.42 & 29.18 \\
\hline Space Experience Indoor $\left(500 \mathrm{ft}^{2}\right)$ & Overall & & 54 & 36.1 & 1.86 & 1.49 & 0 & 4.72 & 1.77 \\
\hline Space Experience Indoor $\left(500 \mathrm{ft}^{2}\right)$ & Day & & 54 & 36.1 & 1.87 & 1.95 & 0 & 7.45 & 1.48 \\
\hline Space Experience Indoor $\left(500 \mathrm{ft}^{2}\right)$ & Night & & 54 & 36.1 & 1.95 & 1.61 & 0 & 5.15 & 1.61 \\
\hline Space Experience Outdoor $\left(500 \mathrm{ft}^{2}\right)$ & Overall & & 54 & 36.1 & 71.48 & 57.79 & 13 & 245.27 & 44.15 \\
\hline Space Experience Outdoor $\left(500 \mathrm{ft}^{2}\right)$ & Day & & 56 & 36.1 & 83.97 & 75.85 & 13 & 296.92 & 52.32 \\
\hline Space Experience Outdoor $\left(500 \mathrm{ft}^{2}\right)$ & Night & & 54 & 36.1 & 52.69 & 58.99 & 0 & 244.04 & 36.44 \\
\hline \multirow[t]{2}{*}{ Space Experience In/Out Choice $\left(500 \mathrm{ft}^{2}\right)$} & Day & ref $=0 \%$ & 29 & 37.1 & - & - & - & - & - \\
\hline & & $>0 \%$ & 27 & 35.1 & 44.03 & 35.87 & 6 & 113 & 32 \\
\hline \multirow[t]{2}{*}{ Percent Time Hard Substrate } & Overall & ref $=0 \%$ & 24 & 31.3 & - & - & - & - & - \\
\hline & & $>0 \%$ & 32 & 39.8 & 12.19 & 8.95 & 1 & 32 & 7 \\
\hline \multirow[t]{2}{*}{ Percent Time Soft Substrate } & Overall & ref $=0 \%$ & 33 & 36.4 & - & - & - & - & - \\
\hline & & $>0 \%$ & 23 & 35.8 & 19.94 & 16.40 & 0 & 50 & 18 \\
\hline \multirow[t]{2}{*}{ Percent Time Soft Substrate } & Night & ref $=0 \%$ & 39 & 36.7 & - & - & - & - & - \\
\hline & & $>0 \%$ & 17 & 34.9 & 33.62 & 17.39 & 15 & 67 & 29 \\
\hline Herd Size & & & 54 & 36.7 & 3.44 & 1.70 & 2 & 8.00 & 3.00 \\
\hline Animal Contact & Overall, Day & & 54 & 36.7 & 1.98 & 1.45 & 0 & 6.00 & 1.00 \\
\hline Animal Contact & Night & & 54 & 36.7 & 1.69 & 1.24 & 0 & 5.00 & 1.00 \\
\hline Social Group Contact & Overall & & 54 & 36.7 & 2.78 & 2.18 & 1 & 10.00 & 2.00 \\
\hline \multirow[t]{2}{*}{ Percent Time Juveniles } & $\begin{array}{l}\text { Overall, Day, } \\
\text { Night }\end{array}$ & $\mathrm{ref}=0 \%$ & 47 & 37.8 & - & - & - & - & - \\
\hline & & $>0 \%$ & 9 & 27.4 & 13.25 & 31.04 & 0 & 100 & 0 \\
\hline
\end{tabular}


Enrichment Diversity

Enrichment Program

Feed Diversity

Feeding Predictability

Musculoskeletal Physical Exam Score

$\begin{array}{rccccccc} & 50 & 35.4 & 2.88 & 0.17 & 3 & 3.27 & 2.86 \\ & 50 & 35.4 & 0.26 & 0.89 & -2 & 1.97 & 0.13 \\ & 50 & 35.4 & 1.37 & 0.27 & 1 & 1.79 & 1.39 \\ \mathrm{ref}=1 & 13 & 32.8 & - & - & - & - & - \\ 2 & 24 & 39.2 & - & - & - & - & - \\ 3 & 13 & 31 & - & - & - & - & - \\ \mathrm{ref}=0 & 29 & 34.1 & - & - & - & - & - \\ 1 & 12 & 37.8 & - & - & - & - & - \\ 2 & 5 & 45.8 & - & - & - & - & - \\ 3 & 1 & 45 & - & - & - & - & -\end{array}$




\section{Multivariate model}

The distance walked multivariate model (Table 3.5) includes age, social group contact, space experience total night, feeding diversity, and feeding schedule. The model predicts that distance walked will decrease by $0.09 \mathrm{~km} /$ day for each additional year in age $(\mathrm{P}=0.014)$. In addition to being an independent variable, age confounds the variables social group contact and feeding diversity; the variable species is included as a confounder of age indicating that species is a factor that is both related to age and distance walked and is included in the model to control for its potential effects. The model predicts that elephants will increase distance walked by $0.4219 \mathrm{~km} /$ day with every additional social group $(\mathrm{P}<0.001)$. Elephants are predicted to decrease their daily walking distance by $0.023 \mathrm{~km}$ for every addition $500 \mathrm{ft}^{2}$ of space experience at night. Two feeding variables are included in the multivariate model. First, the model predicts that elephants with more diverse feeding programs tend to have significantly higher walking distances $(\mathrm{P}=0.027)$. Secondly, the model states that distance walked is not significantly different between elephants with predictable feeding schedules and semipredictable feeding schedules $(\mathrm{P}=0.631)$, however, elephants with unpredictable feeding schedules are predicted to walk $1.2855 \mathrm{~km} /$ day more than elephants with a predictable feeding schedule $(\mathrm{P}=0.044)$. 
Table 3.5: Mean daily walking distance multivariate model $(* P<0.05)$.

\begin{tabular}{lrrrrr}
\hline Parameter & Estimate & $\begin{array}{r}\text { Standard } \\
\text { Error }\end{array}$ & Pr $>|\mathbf{Z}|$ \\
\hline Intercept & 4.01 & 1.917 & 0.036 & \\
Age & -0.09 & 0.037 & 0.014 & $*$ \\
Species: African & - & - & - & \\
Species: Asian & 1.2956 & 0.644 & 0.044 & \\
Social Group Contact & 0.4219 & 0.100 & $<0.001$ & $*$ \\
Space Experience Total Night $\left(500 \mathrm{ft}^{2}\right)$ & -0.023 & 0.009 & 0.009 & $*$ \\
Feed Diversity & 2.7357 & 1.233 & 0.027 & $*$ \\
Feeding Predictability: Predictable & - & - & - & \\
Feeding Predictability: Semi- & -0.37 & 0.770 & 0.631 & \\
Predictable & 1.2855 & 0.639 & 0.044 & $*$ \\
Feeding Predictability: Unpredictable & & & & & \\
\hline
\end{tabular}

$\underline{\text { IV. Discussion }}$

\section{Summary of walking data}

We found that, on average, African savanna and Asian zoo elephants walk nearly six kilometers per day. Previous studies using GPS to measure walking in zoo elephants differ in their methodologies but are generally comparable to our results. Eight adult African savanna elephants at the San Diego Safari Park walked an average of $8.65 \pm 0.64$ $\mathrm{km}$ /day (Miller et al., 2012), while two members of the same herd walked an average of $6.04 \mathrm{~km}$ during trials that included an average of 14.84 hours of data (Rothwell et al., 2011). Seven adult female African elephants at Disney's Animal Kingdom walked an average of $3.68 \mathrm{~km}$ between the hours of 08:00 and 17:00 (Leighty et al., 2009). A recent study at the Melbourne Zoo used a grid overlay system and video analysis estimated five Asian elephant adults walked $9.05 \pm 0.61 \mathrm{~km}$ between 0600 and midnight (Rowell, 2014). As GPS technology and zoo methodologies continue to improve, we can expect 
more increased accuracy and more comprehensive results; however, studies of zoo elephant walking show zoo elephants generally walk within the 5 to $10 \mathrm{~km}$ per day range of wild elephants under non-extreme environmental conditions (Leighty et al., 2009).

\section{Feeding}

Elephants are large herbivores with high metabolic needs but a relatively inefficient digestive system (Hatt \& Clauss, 2006; Sukumar, 2003). To ingest the large quantities of food they require, elephants spend the majority of their time feeding, both in the wild (Spinage, 1994; Sukumar, 2003), and in zoos (Greco et al. 2015). African and Asian zoo elephants spend $65.1 \%$ and $50.5 \%$ of their time feeding, respectively, with an additional $1.4-1.5 \%$ of time spend feeding while walking (Greco et al. 2015). Based on the unique feeding requirements of elephants, some have argued that zoos should strive to replicate wild elephant feeding ecology by distributing food both temporally and spatially, and by adding complexity and processing time to feeding (Veasey, 2006). In general, our results support this assertion, as we found that using unscheduled feeding times and more diverse feedings predict increased walking in zoo elephants.

One possible explanation for the effect of feeding on walking distance is that more dynamic feeding regimens lead to an increase in exploratory behavior. Exploratory behavior is considered an indicator of positive welfare (Young, 2003), and includes both inquisitive exploration - in which an animal actively seeks change or novel stimuli, and inspective exploration - in which an animal responds to an environmental change (Berlyne, 1960; Boissy, 2007; Whitham \& Wielebnowski, 2013). Shepherdson et al. (1993) found that leopard cats switched to an unpredictable temporal feeding schedule 
with food items hidden throughout the enclosure increased their exploratory behavior. In this study the relative effects of temporal and spatial predictability are confounded, and as we did not test spatial predictability directly in our study, it may be an unmeasured factor that also affected walking.

Zoos seeking to initiate a more dynamic feeding system should consider a few factors first. The exhibit must provide sufficient opportunities for the elephants to actually execute exploratory and foraging behaviors, as the inability to respond appropriately to stimuli may mean that motivation to perform these behaviors may not be reduced, resulting in welfare problems (Hughes \& Duncan, 1988); and ideally, empower the animals and return some control to them by integrating behaviorally-contingent feeding opportunities into the system (e.g., species-specific foraging styles in ursids [Carlstead et al., 1991]; fishing behaviors in cats [Shepherdson et al., 1993]). Zoos may also wish to use a unique and reliable signal prior to unscheduled feedings. Not only might this provide the beneficial effects of anticipatory behavior (e.g., salivating) preceding the consummatory act (Boissy et al., 2007); a signal may minimize the negative consequences (e.g., frustration, aggression) that may arise from animals mistaking false signals for the impending arrival of food (Bassett \& Buchanan-Smith, 2007).

\section{Social}

We did not find any evidence to support our hypothesis that herd size would lead to an increase in walking. However, exposure to more social groupings is associated with walking. This effect is difficult to interpret due to the complexities of elephant sociality, 
but a larger number of social groups could better replicate the natural social conditions of wild elephants. African elephants exhibit fission-fusion societies in which core social groups temporarily divide and reunite over the course of hours or days, or may fuse with other social groups to form much larger social units (Archie et al., 2006; Moss, 2011; Sukumar, 2003; Wittemyer et al., 2005). Asian elephants associations have also been characterized as fission-fusion, and Asian elephant females are said to "shuffle amongst a subset of preferred companions" (De Silva et al., 2011). Admittedly it is difficult to apply this finding in a meaningful way in zoos, but at a minimum it highlights the importance of continued consideration of social systems and how the zoo environment can adequately provide appropriate social lives to improve animal activity and welfare.

\section{Space}

Contrary to our original hypothesis, we found that increased space experience at night is negatively correlated with distance walked. One possible explanation is that because elephants with more nighttime space spend more time resting (Chapter Four) they have less time to engage in walking; however, that would suggest a correlation between distance walked and recumbence which we did not find. Regardless of possible explanations, our results do not necessitate decreased space experience to encourage walking in zoo elephants. On the contrary, large spaces are a prerequisite for any number of factors affecting walking distance, including increased social complexity, diverse feeding strategies, and more room to roam when engaged in forage searching behaviors (Veasey, 2006). By this measure, our results support the notion that the quality and complexity of the space are important for the welfare of zoo animals (Hosey et al., 2013), 
including elephants (Hutchins, 2006; Shepherdson, 1999; Veasey, 2006), and zoos

interested in increasing walking in their elephants need not rely solely on larger exhibits.

A holistic approach to elephant welfare dictates that we must also consider the

established benefits of increased space experience, including a decrease in stereotypical

behavior (Greco et al., 2015), an increase in recumbent rest behavior (Chapter Four), and

an increase in the chance of regular ovarian cyclicity (in Asian elephants) (Brown et al., 2015).

\section{Welfare measures}

Measuring walking distance and associated factors in zoo elephants provides some interesting data. However, for zoos interested in finding new ways to improve the welfare of their animals, the question of whether walking is correlated with established measures of welfare is the primary concern. Walking has been proposed as a biologically meaningful metric for measuring the success of elephant programs in achieving improved welfare standards (Hutchins, 2006), but our results provide no strong evidence to suggest that walking is tied to two established measures of welfare - foot health and joint health. One possible explanation is that the sample size and range of measures presented in this population were too limited to identify correlations.

\section{Limitations and perspectives}

GPS data loggers have been used extensively to study elephant movement both in the wild (Blake et al., 2001; Blake et al., 2008; Boettiger et al., 2011; Campos-Arceiz et al., 2008; Douglas-Hamilton, 1998; Graham et al., 2009; Kumar et al., 2010; Ngene et al., 
2010; Thompson et al., 2008) and in zoos (Hacker et al., 2015; Leighty et al., 2008, 2009, 2010; Miller et al., 2012; Rothwell et al., 2011; Soulsby, 2013). Despite continuing improvements in GPS technology, this type of data collection requires some special considerations, which we will briefly address. First, attaching a device to an animal has the potential to change its behavior (Murray \& Fuller, 2000), and GPS collars deployed in the wild have affected short-term movement and activity patterns in a variety of mammalian species (Brooks et al., 2008; Cattet et al., 2008; Dechen-Quinn et al., 2012; Dennis \& Shah, 2012; Morellett et al., 2009; Rode et al., 2014), although the relative effects of capture/handling stress and collar attachment are confounded in these studies. The effect of anklets on elephant behavior has not been examined, but in a previous study, zoo elephants desensitized to wearing GPS collars showed no behavioral effects (Horback et al., 2012). In addition, zoos in our study received the anklets prior to the onset of data collection and we requested they desensitize focal elephants to the anklets; many zoos also proactively built test anklets to use before our anklets arrived.

Next, GPS data loggers must be tested to ensure accuracy and precision. The device used in the current study was also used in a previous study of zoo elephant movement (Miller et al., 2012) during which trials were conducted to determine accuracy and precision. Measurements of 1-m intervals found that the units were accurate at $0.8405 \mathrm{~m}( \pm 0.0635)$, suggesting that anklets may underestimate distances travelled. A stationary unit collecting data every five seconds for 24 hours resulted in an average horizontal shifting value of $0.0087 \mathrm{~m}( \pm 0.0002)$, indicating that the unit is highly precise. Finally, the walking distances in this study include any walking that occurred during keeper-directed exercise and locomotor stereotypies. Based on reports from individual 
zoos (see: Meehan et al., 2015), the elephants in our study receive approximately 2.26 hours of walking-based exercise on average per week (range: 1 to 7). While some walking-based exercise may have occurred on GPS data collection days, we mapped the data to verify that no "outside the exhibit" walks occurred in our elephants, and overall, the amount of time engaged in walking-based exercise is small compared to the total amount of data we collected from the elephants. Likewise, a study of stereotypical behavior in 76 zoo elephants conducted the same year as the current study found that less than $8 \%$ of stereotypic behavior observations involved locomotor movements and only $22.3 \%$ of elephants showed locomotor stereotypies (Greco et al., 2015). The more common forms of stereotypy should have limited effect on GPS anklet data, at least compared to GPS collar data (Miller et al., 2012). We acknowledge that although we have taken steps to minimize error in our dataset, we cannot eliminate it entirely. However, the errors are generally consistent across institutions and independent of the factors associated with distance walked.

\section{Conclusion}

The movement of elephants in zoos has become an issue of concern in recent years due to assumptions about the health and welfare benefits of walking, and the motivations of elephants to explore and investigate their environment. To promote walking and exploration in elephants, zoos have invested in new exhibit design and husbandry programs, and are interested in how these factors are affecting walking. By using GPS anklets to measure walking distance, we found that African and Asian zoo elephants walk an average of $5.34 \mathrm{~km} /$ day. Feeding variables have a particularly strong 
association with walking, as elephants with more dynamic feeding regimens are predicted to walk more. Elephants that spend time in a greater number of social groups are also predicted to walk more. Distance walked is negatively correlated with age and nighttime space experience, the latter suggesting that zoos interested in increasing walking in their elephants need not rely solely on larger exhibits, but can increase walking by adding quality and complexity to exhibits. Finally, despite our inability to establish a definitive link between walking and other measures of elephant welfare, it remains reasonable that such a link exists, but may not be measurable at this scale or in this sub-population of zoo elephants. 
Chapter Four: Using accelerometers to determine factors affecting recumbent rest in African savanna elephants (Loxodonta africana) and Asian elephants (Elephas maximus) in zoos

\section{$\underline{\text { I. Introduction }}$}

Obtaining adequate rest is essential for the good health and welfare of animals (Botreau et al., 2007; Broom \& Fraser, 2007), yet few studies of zoo animal welfare focus on resting behaviors, perhaps due to the difficulty of measuring and interpreting these behaviors. For example, many species perform rest both while standing rest and recumbent; of these, the welfare implications of recumbence are better understood due to extensive research on cattle. Cattle are highly motivated to lie down (Jensen et al., 2005), and cattle that have been deprived of opportunities for recumbence, feeding, and social contact will prioritize compensatory recumbence over other behaviors (Metz, 1985), (Munksgaard et al., 2005). Reducing opportunities for cattle to lie down can also affect growth hormone levels (Munksgaard \& Løvendahl, 1993) and result in various behavioral or physiological indications of stress (Munksgaard et al., 1999). In addition, cattle that spend more time standing are at a greater risk for lameness and hoof problems (Bell et al., 2009). The amount of recumbence shown by cattle depends on the type of surface on which they are resting: hard concrete floors result in significantly less time spent lying down (Haley et al., 2001).

Another important component of resting is sleep. Many species (e.g., cattle, horses, elephants; [Broom \& Fraser, 2007; Tobler, 1995]) require recumbence for some types of sleep; in these species a lack of recumbence may lead to sleep deprivation. The 
health and welfare consequences of sleep deprivation have been well-studied in humans and laboratory animals. In a variety of mammalian species, sleep deprivation causes disruptions in vital biological processes including immune function, thermoregulation, energy conservation, tissue restoration, and higher cognitive function (Brown et al., 2012; Everson et al., 1989; Everson, 1995; Rechtschaffen \& Bergmann, 2002; Toth, 1995).

Like cattle and horses, the resting postures of African savanna elephants and Asian elephants include both standing rest and recumbent rest. Standing rest often precedes recumbence (Tobler, 1992), and recumbent elephants seem to quickly fall asleep: they are immediately motionless with their eyes closed (Tobler, 1992), and display heavy, sometimes irregular respiration (Hartmann et al., 1968), twitching of the musculature and eyelids (Hartmann et al., 1968; Tobler, 1992), snoring (Moss, 1975; Wyatt \& Eltringham, 1974), and sometimes loud vocalizations (Tobler, 1992). Elephant sleep has not been described using EEG, so the exact nature of sleep occurring during recumbence is unknown. Regardless, recumbence is a natural resting behavior exhibited by elephants both in the wild (Adams \& Berg, 1980; Guy, 1976; Hendrichs \& Hendrichs, 1971; McKay, 1973; Moss, 1975; Sikes, 1971; Wyatt \& Eltringham, 1974) and in managed care, (Brockett et al., 1999; Hartmann et al., 1968; Kandler, 2010; Kühme, 1963; McKnight, 1995; Meller et al., 2007; Tobler, 1992; Weisz et al., 2000; Wilson et al., 2006).

Our study is the first large-scale multi-species investigation of zoo elephant recumbence and was a component of the Using Science to Understand Zoo Elephant Welfare project, a multi-institutional collaborative effort to produce scientific data that will support decision making with regard to best practices in elephant management 
(Carlstead et al., 2013). The two objectives for the current study were to: 1) quantify and describe zoo elephant recumbence to better understand its timing, patterns, and prevalence, and 2) determine the potential effects of a variety of social, housing, management, and demographic factors on recumbence. We hypothesized that the factors most closely associated with recumbence would be the types of flooring substrate on which elephants spent time and the amount of space at night in which the elephants were housed.

\section{$\underline{\text { II. Methods }}$}

\section{Ethics statement}

This study was authorized by the management at each participating zoo and, where applicable, was reviewed and approved by zoo research or IACUC committees. Our study was non-invasive.

\section{Subjects and facilities}

Zoos that were accredited members of the Association of Zoos and Aquariums in 2012 were eligible for participation in this study provided that they managed only African or Asian elephants in a non-mixed species herd, and their herd included at least two adult female elephants who were not pregnant or experiencing severe illness or injury. A total of 49 zoos participated in the study. We used simplified random sampling to select two adult females (age $\geq 12$ years) as subjects from each zoo; however, 26 zoos only had two eligible subjects so there was no randomization. In one case there were four subjects from one zoo; this zoo housed African and Asian elephants in separate 
exhibits. Three subjects were removed from the dataset prior to analysis because they were transferred between zoos or died during the 2012 study year.

\section{Data collection}

All data were collected between May 2012 and November 2012. We used historical weather data (NOAA, 2011) to select a one month data collection period at each location that minimized inter-zoo variation in predicted daily maximum temperature (range: $22.3 \mathrm{C}$ to $34.1 \mathrm{C}$ ). We instructed zoos to collect five non-consecutive days of data (24 hours/day) from each subject within a one-month timeframe. Zoos could collect data from both subjects on the same day, or use an alternating schedule.

We used an anklet-based system as described previously (Chapter Three; Miller et al., 2012) to collect data (Fig. 4.1). We shipped custom-fit leather anklets (Excelsior Leather, California, USA) to each zoo; elephant care staff attached the anklets to one of the front legs of each subject. A leather pouch attached to the anklet contained a waterproof case (OtterBox Drybox OTR3-1000S, OtterBox, Colorado, USA) inside of which was a HOBO Pendant G Data Logger accelerometer (model UA-004-64, Onset Computer Corporation, Massachusetts, USA) to collect recumbence data, and a GPS data logger used to collect data for a related study (Chapter Three).

Accelerometers are data loggers that can measure g-force and degree of tilt; we chose to evaluate recumbence using g-force measurement following previous studies of cattle recumbence using the same device (Ito et al., 2009; Ledgerwood et al., 2010). The accelerometer was placed inside the anklet such that the $\mathrm{x}$-axis was perpendicular to the 
ground pointing dorsally, and the y- and z-axes were parallel to the ground. We programmed the accelerometers to collect $\mathrm{x}$-axis data at one-minute intervals.

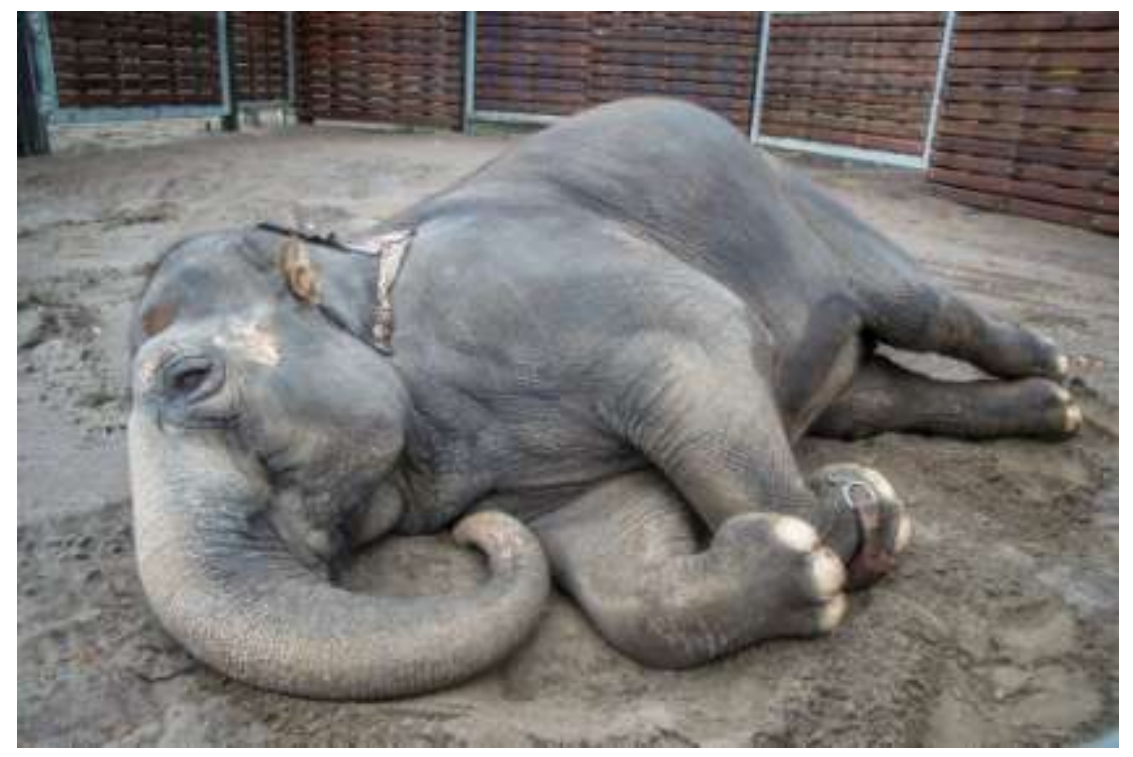

Figure 4.1: Recumbent Asian zoo elephant wearing an anklet. Photo credit: Michael Durham/Oregon Zoo.

\section{Data processing}

Of the 49 original participating zoos, 40 zoos successfully collected data from 72 elephants. We downloaded the data using HOBOware Pro software (v. 3.2.0, Onset Computer Corporation) and exported it into Microsoft Excel (Microsoft Corporation, Washington, USA). We then followed established data processing methods (Ledgerwood et al., 2010) by adding a constant (3.2) to all g-force values (range: -3.2 to 3.2) to make them positive (range: 0 to 6.4 ), then coding values $<2.55$ as standing and $\geq 2.55$ as lying. All lying values indicate accelerometer tilt of $\geq 50^{\circ}$, a cutoff selected based on visual observations of recumbence in cattle (Ledgerwood et al., 2010). Before the study began we validated these methods for elephants by outfitting two subjects with anklets and 
videotaping their behaviors over two nights. The accelerometers retrieved from the two elephants reported nightly recumbence duration with $96 \%$ and $97 \%$ accuracy. We also tested inter-unit agreement by including two accelerometers in the anklet of one elephant; the data were identical across units.

We omitted standing and lying bouts that consisted of only a single reading (e.g., a one-minute interval of "standing" sandwiched between "lying" bouts) because these readings may represent subtle leg movements during a period of consistent orientation (Endres \& Barberg, 2007; Ito et al., 2009). We summed all other lying time to calculate

recumbence (hours) for each day of data, and we averaged these daily values to calculate mean daily recumbence (hours/day). In addition, we calculated the nighttime (20:00 07:00) mean bout frequency by averaging the number of nightly recumbence bouts for each elephant, then averaging across all elephants. Finally, we calculated the nighttime mean bout duration by averaging the duration of nightly recumbent bouts for each elephant, then averaging across all elephants; however, we excluded nights on which elephants did not lay down to avoid under-estimating bout duration.

\section{Independent variables}

Independent variables were selected based on hypotheses regarding their potential association with recumbence. Definitions for the variables selected for testing in this study are described in Table 4.1. Details on the collection and calculation of independent variables are presented by Meehan et al. (2015), Prado-Oviedo et al. (2015), Greco et al. (2015), and Miller et al. (2015). Collection and calculation of the distance walked variable is presented in Chapter Three. 
We checked all continuous independent variables for outliers and removed any values that were greater than three standard deviations away from the mean. We adjusted some variables from continuous to binary because of zero-values for a high number of subjects within the sub-population of elephants in our study. Adjusted variables included two space variables (space experience in/out choice and percent time in/out choice), two flooring variables (percent time hard substrate and percent time soft substrate) and two social variables (percent time housed separately and percent time juveniles). 
Table 4.1: Definitions of independent variables tested for correlation with recumbence.

\begin{tabular}{|c|c|}
\hline Variable & Description \\
\hline Age & Age of elephant (years) \\
\hline Origin & Captive or wild born \\
\hline Space Experience & Average size of the environment an elephant spends time in weighted by the amount of time spent in that environment \\
\hline Total & For all environment types \\
\hline Indoor & For indoor environments only \\
\hline In/Out Choice & For environments where there is a choice of indoors or outdoors \\
\hline Outdoor & For outdoor environments only \\
\hline Indoor & Time spent in indoor environments \\
\hline In/Out Choice & Time spent in environments with an indoor/outdoor choice \\
\hline Outdoor & Time spent in outdoor environments \\
\hline Soft Substrate & Time spent in environment with $100 \%$ grass, sand, or rubber substrate \\
\hline Hard Substrate & Time spent in environment with $100 \%$ concrete or stone aggregate substrate \\
\hline Housed Separately & Time spent housed in a social group of one \\
\hline Juveniles (<7 years old) & Time spent in social groups where an elephant 7 years or younger was present \\
\hline Social Experience & Average size of a social group an elephant spends time with weighted by the amount of time spent in that social group \\
\hline Foot Physical Exam Score & Score of 0-12 indicating abnormalities on nails, pads, and interdigital space on any foot \\
\hline Walking Distance & Distance walked per day while outdoors, averaged over all days of data collection \\
\hline Temperature & Average daily temperature at zoo, averaged over all days of data collection \\
\hline Enrichment Program & $\begin{array}{l}\text { Standardized factor score created using a polychoric PCA to examine the frequency of use of the different components } \\
\text { of an enrichment program }\end{array}$ \\
\hline Enrichment Diversity & Shannon diversity index score of enrichment activities types and frequencies conducted at zoo \\
\hline Exercise Diversity & Shannon diversity index score of exercise types and frequencies conducted at zoo \\
\hline Herd Size & Total number of elephants at zoo \\
\hline
\end{tabular}




\section{Statistical analysis}

To determine whether there were interspecific differences in patterns of recumbence, we used two-sample Student's t-tests assuming equal variances to test three null hypotheses: that both species had the same (1) mean daily recumbence; (2) mean number of nighttime recumbence bouts; and (3) mean duration of nighttime recumbence bouts.

Univariate analyses were conducted on all independent variables of interest across all subjects. There was a significant correlation between species and mean daily recumbence $(\mathrm{P}<0.001)$, thus, separate multivariate models were created for African elephants and Asian elephants. Variables with a significance level of $\mathrm{P}<0.15$ were tested for possible confounding effects of age, species, and origin, and were allowed to continue in the hierarchical model building process. Multivariate models were then fit using generalized estimating equations (GEE), which allows for repeated measurement and clustering of individual animals within zoos. At the multivariate stage, only variables with a significant level of $\mathrm{P}<0.05$ were included. Models were built by assessing individual predictors and conducting hierarchical selection based on quasilikelihood under the independence model criterion (QIC) values and parameter estimates of explanatory variables. Models exhibiting multi-collinearity, as defined by a variance inflation factor (VIF) of greater than 10 and a Condition Index (CI) of greater than 30, were not considered for further analysis. The African elephant model used an autoregressive correlation matrix type, while the Asian elephant model specified an independent correlation structure. Statistical analyses were conducted by using SAS 
software, version 9.3 [PROC GENMOD, with options REPEATED, CORR=IND or AR, and DIST= NORMAL; SAS Institute, Inc., Cary, NC].

III. Results

Summary of recumbence data

Our final dataset included 344 days of data, collected between May 7, 2012 and November 1, 2012. A full 24 hours of data were collected on 277 days; on 67 days anklets were removed before a full 24 hours of data were collected, resulting in an average of 31 minutes (range: 2 to 105) when recumbence data were not available. Any recumbence occurring during these times was not recorded, thus, the mean daily recumbence values may slightly underestimate actual values. For the majority of elephants $(n=61)$ five days of data were collected, but in some cases the data were limited to four days $(n=6)$ or three days $(n=5)$.

Our final dataset included 72 elephants at 40 zoos, including 44 African elephants (61.1\%) and 28 Asian elephants (39.9\%) (Fig. 4.2). The mean age of African elephants was 32.6 years (range: 20 to 52); the mean age of Asian elephants was 40.0 years (range: 16 to 61$)$. 


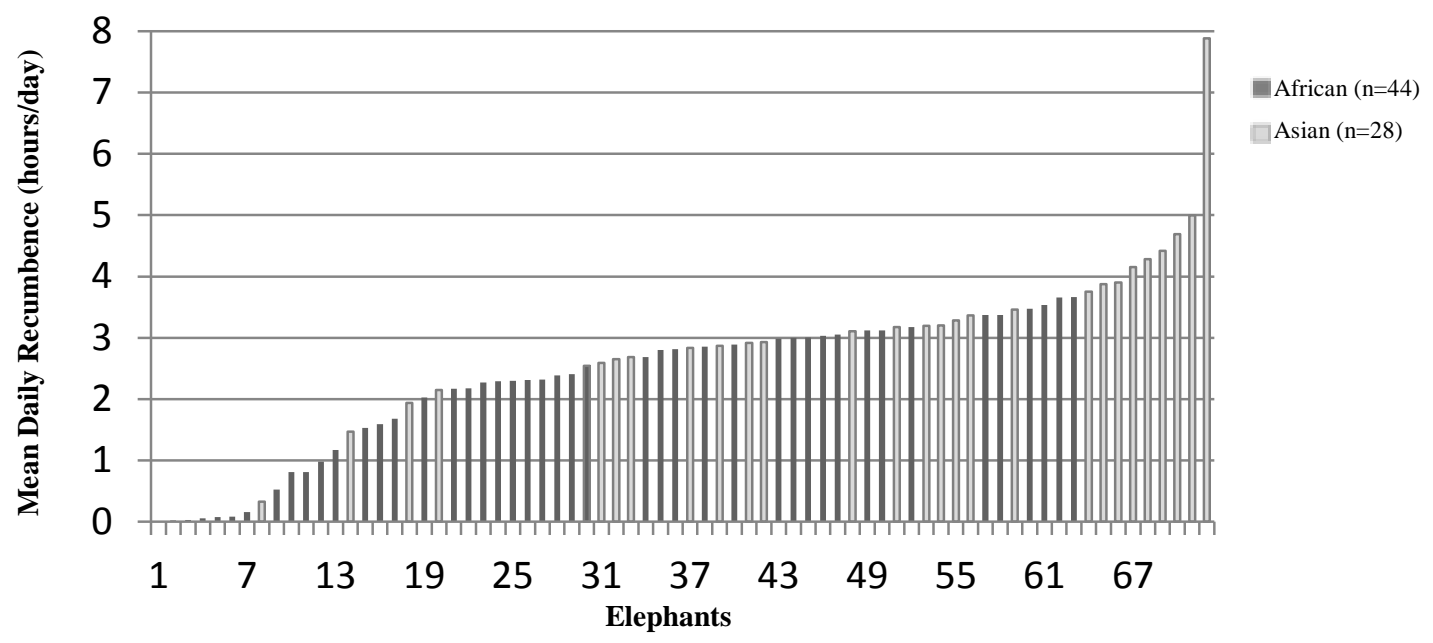

Figure 4.2: Recumbence in African and Asian zoo elephants.

Mean daily recumbence for all elephants was an average of 2.56 hours/day. African elephants had significantly lower recumbence (2.14 hours/day) than Asian elephants (3.22 hours/day) ( $\mathrm{P}$ < 0.001) (Table 4.2). Mean nighttime bout frequencies in African and Asian elephants were not significantly different at 3.10 and 3.08 bouts/night, respectively $(\mathrm{P}=0.96)$ (Table 4.2). Africans and Asians were different in mean nighttime bout duration $(\mathrm{P}<0.001)$ with African elephants recumbent an average of 39 minutes/bout and Asian elephants recumbent an average of 66 minutes/bout (Table 4.2). Variations in the standing and lying patterns of African and Asian elephants can be seen by comparing the behavior of representative individuals (Fig. 4.3). African and Asian elephants showed similar mean daily recumbence profiles: recumbence rarely occurred during the day, started to increase at 20:00, and reached a peak at 04:00 before sharply dropping off (Fig. 4.4). 
Table 4.2: Summary of recumbence data for African and Asian zoo elephants. A t-test was used to test for a difference in the means between species in each of the variables $(* \mathrm{P}<0.05)$.

\begin{tabular}{llrrrrr}
\hline & & $\begin{array}{r}\text { Combined } \\
(\mathbf{n = 7 2})\end{array}$ & $\begin{array}{r}\text { African } \\
(\mathbf{n = 4 4 )}\end{array}$ & $\begin{array}{r}\text { Asian } \\
(\mathbf{n = 2 8})\end{array}$ & P & \\
\hline \multirow{2}{*}{ Mean Daily } & Mean & 2.56 & 2.14 & 3.22 & $<0.001$ & $*$ \\
Recumbence & Min. & 0 & 0.02 & 0 & & \\
(Hours/Day) & Max. & 7.89 & 3.67 & 7.89 & & \\
& S.D. & 1.37 & 1.14 & 1.46 & & \\
\hline \multirow{2}{*}{ Mean Nighttime } & Mean & 3.09 & 3.10 & 3.08 & 0.96 & \\
Bout Frequency & Min. & 0.00 & 0.00 & 0.40 & & \\
(Bouts/Night) & Max. & 6.33 & 5.80 & 6.33 & & \\
& S.D. & 1.44 & 1.45 & 1.45 & & \\
\hline \multirow{2}{*}{ Mean Nighttime } & Mean & 0.83 & 0.65 & 1.10 & $<0.001$ & $*$ \\
Bout Duration & Min. & 0.03 & 0.03 & 0.42 & & \\
(Hours/Bout) & Max. & 1.97 & 1.43 & 1.97 & & \\
& S.D. & 0.42 & 0.30 & 0.43 & & \\
\hline
\end{tabular}



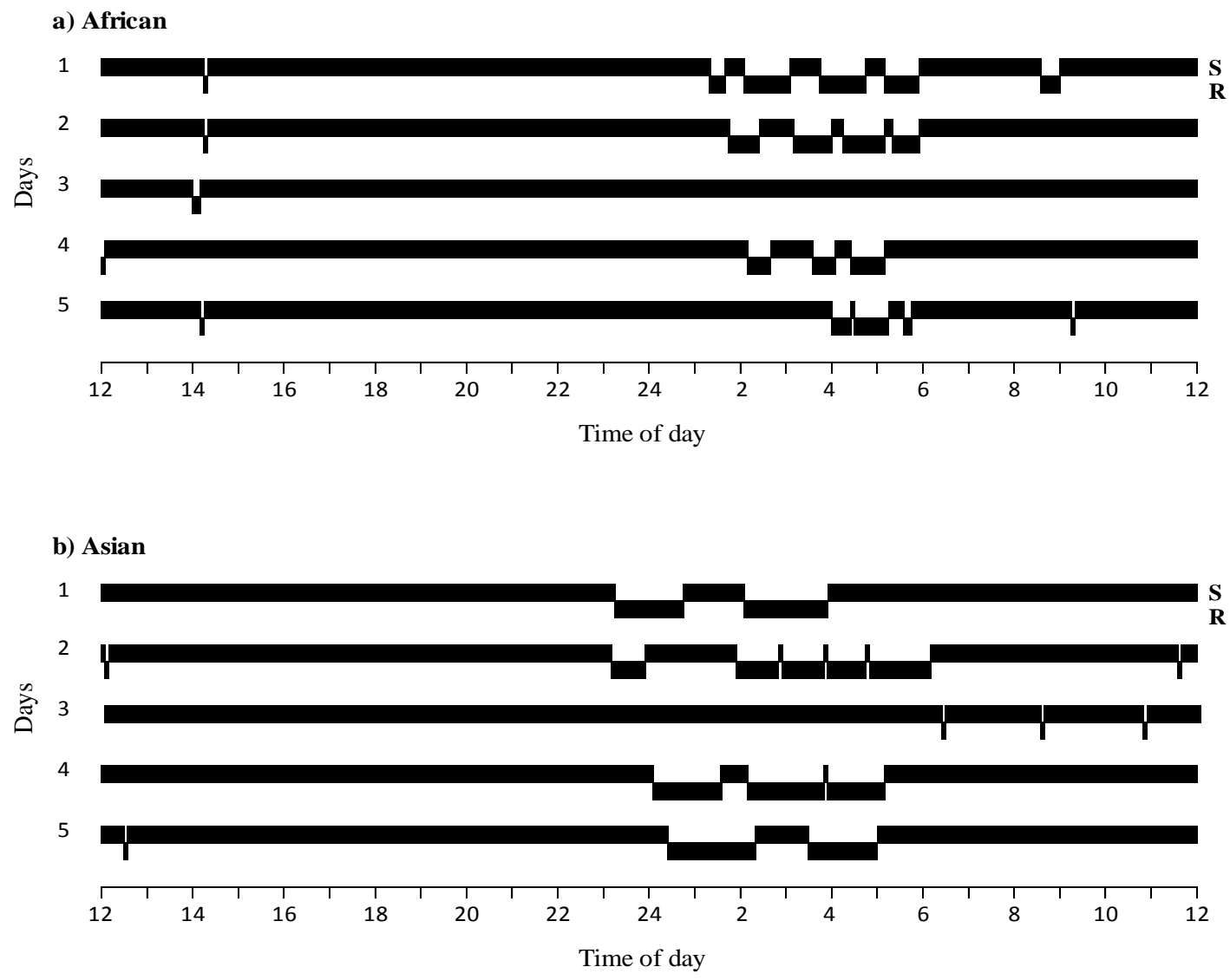

Figure 4.3: Standing and recumbence patterns of representative African and Asian zoo elephants. Data from an individual African (a) and Asian (b) zoo elephant over five days in 2012. These elephants were coincidentally both non-recumbent on the third day of data collection. $\mathrm{S}=$ standing; $\mathrm{R}=$ recumbent. 


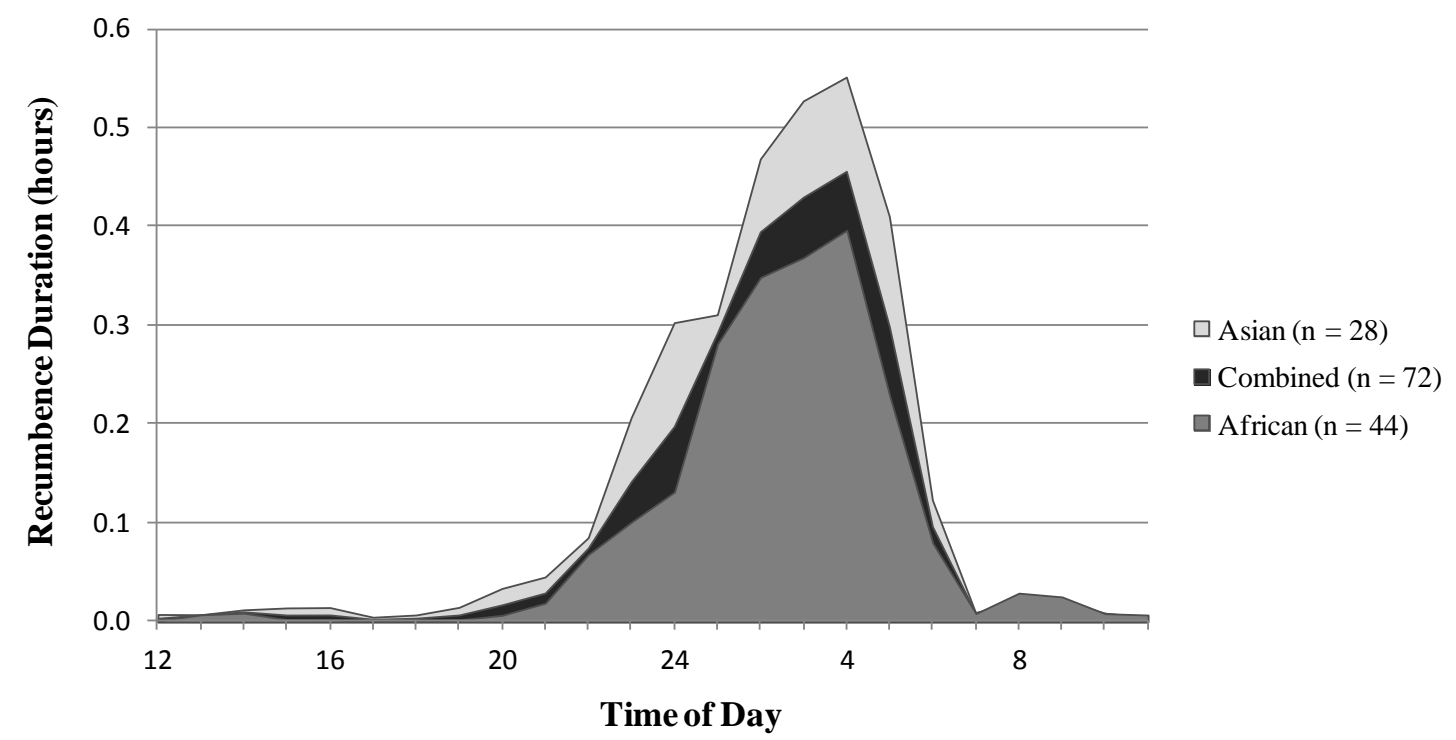

Figure 4.4: Recumbence profile showing daily distributions of recumbence in zoo elephants. The lines of the curves connect mean hourly values. Areas under the curves represent total time recumbent. The small increase in recumbence between 08:00 and 09:00 may reflect anklet attachment/removal or morning rituals (e.g., baths or exercise routines).

A number of elephants showed some form of non-recumbence. Seven elephants (six African, one Asian) were classified as highly non-recumbent because they lay down for less than one hour total over five days of data collection. An additional 15 elephants (nine African, six Asian) were classified as intermittently non-recumbent because they lay down for less than ten minutes per day on three days of data collection $(n=1)$, two days $(n=1)$, or one day $(n=13)$. There was no significant difference between species in the prevalence of high non-recumbence $(\mathrm{P}=0.182)$ and intermittent non-recumbence $(\mathrm{P}$ $=0.93)$. In intermittently non-recumbent elephants we found no observable trend between the days they did not lie down and mean daily temperature: seven elephants were non-recumbent on days that were warmer than the mean daily temperature they experienced during data collection, while eight were non-recumbent on cooler days. We 
also found no effect of changes in outdoor access on recumbence, as only one elephant consistently became non-recumbent on nights that indoor/outdoor access was changed.

\section{Univariate analyses}

We evaluated a variety of demographic, housing, social, and management factors as predictors of recumbence (Tables 4.3 and 4.4). In the African elephant univariate results (Table 4.3), mean daily recumbence was negatively correlated with age and percent time hard substrate overall, day, and night. Recumbence was also negatively correlated with social experience day, and percent time housed separately overall and night. There was a positive correlation between recumbence and the variables space experience total night and space experience outdoor night. Finally, recumbence was correlated with origin, however, the small sample size in the significant category precluded any meaningful interpretation of the results.

In the Asian elephant univariate results (Table 4.4), mean daily recumbence was negatively correlated with space experience indoor day and percent time indoor day, as well as percent time hard substrate night, animal contact night, and social experience overall. Recumbence was positively correlated with percent time soft substrate overall, day, and night, and percent time housed separately overall, day, and night. The population level descriptive statistics for the significant African and Asian elephant univariate analyses are shown in Table 4.5. 
Table 4.3: Univariate correlations between mean daily recumbence and independent variables in African zoo elephants (*P $<0.15)$.

\begin{tabular}{|c|c|c|c|c|c|c|c|c|c|c|c|c|c|c|}
\hline \multirow{2}{*}{ Variables } & \multirow{2}{*}{$+/-^{b}$} & \multirow[b]{2}{*}{ Reference } & \multicolumn{3}{|c|}{ Overall } & \multicolumn{4}{|c|}{ Day $^{\mathrm{a}}$} & \multicolumn{5}{|c|}{ Night $^{a}$} \\
\hline & & & $\mathbf{n}$ & Beta & $\mathbf{P}$ & & $\mathbf{n}$ & Beta & $\mathbf{P}$ & & $\mathbf{n}$ & Beta & $\mathbf{P}$ & \\
\hline \multicolumn{15}{|l|}{ Demographics } \\
\hline Age & - & & 44 & -0.0873 & $<0.001$ & $*$ & & & & & & & & \\
\hline \multirow{2}{*}{ Origin } & & ref $=$ Wild & 43 & & & & & & & & & & & \\
\hline & + & Captive & 1 & -2.1126 & $<0.001$ & * & & & & & & & & \\
\hline \multicolumn{15}{|l|}{ Space } \\
\hline Space Experience Total $\left(500 \mathrm{ft}^{2}\right)$ & + & & 42 & 0.0029 & 0.363 & & 44 & -0.0002 & 0.925 & & 42 & 0.0070 & $<0.001$ & $*$ \\
\hline Space Experience Indoor $\left(500 \mathrm{ft}^{2}\right)$ & + & & 43 & -0.0694 & 0.259 & & 44 & -0.0463 & 0.414 & & 43 & -0.0632 & 0.321 & \\
\hline Space Experience Outdoor $\left(500 \mathrm{ft}^{2}\right)$ & + & & 43 & 0.0005 & 0.830 & & 44 & -0.0008 & 0.663 & & 42 & 0.0065 & 0.002 & $*$ \\
\hline \multirow{2}{*}{$\begin{array}{l}\text { Space Experience In/Out Choice (500 } \\
\mathrm{ft}^{2} \text { ) }\end{array}$} & & $\mathrm{ref}=0 \%$ & 18 & & & & 22 & & & & 18 & & & \\
\hline & + & $>0 \%$ & 26 & 0.1365 & 0.681 & & 22 & -0.9450 & 0.749 & & 26 & 0.0897 & 0.782 & \\
\hline Percent Time Indoor & - & & 44 & -0.0060 & 0.456 & & 44 & 0.0006 & 0.944 & & 44 & -0.0069 & 0.191 & \\
\hline Percent Time Outdoor & + & & 44 & 0.0003 & 0.968 & & 44 & -0.0020 & 0.717 & & 44 & 0.0016 & 0.750 & \\
\hline \multirow[t]{2}{*}{ Percent Time In/Out Choice } & & $\mathrm{ref}=0 \%$ & 18 & & & & 22 & & & & 18 & & & \\
\hline & + & $>0 \%$ & 26 & 0.1365 & 0.681 & & 22 & -0.1498 & 0.622 & & 26 & 0.1365 & 0.681 & \\
\hline \multicolumn{15}{|l|}{ Flooring } \\
\hline \multirow[t]{2}{*}{ Percent Time Hard Substrate } & & $\mathrm{ref}=0 \%$ & 20 & & & & 24 & & & & 21 & & & \\
\hline & - & $>0 \%$ & 24 & -0.6728 & 0.018 & $*$ & 20 & -0.6473 & 0.029 & $*$ & 23 & -0.7492 & 0.007 & $*$ \\
\hline \multirow[t]{2}{*}{ Percent Time Soft Substrate } & & $\mathrm{ref}=0 \%$ & 22 & & & & 26 & & & & 25 & & & \\
\hline & + & $>0 \%$ & 22 & 0.0400 & 0.901 & & 18 & 0.0572 & 0.860 & & 19 & 0.1458 & 0.667 & \\
\hline \multicolumn{15}{|l|}{ Social } \\
\hline Herd Size & + & & 44 & 0.0220 & 0.711 & & & & & & & & & \\
\hline Animal Contact & + & & 42 & -0.1358 & 0.192 & & 42 & -0.1358 & 0.192 & & 42 & -0.0547 & 0.767 & \\
\hline Social Experience & + & & 42 & -0.2972 & 0.221 & & 42 & -0.1925 & 0.146 & & 42 & 0.0092 & 0.974 & \\
\hline \multirow[t]{2}{*}{ Percent Time Juveniles (age <7) } & & $\mathrm{ref}=0 \%$ & 33 & & & & 33 & & & & 34 & & & \\
\hline & + & $>0 \%$ & 11 & 0.0170 & 0.963 & & 11 & 0.0170 & 0.963 & & 10 & -0.0939 & 0.823 & \\
\hline \multirow[t]{2}{*}{ Percent Time Housed Separately } & & $\mathrm{ref}=0 \%$ & 28 & & & & 33 & & & & 28 & & & \\
\hline & - & $>0 \%$ & 15 & -0.6010 & 0.098 & & 11 & -0.2172 & 0.580 & & 16 & -0.7035 & 0.054 & \\
\hline \multicolumn{15}{|l|}{ Management } \\
\hline Enrichment Diversity & + & & 42 & -0.8334 & 0.269 & & & & & & & & & \\
\hline Enrichment Program & + & & 42 & -0.0841 & 0.652 & & & & & & & & & \\
\hline Exercise Diversity & + & & 42 & 0.1033 & 0.740 & & & & & & & & & \\
\hline
\end{tabular}


Other

Foot Physical Exam Score

Temperature

$\begin{array}{lll}39 & -0.0463 & 0.614\end{array}$

Walking Distance

$\begin{array}{cccc}- & 39 & -0.0463 & 0.614 \\ + & 44 & -0.0211 & 0.268 \\ + & 32 & 0.0231 & 0.829\end{array}$

${ }^{a}$ Day and night are defined as the number of hours in a 24 hour period considered daytime or nighttime according to management schedule.

${ }^{\mathrm{b}}$ Hypothesized direction of relationship between mean daily recumbence and variable. 
Table 4.4: Univariate correlations between mean daily recumbence and independent variables in Asian zoo elephants.

\begin{tabular}{|c|c|c|c|c|c|c|c|c|c|c|c|c|c|c|}
\hline \multirow[b]{2}{*}{ Variables } & \multicolumn{6}{|c|}{ Overall } & \multicolumn{4}{|c|}{ Day $^{\mathrm{a}}$} & \multicolumn{4}{|c|}{ Night $^{a}$} \\
\hline & $+/-^{b}$ & Reference & $\mathbf{n}$ & Beta & $\mathbf{P}$ & & $\mathbf{n}$ & Beta & $\mathbf{P}$ & & $\mathbf{n}$ & Beta & $\mathbf{P}$ & \\
\hline \multicolumn{15}{|l|}{ Demographics } \\
\hline Age & - & & 28 & 0.0163 & 0.236 & & & & & & & & & \\
\hline Origin & & ref $=$ Wild & 21 & & & & & & & & & & & \\
\hline & + & Captive & 7 & -0.2905 & 0.576 & & & & & & & & & \\
\hline \multicolumn{15}{|l|}{ Space } \\
\hline Space Experience Total $\left(500 \mathrm{ft}^{2}\right)$ & + & & 27 & 0.0084 & 0.462 & & 28 & -0.0060 & 0.494 & & 27 & 0.0085 & 0.465 & \\
\hline Space Experience Indoor $\left(500 \mathrm{ft}^{2}\right)$ & + & & 27 & -0.0813 & 0.553 & & 28 & -0.1361 & 0.028 & $*$ & 28 & -0.1030 & 0.267 & \\
\hline Space Experience Outdoor $\left(500 \mathrm{ft}^{2}\right)$ & + & & 27 & 0.0029 & 0.647 & & 27 & 0.0020 & 0.718 & & 27 & 0.0006 & 0.910 & \\
\hline $\begin{array}{l}\text { Space Experience In/Out Choice (500 } \\
\mathrm{ft}^{2} \text { ) }\end{array}$ & & ref $=0 \%$ & 11 & & & & 19 & & & & 13 & & & \\
\hline & + & $>0 \%$ & 17 & 0.3993 & 0.511 & & 9 & 0.2111 & 0.633 & & 15 & 0.2128 & 0.695 & \\
\hline Percent Time Indoor & - & & 27 & -0.0121 & 0.432 & & 27 & -0.0285 & 0.038 & $*$ & 28 & -0.0107 & 0.261 & \\
\hline Percent Time Outdoor & + & & 28 & 0.0078 & 0.397 & & 28 & 0.0035 & 0.647 & & 28 & 0.0057 & 0.444 & \\
\hline Percent Time In/Out Choice & & $\mathrm{ref}=0 \%$ & 11 & & & & 19 & & & & 13 & & & \\
\hline & + & $>0 \%$ & 17 & 0.3993 & 0.511 & & 9 & 0.2111 & 0.633 & & 15 & 0.2128 & 0.695 & \\
\hline \multicolumn{15}{|l|}{ Flooring } \\
\hline Percent Time Hard Substrate & & $\mathrm{ref}=0 \%$ & 10 & & & & 11 & & & & 13 & & & \\
\hline & - & $>0 \%$ & 17 & -0.0489 & 0.919 & & 16 & 0.1510 & 0.770 & & 15 & -0.8153 & 0.079 & \\
\hline Percent Time Soft Substrate & & $\mathrm{ref}=0 \%$ & 11 & & & & 13 & & & & 16 & & & \\
\hline & + & $>0 \%$ & 17 & 0.9712 & 0.029 & * & 15 & 0.8575 & 0.064 & & 12 & 0.7927 & 0.123 & \\
\hline \multicolumn{15}{|l|}{ Social } \\
\hline Herd Size & + & & 26 & -0.2225 & 0.447 & & & & & & & & & \\
\hline Animal Contact & + & & 27 & -0.3415 & 0.323 & & 27 & -0.3415 & 0.323 & & 27 & -0.6850 & 0.099 & \\
\hline Social Experience & + & & 28 & -0.7595 & 0.130 & & 28 & -0.6585 & 0.183 & & 28 & -0.5736 & 0.212 & \\
\hline Percent Time Juveniles (age <7) & & $\mathrm{ref}=0 \%$ & 24 & & & & 24 & & & & 24 & & & \\
\hline & + & $>0 \%$ & 4 & -0.3475 & 0.614 & & 3 & -0.7608 & 0.150 & & 3 & 0.1358 & 0.775 & \\
\hline Percent Time Housed Separately & & $\mathrm{ref}=0 \%$ & 9 & & & & 15 & & & & 14 & & & \\
\hline & - & $>0 \%$ & 19 & 1.0513 & 0.029 & * & 13 & 0.9976 & 0.050 & & 14 & 0.9357 & 0.045 & * \\
\hline \multicolumn{15}{|l|}{ Management } \\
\hline Enrichment Diversity & + & & 23 & 0.5847 & 0.730 & & & & & & & & & \\
\hline Enrichment Program & + & & 23 & -0.0522 & 0.751 & & & & & & & & & \\
\hline Exercise Diversity & + & & 22 & -0.2199 & 0.773 & & & & & & & & & \\
\hline
\end{tabular}


9Other

\section{Foot Physical Exam Score}

Temperature

Walking Distance

$\begin{array}{cccc}- & 24 & 0.0502 & 0.634 \\ + & 28 & 0.0264 & 0.554 \\ + & 23 & -0.0792 & 0.418\end{array}$

${ }^{a}$ Day and night are defined as the number of hours in a 24 hour period considered daytime or nighttime according to management schedule.

${ }^{\mathrm{b}}$ Hypothesized direction of relationship between mean daily recumbence and variable. 
Table 4.5: Independent variables that had a significant univariate correlation with recumbence in African and Asian zoo elephants. The sample size and mean age of elephants used in the correlation is provided. Variable data, where applicable, provides context for the experience of the elephants included in the analysis.

\begin{tabular}{|c|c|c|c|c|c|c|c|c|c|c|}
\hline \multirow[b]{2}{*}{ Species } & \multirow[b]{2}{*}{ Variable } & \multirow[b]{2}{*}{ Mgmt. } & \multirow[b]{2}{*}{ Reference } & \multirow[b]{2}{*}{$\mathbf{n}$} & \multirow[b]{2}{*}{$\begin{array}{c}\text { Mean } \\
\text { Age }\end{array}$} & \multicolumn{5}{|c|}{ Variable } \\
\hline & & & & & & Mean & SD & Min & Max & Median \\
\hline African & Age & & & 44 & - & 32.59 & 6.57 & 20 & 52 & 32 \\
\hline \multirow[t]{2}{*}{ African } & Origin & & ref=Wild & 43 & 33 & - & - & - & - & - \\
\hline & & & Captive & 1 & 34 & - & - & - & - & - \\
\hline African & Space Experience Total $\left(500 \mathrm{ft}^{2}\right)$ & Night & & 42 & 33 & 43.99 & 51.13 & 0.89 & 227.42 & 27.53 \\
\hline African & Space Experience Outdoor $\left(500 \mathrm{ft}^{2}\right)$ & Night & & 43 & 33 & 57.34 & 59.72 & 0 & 244.04 & 37.89 \\
\hline \multirow[t]{2}{*}{ African } & Percent Time Hard Substrate & Overall & ref $=0 \%$ & 20 & 31 & - & - & - & - & - \\
\hline & & & $>0 \%$ & 24 & 35 & 15.81 & 8.55 & 2.25 & 32.24 & 15.05 \\
\hline \multirow[t]{2}{*}{ African } & Percent Time Hard Substrate & Day & ref $=0 \%$ & 24 & 31 & - & - & - & - & - \\
\hline & & & $>0 \%$ & 20 & 35 & 10.48 & 7.81 & 1.13 & 24.15 & 11.32 \\
\hline \multirow[t]{2}{*}{ African } & Percent Time Hard Substrate & Night & $\mathrm{ref}=0 \%$ & 21 & 31 & - & - & - & - & - \\
\hline & & & $>0 \%$ & 23 & 34 & 25.55 & 16.72 & 5.65 & 53.33 & 23.47 \\
\hline African & Social Experience & Day & & 42 & 34 & 19.91 & 13.72 & 6.76 & 56.26 & 14.70 \\
\hline \multirow[t]{2}{*}{ African } & Percent Time Housed Separately & Overall & $\mathrm{ref}=0 \%$ & 28 & 31 & - & - & - & - & - \\
\hline & & & $>0 \%$ & 15 & 35 & 22.92 & 17.69 & 1.40 & 57.10 & 19.90 \\
\hline \multirow[t]{2}{*}{ African } & Percent Time Housed Separately & Night & ref $=0 \%$ & 28 & 31 & - & - & - & - & - \\
\hline & & & $>0 \%$ & 16 & 35 & 44.51 & 34.11 & 3.83 & 100.00 & 37.57 \\
\hline Asian & Space Experience Indoor $\left(500 \mathrm{ft}^{2}\right)$ & Day & & 28 & 40 & 1.66 & 2.23 & 0 & 8.046 & 1.12 \\
\hline Asian & Percent Time Indoor & Day & & 27 & 40 & 12.31 & 11.81 & 0 & 36.29 & 10 \\
\hline \multirow[t]{2}{*}{ Asian } & Percent Time Hard Substrate & Night & $\mathrm{ref}=0 \%$ & 13 & 39 & - & - & - & - & - \\
\hline & & & $>0 \%$ & 15 & 41 & 20.15 & 19.33 & 2.21 & 53.41 & 8.59 \\
\hline \multirow[t]{2}{*}{ Asian } & Percent Time Soft Substrate & Overall & $\mathrm{ref}=0 \%$ & 11 & 44 & - & - & - & - & - \\
\hline & & & $>0 \%$ & 17 & 37 & 15.84 & 11.06 & 0.36 & 31.41 & 18.41 \\
\hline \multirow[t]{2}{*}{ Asian } & Percent Time Soft Substrate & Day & $\mathrm{ref}=0 \%$ & 13 & 46 & - & - & - & - & - \\
\hline & & & $>0 \%$ & 15 & 35 & 10.44 & 9.54 & 0.36 & 29.17 & 8.55 \\
\hline \multirow[t]{2}{*}{ Asian } & Percent Time Soft Substrate & Night & $\mathrm{ref}=0 \%$ & 16 & 42 & - & - & - & - & - \\
\hline & & & $>0 \%$ & 12 & 37 & 27.05 & 9.32 & 14.69 & 48.48 & 26.25 \\
\hline
\end{tabular}




\begin{tabular}{|c|c|c|c|c|c|c|c|c|c|c|}
\hline Asian & Animal Contact & Night & & 27 & 41 & 1.00 & 0.73 & 0.00 & 3.00 & 1.00 \\
\hline Asian & Social Experience & Overall & & 28 & 40 & 18.92 & 10.32 & 0.66 & 44.99 & 15.74 \\
\hline \multirow[t]{2}{*}{ Asian } & Percent Time Housed Separately & Overall & $\mathrm{ref}=0 \%$ & 9 & 41 & - & - & - & - & - \\
\hline & & & $>0 \%$ & 19 & 40 & 38.72 & 38.22 & 1.83 & 100 & 25 \\
\hline \multirow[t]{2}{*}{ Asian } & Percent Time Housed Separately & Day & $\mathrm{ref}=0 \%$ & 15 & 42 & - & - & - & - & - \\
\hline & & & $>0 \%$ & 13 & 37 & 39.25 & 39.77 & 5.26 & 100 & 19.51 \\
\hline \multirow[t]{2}{*}{ Asian } & Percent Time Housed Separately & Night & $\mathrm{ref}=0 \%$ & 14 & 35 & - & - & - & - & - \\
\hline & & & $>0 \%$ & 14 & 45 & 68.45 & 37.82 & 8.15 & 100 & 86.11 \\
\hline
\end{tabular}




\section{African elephant multivariate model}

The African elephant multivariate model includes percent time hard substrate overall and space experience outdoor night (Table 4.6). The model predicts that elephants who spend any time on $100 \%$ concrete or stone aggregate substrate ("all-hard") are recumbent 0.6 hours less per day than elephants who spend no time on all-hard substrate. The model also predicts that elephants who experience more outdoor space at night are significantly more recumbent that those who experience less outdoor space at night. For example, elephants that experience an additional $500 \mathrm{ft}^{2}$ of outdoor space during the night are predicted to have an increase in recumbence of 0.0055 hours per day; this translates to a 0.48 hour increase per additional acre.

Table 4.6: African zoo elephant multivariate mean daily recumbence model $(* P<0.05)$.

\begin{tabular}{lrrr}
\hline Parameter & Estimate & Standard Error & Pr $>|Z|$ \\
\hline Intercept & 2.1941 & 0.217 & $<0.001$ \\
0\% time hard substrate & - & - & - \\
$>0 \%$ time hard substrate & -0.6004 & 0.245 & $0.014 *$ \\
Space experience outdoor night & 0.0055 & 0.002 & $0.001 *$ \\
\hline
\end{tabular}

\section{Asian elephant multivariate model}

The Asian elephant multivariate model includes percent time soft substrate overall and percent time housed separately night (Table 4.7). The model predicts that elephants who spend any time on $100 \%$ grass, sand, or rubber substrate ("all-soft) are recumbent 1.1 hours more per day than those who spend no time on all-soft substrate. 
The variable age is included as a confounder of percent time soft substrate overall indicating that age is a factor that is both related to being on hard surfaces and being recumbent; age is included in the model to control for its potential effects. The model also predicts that elephants who are alone for any amount of time during the night are recumbent 0.77 hours more than elephants who are never alone.

Table 4.7: Asian zoo elephant multivariate mean daily recumbence model $(* P<0.05)$.

\begin{tabular}{lrrrr}
\hline Parameter & Estimate & Standard Error & Pr $>|\mathbf{Z}|$ \\
\hline Intercept & 1.6455 & 0.733 & 0.025 & \\
0\% time soft substrate & - & - & - \\
$>0 \%$ time soft substrate & 1.0564 & 0.352 & 0.003 & $*$ \\
0\% time housed separately & - & - & - & \\
$>0 \%$ time housed separately & 0.7698 & 0.387 & 0.047 & $*$ \\
Age & 0.0156 & 0.107 & 0.358 & \\
\hline
\end{tabular}

\section{Substrate}

Substrate variables appeared in multivariate models for both species (Tables 4.6 and 4.7). This suggests a strong relationship between substrate and recumbence. For a look at the compounding effect of hard and soft substrate on recumbence, we identified two subsets of elephants representing opposite ends on a gradient of substrate exposure. In the first category were elephants $(\mathrm{n}=21)$ who were never on all-soft substrate and spent some amount of time (mean $=15 \%$, range: 3 to $32 \%$ ) on all-hard substrate. In the second category were elephants $(n=18)$ with the opposite experience: they were never on all-hard substrate and spent some amount of time (mean $=25 \%$, range: 2 to $50 \%$ ) on 
all-soft substrate. Fig. 4.5 shows the differences in recumbence between these two subsets of elephants, and the finding that a decrease in time on all-hard substrate - in conjunction with an increase in time on all-soft substrate - is associated with a substantial increase in recumbence in both African and Asian elephants.

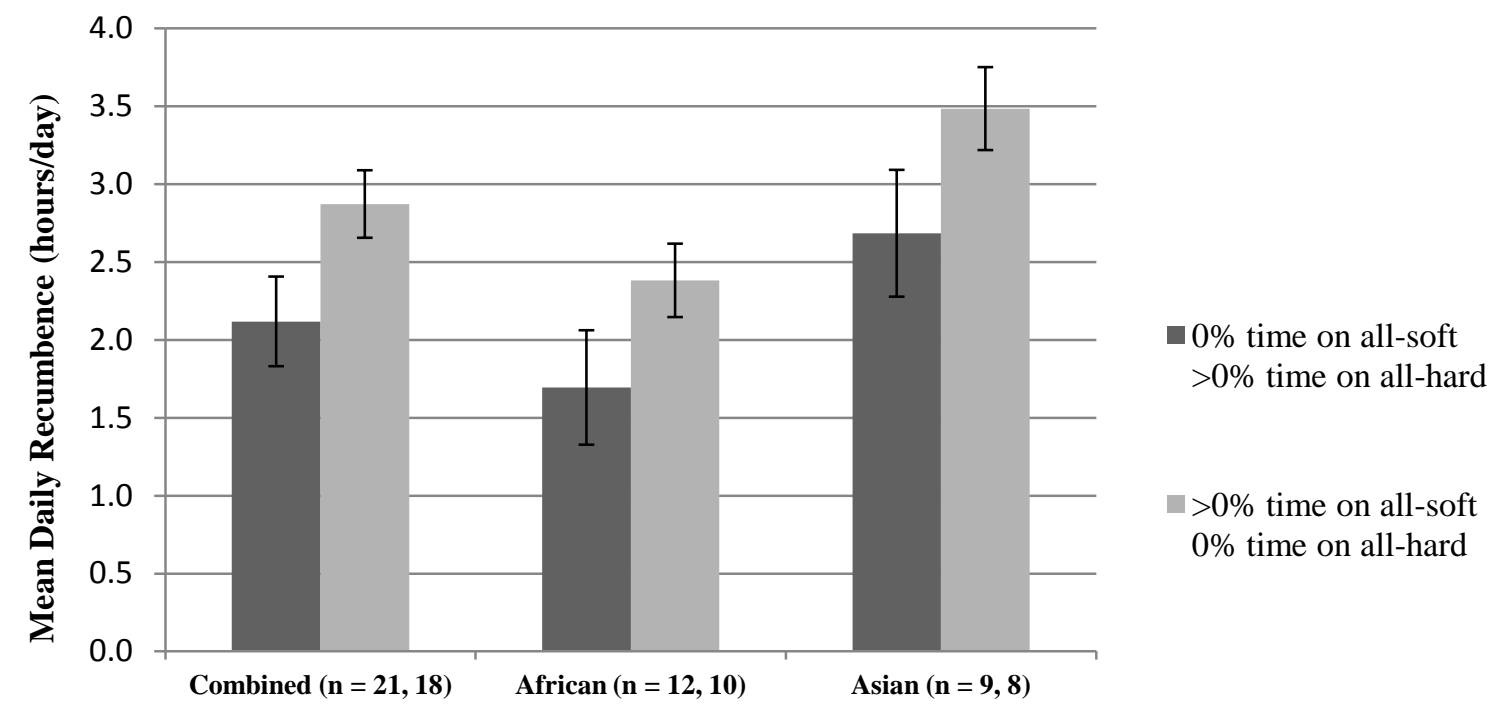

Figure 4.5: Recumbence of elephants in two categories based on their exposure to all-hard and allsoft substrate. Error bars represent \pm 1 standard error of the mean.

\section{$\underline{\text { IV. Discussion }}$}

\section{Recumbence patterns, timing and prevalence}

We found that on average, African elephants lay down for just over two hours per day and Asian elephants lay down for just over three hours per day. Recumbence occurred almost exclusively at night. Our results correspond with other large studies of recumbence in elephants under managed care: adult female African elephants $(n=11)$ in European zoos lay down an average of 2.0 hours per night (Kandler, 2010), while adult female Asian elephants $(n=8)$ at a zoo and circus lay down an average of 3.4 hours per 
night (Tobler, 1992). Our results also correspond with available data from wild African elephants $(n=4)$ that lay down for between one and two hours per night on average (Wyatt \& Eltringham, 1974); no data are available for nighttime recumbence in wild Asian elephants.

Sleep appears to be the primary function of recumbence, as elephants entering a recumbent posture appear to fall asleep almost immediately (Tobler, 1992). Thus, differences in recumbence between African and Asian elephants likely reflect interspecific variation in sleep requirements. Sleep patterns appear to be determined primarily by ecological variables (Siegel, 2009). For example, some species show a trade-off between time available for sleep and time available for foraging (Capellini et al., 2008). Wild Asian elephants may inhabit more resource-rich areas than wild African elephants, allowing them to fulfill their nutritional requirements in less time. Asian zoo elephants spend significantly less time feeding than African zoo elephants (Greco et al., 2015), but whether this is a real species difference or a difference in feeding methods is not known. Another ecological variable that may explain interspecific variation in sleep is predation risk. Species that sleep more tend to use less exposed sleeping sites (Capellini et al., 2008; Lesku et al., 2006). Asian elephants may be more likely than African (savanna) elephants to inhabit dense forested areas that conceal them from predators and allow for more sleep. Regardless of the cause of the difference in recumbence, our results suggest that animal welfare indices based on behavior should take into account the potential for significant differences between elephant species.

African and Asian elephants showed similar timing of recumbence behavior, being mainly recumbent between 01:00 and 05:00 with a peak at 04:00, in agreement 
with other studies (Tobler, 1992; Wyatt \& Eltringham, 1974). The timing of recumbence may have management implications. For example, zoos that have nighttime elephant care staff or automated feeders may wish to minimize disturbances to sleeping elephants during peak recumbence hours; indeed, automated feeders have been shown to interrupt recumbence in zoo elephants (Kandler, 2010).

\section{Non-recumbence}

Nearly one-third of elephants in our study were either highly or intermittently non-recumbent. We found no evidence that non-recumbence was affected by abnormally hot or cold temperatures, or by sudden changes in indoor/outdoor access at night. Agerelated health problems (e.g., arthritis) could be limiting recumbence in some individuals (Weisz et al., 2000); however, we observed the behavior across a range of ages, so this is unlikely to be the sole cause of non-recumbence. We also considered that nonrecumbence may be a normal and adaptive behavior in elephants. For example, animals living in groups may use vigilance to increase the probability of predator detection (Burger \& Gochfeld, 1994). Although wild African elephants are rarely vigilant during the day (Burger \& Gochfeld, 1994), vigilance may be more important at night when the majority of predation attempts on elephants occur (Joubert, 2006; Power \& Compion, 2009). Non-recumbence may also be a specific form of vigilance called sentinel behavior. African zoo elephants have been observed standing in close proximity to a recumbent elephant for extended periods of time (Wilson et al., 2006) and "taking turns" being recumbent (Adams \& Berg, 1980). However, no studies of zoo elephants have closely examined vigilance or sentinel behavior. Finally, non-recumbence may be an 
abnormal behavioral consequence of the zoo environment, with no physiological or ecological function. In this case, the welfare of non-recumbent elephants may be impacted by sleep deprivation.

\section{Substrate}

Of all the independent variables we tested, substrate had the strongest effect on recumbence, and a substrate variable was present in nearly every model during the model-building process. Our African model predicted that elephants who spend time on all-hard substrate are recumbent 0.6 hours less than elephants who are never on all-hard substrate: a 28\% decrease in recumbence. Along the same lines, the Asian model predicted an increase in recumbence of 1.1 hours per day for elephants who spend time on all-soft substrate when compared to elephants who are never on all-soft substrate: a $32 \%$ increase in recumbence.

The intuitive finding that hard substrate types like concrete and stone are not conducive to recumbence is supported by similar findings in cattle (Haley et al., 2001). By limiting recumbence, hard substrate may be contributing to sleep deprivation or sleep disturbance, or causing stress or frustration in animals that are reluctant to exhibit natural resting postures. Our results add to a growing body of evidence suggesting that hard substrate negatively impacts animal welfare. Concrete has been associated with higher rates of sole hemorrhages (Bergsten \& Frank, 1996) and swollen knees (Rushen et al., 2007) in cattle, and with incidents of foot and joint disease in zoo elephants (Miller et al., 2015). Meanwhile, the reduction and removal of hard substrate from zoo elephant exhibits is already underway. A 2006 survey (Lewis et al., 2010), following up on 1997 
survey results (Dimeo-Ediger, 2001), found that the proportion of concrete flooring in elephant barns had reduced $22 \%$ in the intervening years. In addition, nearly half of responding zoos planned to further reduce the proportion of concrete flooring in their indoor facilities over the next 10 years (Lewis et al., 2010). Despite these ongoing efforts, we found that 18 of 40 zoos in our study (45\%) had elephants housed in environments with all-hard substrate at some time in 2012. This is in addition to the time these elephants spent in mixed substrate environments that included hard and soft substrate. The continued prevalence of hard substrate in zoo environments indicates that zoos must remain proactive in their attempts to incorporate soft substrate into both indoor and outdoor areas. Furthermore, we suggest continued research into soft substrate types (i.e., sand, grass, and rubber), in order to determine which of are most effective at promoting health, welfare, and natural behaviors in zoo elephants. For example, research in horses as shown that despite both straw and wood shavings both being arguably soft substrate, horses that are given a choice between the two preferentially spend time on straw (Mills et al., 2000), and exhibit more bedding-related activities (Mills et al., 2000), and lateral recumbence (Pedersen et al., 2004) on straw.

Our model suggests that substrate directly affects zoo elephant recumbence; that is, it is not a proxy for other related measurements such as time spent inside or outside. Notably, recumbence occurred almost exclusively at night, and yet there was no correlation between recumbence and the percent of time that elephants are indoor or outdoor at night. 


\section{Space}

Research has shown that recumbence increases when more stall space is provided to cattle (Tucker et al., 2004) and horses (Raabymagle \& Ladewig, 2006). However, the housing conditions of zoo elephants are more complex, and even at night may include being shifted between environments of different sizes for varying amounts of time. Therefore, we created a variable called space experience, which takes into account both the size of the environment and the amount of time an elephant spends in that environment (Meehan et al., 2015). We found a positive correlation between outdoor space experience at night and recumbence in African elephants. For example, our model predicted that an African elephant that experiences an additional acre of outdoor space at night will show an increase in recumbence of 0.48 hours - a potentially important contribution to the mean daily recumbence of an African elephant.

There are a variety of ways by which zoos can increase outdoor space experience at night. Providing access to a consistent amount of additional space is certainly one way. However, space experience allows for a flexible consideration of both space and time, so zoos can work within their own housing and management constraints to find ways to increase space experience (for more details see Meehan et al., 2015). Notably, increases in space experience may have additional welfare benefits, as space experience is positively correlated with regular ovarian cyclicity in Asian elephants (Brown et al., 2015) and negatively correlated with stereotypical behavior in African and Asian elephants (Greco et al., 2015). Whether increases in space experience will eventually begin to reach a level of diminishing returns is an important area for future research. 


\section{Social}

The initiation and termination of recumbence bouts is often synchronized amongst elephants in zoos (Kühme, 1963; Tobler, 1992), and in the wild (Wyatt \& Eltringham, 1974). This suggests that recumbence is a highly social behavior. In our study, we hypothesized that elephants who were never alone would show more recumbence, assuming that a more natural social environment would be more likely to result in the expression of natural behaviors. However, the Asian elephant multivariate model showed a positive correlation between recumbence and time housed separately, and the final model predicted that Asian elephants who spend time alone are recumbent for an additional 0.77 hours per day. Why might Asian elephants who spend time alone be more recumbent? One possible explanation is that elephants housed alone do not experience overcrowding. Cattle, for example, were significantly less recumbent when the number of cows per stall increased by 50\% (Fregonesi et al., 2007). Being housed alone may also help Asian elephants avoid being disturbed by dominant members of the social group. Again, there is evidence for this in cattle, where subordinate cattle are recumbent significantly less than middle-ranked or high-ranked cows (Galindo \& Broom, 2000). Future research will be needed to better understand the nocturnal social lives of elephants and their effect on rest and recumbence.

\section{Age}

Previous research has shown that adult elephants are recumbent less than infants, juveniles, and sub-adults (Brockett et al., 1999; Kandler, 2010; Posta et al., 2013; Tobler, 1992; Wilson et al., 2006). We found some evidence that this trend continues in African 
(but not Asian) elephants; that is to say, as adult African elephants continue to get older, they are recumbent less and less. Whether this trend is related to age-related health problems or merely reflects changes in sleep requirements (or both), we cannot say.

\section{Conclusion}

Recumbence is a natural resting behavior exhibited by African and Asian

elephants both in the wild and zoos, and research suggests recumbence may affect animal welfare in species that rest in this posture. Using anklets equipped with accelerometers we found that African elephants are recumbent an average of 2.14 hours/day, which is significantly less than Asian elephants at 3.22 hours/day. African elephants are predicted to be recumbent more if they experience more space at night, while Asian elephants are predicted to be recumbent more if they spend time housed alone. Both species showed a similar response to substrate, such that African elephant spending time on all-hard substrates are predicted to be recumbent less, while Asian elephants spending time on allsoft substrates are predicted to be recumbent more. Our results are the first comprehensive dataset on this behavior in elephants and have provided the first dataset to help gauge what an adequate amount of recumbence is for zoo elephants. Zoos can use this data to compare recumbence in their elephants to other zoos; they may also use our data on peak recumbence times to avoid nighttime disturbances that may affect rest. Our discovery that occasional non-recumbence is a common behavior in zoo elephants also introduces a new area of research that may have important animal welfare consequences. Finally, we established that zoos should continue their efforts to replace hard substrate 
with soft substrate in order to provide zoo elephants with an environment where they can comfortably express recumbence behavior, should they choose to do so. 
Chapter Five: Conclusion

Zoos seeking to improve the lives of African and Asian elephants rely on objective research on welfare indicators and guidance on how their exhibits and husbandry practices can better meet the needs of elephants. Two natural behaviors exhibited by elephants that may impact welfare are walking and recumbent rest. I conducted the first multi-institutional measurement of these behaviors, identified associated factors, and explored the application of GPS technology towards the study of zoo animal movement. I also looked for correlations between the distance walked by zoo elephants and foot health and joint health.

In Chapter Two, I reviewed the basics of GPS technology, and provided details on the important methodological techniques used to improve GPS performance and data accuracy. This chapter is the first overview of GPS applications in zoo environments, and should be a useful resource for future researchers. GPS has been used successfully in a number of studies in zoos, and system performance continues to improve. Researchers are also becoming more comfortable with the technology, and are applying more advanced data processing techniques to improve accuracy, and by extension, study conclusions. Scientists are also applying GPS to answer more diverse research questions. The original zoo elephant GPS study looked at elephant location only to better understand other behaviors (Leighty et al., 2008), but follow-up studies directly investigated walking (Leighty et al., 2009), activity levels (Rothwell et al., 2011), social relationships (Hacker et al., 2015), and the use of space and exhibit resources (Leighty et al., 2010). Future studies could investigate, for example, the use of exhibit space as a 
function of visitor perimeter, which could have important exhibit design implications. Zoos are also using established GPS methodologies for long-term studies, tracking a herd of elephants through changes in age, herd structure, and exhibit updates (D. Shepherdson, personal communication, January 15, 2015).

Chapter Three focused on walking in zoo elephants as measured by GPS anklets. I analyzed 259 days of data from 56 African and Asian elephants and found that they walked an average of $5.3 \mathrm{~km} /$ day with no significant difference between species. My analysis identified variables correlated with walking; one finding of particular interest was that walking increased in more dynamic feeding environments. I also found that walking is negatively correlated with space experience, contrary to my original hypothesis. Together these findings indicate that zoos seeking to increase walking in their elephants should not focus solely on increasing the exhibit size, but should introduce complexity and novelty to the environment. I did not, however, find any compelling evidence that walking is correlated with foot health or joint health. This was due in part to the small sample size found in my study despite the multi-institutional approach; this limitation is considered one of the primary challenges to zoo research (Kuhar et al., 2006; Plowman, 2008). Finally, I found no evidence to support my hypothesis that walking is influenced by herd size or enrichment program. (It should be noted, however, that increasing the time and activity related to foraging is a priority for enrichment [Shepherdson, 1999], thus, feeding-based enrichment per se is an extremely important consideration during discussions of zoo elephant walking.)

Now that the variables associated with walking have been identified by a correlational analysis, experimental studies are needed to establish causation between 
these variables and distance walked. A study designed to test the effect of feeding schedule on walking distance would be relatively straightforward, thanks to the automated feeding devices some zoos have installed in their exhibits (Binder, 2014). In this case, a study using a repeated treatment design (commonly applied in zoo studies [Swaisgood \& Shepherdson, 2005]) would, for a number of iterations, alternate between a control stage - where the feeders are programmed to deliver food at predictable intervals for some period of time (e.g., 20 days), and a treatment stage - where food delivery is unscheduled (20 days). Based on my results (Chapter Three), elephants would be predicted to walk as much as $1.3 \mathrm{~km} /$ day more when receiving unscheduled feedings versus a predictable feeding schedule.

Briefly, there is also the potential for creative applications of GPS research outside the realm of zoo animal welfare. For example, GPS data loggers could be used in visitor studies to better understand the spatiotemporal habits of zoo visitors, including the exhibits or zoo resources they most frequent, the effect of new exhibits or interpretive elements on stay time, and the routes they take through the zoo. A proof of concept study investigating this possibility at one zoo was successful (McBeath, 2009), as was a comparable study that took place in three national parks (D'Antonio et al., 2010).

In Chapter Four I investigated recumbence behaviors in zoo elephants via accelerometers. I analyzed 344 days of data from 72 elephants and found that elephants were recumbence an average of 2.56 hours/day. African elephants had significantly lower recumbence (about two hours/day) than Asian elephants (about three hours/day). Surprisingly, nearly one-third of elephants were non-recumbent on at least one night; further research is necessary to understand whether this behavior has welfare 
consequences. My analysis supported my hypothesis that African and Asian elephant recumbence is affected by flooring substrate, thus, I recommend that zoos continue their efforts to replace hard substrate with soft substrate in order to provide zoo elephants with an environment that better facilitates recumbent rest. I also found evidence that elephants are more recumbent if they spend more time in larger spaces at night, although this association was limited to African elephants.

Experimental tests can now help elucidate both the predicted and unexpected relationships between the variables identified in my research and distance walked. For example, I was surprised to find that Asian elephants that spent time housed alone are predicted to be recumbent more. A similar response is seen in cattle, and one proposed explanation suggests this may be due to dominant members of the social group disturbing other individuals. Likewise, the (anecdotal) consensus among elephant care staff is that female Asian elephants are reluctant to assume vulnerable recumbent postures when housed together because their herds are often composed of unrelated females. African herds, on the other hand, are more likely to be composed of related individuals that exhibit fewer antagonistic behaviors. A recumbence study that analyzed coefficient of relatedness across a number of zoo herds could test this hypothesis; however, the small sample sizes and confounding variables (e.g., different substrates) could make this difficult. Next, zoo researchers could design experiments to directly test the effect of substrate on recumbence. Although I found evidence that elephants are more recumbent on softer substrate, this conclusion contrasts a study at the Oregon Zoo, which measured elephant behavior before and after the installation of rubberized flooring (Meller et al., 2007). When housed in a room in which the new flooring was installed, the elephants 
showed a significant decrease in recumbence from baseline, and a significant increase in standing rest; this effect was not replicated in the other room treated in the same fashion, however. The authors propose that elephants may prefer to sleep while standing, and the new flooring provides a more comfortable surface that alleviates pressure on the feet and joints. While this study took advantage of the scheduled installation of new, semipermanent flooring, an ideal study design would measure recumbence during the repeated addition and removal of soft and hard substrates of various types to better establish causation, if present.

Although accelerometers have been used to measure a number of zoo animal behaviors (e.g., activity levels [Takahashi, 2009], travel distances [Rothwell et al., 2011; Sellers \& Crompton, 2004]), feeding, walking, and swaying [Soltis et al., 2012]), more possibilities come from the novel uses seen in livestock research. For example, accelerometers have been used to measure differences in acceleration between legs to identify asysmmetric stepping (Chapinal et al., 2011; Flower \& Weary, 2009), and to distinguish walking, trotting, and galloping in calves (de Passillé et al., 2010). Asymmetric stepping is a sign of lameness, which may have implications for zoo elephants due to the prevalence of foot and musculoskeletal pathologies. Running is considered a play behavior in calves (Rushen et al., 2010), and is (controversially) considered a way to measure a positive affective state (Yeates \& Main, 2008).

Livestock researchers have even tested the ability of accelerometers to differentiate between NREM and REM sleep stages, albeit with limited success (Hokkanen et al., 2011). 
Zoo researchers must be prepared to resist the lure of GPS technology when it is not the appropriate tool for their study objectives or circumstances. For example, researchers measuring Asian zoo elephant movement with video analysis noted that GPS would have required extensive training of staff and animals before data collection could begin, and video monitoring allows for direct observations when needed (e.g., monitoring pregnant females) (Rowell, 2014). Another possible technique for studying zoo animal movements comes from the growing availability and affordability of radio frequency identification (RFID) technology (Reynolds, 2007). Dallas Zoo adopted RFID for its "TangaTracker" system to monitor the movement of its elephants. The system uses RFID tags work in anklets, and was chosen, at least in part, due to hesitancy surrounding elephants wearing bulky GPS collars (PRLog, 2012). Although there have been no published reports on the success of TangaTracker, RFID has the advantage of bypassing the limitations of GPS (Chapter Two), but requires a much greater initial investment of time and resources, making it unfeasible for multi-institutional research at present. Perhaps the most advanced system is the International Cooperation for Animal Research Using Space initiative (ICARUS, 2014). Rather than piggy-backing off other established systems (e.g., the use of GPS-equipped collars), this program was developed specifically with the intent of tracking migratory patterns. The relatively low orbit of the ICARUS satellites, and advancements in transmitter miniaturization technology will allow tracking of animals as small as honeybees when the project begins in 2015 (ICARUS, 2014). Whether or not it will be feasible to use this system with zoo animals on smaller scales is currently unknown, but if it can be done, zoo researchers will likely find a way to apply it to studies of animal welfare. 
GPS devices and accelerometers can also be utilized simultaneously to enhance our understanding of animal behavior and welfare. For example, the preference of an animal for different substrates in their exhibit could be determined if the researcher knew the location of the recumbence bout, and the types and percent coverage of substrate options available. I have already initiated this type of study in zoo elephants using data collected during the Elephant Welfare Project. I have identified a sub-population of 46 elephants with 157 nights of data to analyze for this project. These elephants have at least two nights of data during which they experienced the same social and housing arrangement. On each night the elephants lay down for at least one recumbence bout of more than 15 minutes, allowing me to increase location accuracy by averaging GPS fixes. Only elephants that had multiple substrates to select from - some combination of grass, sand, dirt, rubber, concrete, stone, and other - were included, and I have identified and quantified the available substrates for each elephant. I have also used ArcMap software to create maps showing where recumbence bouts occurred at a number of zoos. To complete this study, I will be request that participating zoos identify the exact substrate present at the recumbent sites, so that I may establish whether their elephants exhibited preferential substrate selection. Preference tests of this sort are rarely used in zoos (but see Meller et al., 2007) but could provide valuable data to improve animal welfare (Mason \& Veasey, 2010). However, establishing whether or not animals prefer substrates that actually optimize their welfare is another area that would require investigation.

Zoos with the goal of increasing walking or recumbence now have a list of factors associated with these behaviors - and the relative importance of each of those factors - 
and can use them to make exhibit or husbandry modifications that provide the proper environmental context for elephants to express these behaviors. I have also identified some areas for future experimental studies to better elucidate the relationship between these variables and walking and recumbence. However, it should be noted that these behaviors have a distinct disadvantage when compared to more established welfare indicators such as foot health: we do not know the "ideal" amount of these behaviors for the maximization of animal welfare. Appropriate levels of walking and recumbent rest have presumed welfare benefits, and we presented some evidence from the literature for these benefits in Chapters Three and Four. Yet due to this lack of a benchmark value, we are unable to create an individual prescription stating that a certain elephant should walk or rest more or less, nor can we say anything about the zoo elephant population as a whole. Often in these situations, wild-type behaviors are proposed as a yardstick by which to gauge appropriate behaviors (Hutchins, 2006; Veasey, 1999), but not only is data limited from wild elephants, the use of comparisons with the behavior of wild conspecifics has been questioned. Veasey et al. (1996) provide the example of a captive giraffe lying down more than a wild conspecific; the authors point out that wild giraffes may lie down less due to the risks of predation, and therefore the more recumbent captive giraffe should not be presumed to have poor welfare. In general, this conclusion rings true. However, if the captive giraffe was to lay down a great deal less than the wild giraffe, despite a relatively safer environment, this may raise questions in the mind of a researcher. Likewise, for zoos at which elephants exhibit relatively low amount of walking or recumbence when compared to the sub-population data presented in Chapters 
Three and Four, they should consider whether they might need to take action to facilitate these behaviors at their zoo.

African and Asian zoo elephants are particularly vulnerable to health and welfare problems, and researchers are interested in identifying and measuring behaviors that may affect welfare. This work assessed walking and recumbent rest in African and Asian zoo elephants, and identified a variety of factors that are associated with these behaviors. Zoos can use this information to prioritize modifications to their facilities and animal management programs to provide an environment that encourages zoo elephants to express walking and recumbence behavior, should they choose to do so. 


\section{References}

Adams J, Berg J. 1980. Behavior of female African elephants (Loxodonta africana) in captivity. Appl Anim Ethol 6:257-276.

Ali T. 2012. Positioning with wide-area GNSS networks: concept and application. Positioning 3(1):1-6.

Anderson DM. 2007. Virtual fencing - past, present and future. Rangeland J 29:65-78.

Archie EA, Moss CJ, Alberts SC. 2006. The ties that bind: Genetic relatedness predicts the fission and fusion of groups in wild African elephants (Loxodonta africana). Proceedings of the Royal Society B: Biological Sciences 273:513-522.

AZA. 2014. Association of Zoos \& Aquariums Animal Welfare Committee. <https://www.aza.org/Membership/detail.aspx?id=378>. Accessed 2015-01-19.

Bassett L, Buchanan-Smith HM. 2007. Effects of predictability on the welfare of captive animals. Appl Anim Behav Sci 102:223-245.

Belant JL. 2009. Effects of antenna orientation and vegetation on global positioning system telemetry collar performance. Northeastern Nat 16(4):577-584.

Bell NJ, Bell MJ, Knowles TG, Whay HR, Main DJ, Webster AJ. 2009. The development, implementation and testing of a lameness control programme based on HACCP principles and designed for heifers on dairy farms. Vet J 180(2):178-188.

Bergsten C, Frank B. 1996. Sole haemorrhages in tied primiparous cows as an indicator of periparturient laminitis: Effects of diet, flooring and season. Acta Vet Scand 37(4):383-394.

Berlyne DE. 1960. Conflict, arousal and curiosity. New York: McGraw-Hill. 350 p.

Bettinger P, Fei S. 2010. One year's experience with a recreation-grade GPS receiver. Math Comput for Nat Res Sci 2(2):153-160.

Binder M. 2014. Elephants at the Oregon Zoo switch to unpredictable feeders that encourage natural foraging. 2014 June 06. Oregon Live.

<www.oregonlive.com/portland/index.ssf/2014/06/elephants_at_the_oregon_zoo_sw.htm 1>. Accessed 2015-01-19.

Blake S, Douglas-Hamilton I, Karesh WB. 2001. GPS telemetry of forest elephants in Central Africa: Results of a preliminary study. Afr J Ecol 39:178-186. 
Blake S, Deem SL, Strindberg S, Maisels F, Momont L, Isia I-B, Douglas-Hamilton I, Karesh WB, Kock MD. 2008. Roadless wilderness area determines forest elephant movements in the Congo basin. PLoS ONE 3(10):e3546.

Blanc F, Brelurut A. 1997. Short-term behavioral effects of equipping red deer hinds with a tracking collar. Mamm Biol 62:18-26.

Boettiger AN, Wittemyer G, Starfield R, Volrath F, Douglas-Hamilton I, Getz WM. 2011. Inferring ecological and behavioral drivers of African elephant movement using a linear filtering approach. Ecology. 92(8):1648-57.

Boissy A, Manteuffel G, Jensen MB, Moe RO, Spruijt B, Keeling LJ, Winckler C, Forkman B, Dimitrov I, Langbein J, Bakken M, Veissier I, Aubert A. 2007. Assessment of positive emotions in animals to improve their welfare. Physiol Behav 92:375-397.

Bolstad P, Jenks A, Berkin J, Horne K, Reading WH. 2005. A comparison of autonomous, WAAS, real-time, and post-processed Global Positioning Systems (GPS) accuracies in northern forests. North J Appl For 22(1):5-11.

Bolstad P. 2012. GIS fundamentals: a first text on geographic information systems. 4th ed. White Bear Lake (MN): Eider Press. 674 p.

Botreau R, Veissier I, Butterworth A, Bracke MBM, Keeling LJ. 2007. Definition of criteria for overall assessment of animal welfare. Anim Welf 16:225-228.

Bowman JL, Kochanny CO, Demarais S, Leopold BD. 2000. Evaluation of a GPS collar for white-tailed deer. Wildl Soc Bull 28:141-145.

Brockett R, Stoinski T, Black J, Markowitz T, Maple T. 1999. Nocturnal behavior in a group of unchained female African elephants. Zoo Biol 18:101-109.

Brooks C, Bonyongo C, Harris S. 2008. Effects of Global Positioning System collar weight on zebra behavior and location error. J Wildl Manage 72(2):527-534.

Broom DM, Fraser AF. 2007. Domestic animal behaviour and welfare. 4th ed. Wallingford: CAB International. 437 p.

Broom DM, Johnson KG. 1993. Stress and animal welfare. London: Chapman \& Hall. $211 \mathrm{p}$.

Brown DD, LaPoint S, Kays R, Heidrich W, Kümmeth F, Wikelski M. 2012.

Accelerometer-informed GPS telemetry: Reducing the trade-off between resolution and longevity. Wildl Soc Bull 36:139-146. 
Brown DD, Kays R, Wikelski M, Wilson R, Klimley P. 2013. Observing the unwatchable through acceleration logging of animal behavior. Animal Biotelemetry 1:20.

Brown JL, Olson D, Keele M, Freeman EW. 2004a. Survey of the reproductive cyclicity status of Asian and African elephants in North America. Zoo Biol 23(4):309-321.

Brown JL, Walker SL, Moeller T. 2004b. Comparative endocrinology of cycling and noncycling Asian (Elephas maximus) and African (Loxodonta africana) elephants. Gen Comp Endocrinol 136:360-370.

Brown JL, Paris S, Prado-Oviedo N, Meehan CL, Hogan J, Morfeld K, Carlstead K. (in prep). Reproductive health assessment of female elephants in North American zoos and association of husbandry practices with reproductive dysfunction in African savannah elephants (Loxodonta africana).

Brown RE, Basheer R, McKenna JT, Strecker RE, McCarley RW. 2012. Control of sleep and wakefulness. Physiol Rev 92:1087-1187.

Burger J, Gochfeld M. 1994. Vigilance in African mammals: Differences among mothers, other females, and males. Behaviour 131(3):153-169.

Burghardt GM, Ward B, Rosscoe R. 1996. Problem of reptile play: Environmental enrichment and play behavior in a captive Nile soft-shelled turtle, Trionyx triunguis. Zoo Bio 15:223-238.

Burke T, Page B, Van Dyk G, Millspaugh J, Slotow R. 2008. Risk and ethical concerns of hunting male elephant: Behavioural and physiological assays of the remaining elephants. PLoS ONE 3(6): e2417

Campos-Arceiz A, Larrinaga AR, Weerasinghe UR, Takatsuki S, Pastorini J, Leimgruber P, Fernando P, Santamaría L. 2008. Behavior rather than diet mediates seasonal differences in seed dispersal by Asian elephants. Ecology 89(10):2684-2691.

Capellini I, Barton RA, McNamara P, Preston BT, Nunn CL. 2008. Phylogenetic analysis of the ecology and evolution of mammalian sleep. Evolution 62:1764-1776.

Carlstead K, Seidensticker J, Baldwin R. 1991. Environmental enrichment for zoo bears. Zoo Biol 10:3-16.

Carlstead K, Mench JA, Meehan C, Brown JL. 2013. An epidemiological approach to welfare research in zoos: The Elephant Welfare Project. J Appl Anim Welf Sci 16(4):319-337. 
Casper RM. 2009. Guidelines for the instrumentation of wild birds and mammals. Anim Behav 78:1477-1483.

Cattet M, Boulanger J, Stenhouse G, Powell RA, Reynolds-Hogland MJ. 2008. An evaluation of long-term capture effects in ursids: Implications for wildlife welfare and research. J Mammal 89:973-990.

Cerruti AP, Kintner Jr. PM, Gary DE, Mannucci AJ, Meyer RF, Doherty P, Coster AJ. 2008. Effect of intense December 2006 solar radio bursts on GPS receivers. Space Weather 6(10).

Chaiyarat R, Kongprom U, Manathamkamon D, Wanpradab S, Sangarang S. 2012. Captive breeding and reintroduction of the oriental pied hornbill (Anthracoceros albirostris) in Khao Kheow Open Zoo, Thailand. Zoo Biol 31(6):683-693.

Chapinal N, de Passillé AM, Weary DM, von Keyserlingk MAG, Rushen J. 2009. Using gait score, walking speed, and lying behavior to detect hoof lesions in dairy cows. J Dairy Sci 92:4365-4374.

Clubb R, Mason G. 2002. A review of the welfare of elephants in European zoos. Horsham, UK: RSPCA. 280 p.

Clubb R, Mason G. 2003. The welfare of zoo elephants in Europe: mortality, morbidity and reproduction. In: Proceedings of the Fifth Annual Zoo Research Symposium, Marwell Zoological Park, Federation of Zoological Gardens of Great Britain and Ireland, London, 67-76.

Clubb R, Lee P, Mar KU, Moss C, Rowcliffe M, Mason GJ. 2008. Compromised survivorship in zoo elephants. Science 322(5908):1649.

Clubb R, Rowcliffe M, Lee P, Mar KU, Moss C, Mason GJ. 2009. Fecundity and population viability in female zoo elephants: Problems and possible solutions. Anim Welf 18:237-247.

Colombo OL. 1986. Ephemeris errors of GPS satellites. Bulletin géodésique 60(1):64-84.

Csuti B, Sargent EL, Bechert US. 2001. The elephant's foot: Prevention and care of foot conditions in captive Asian and African elephants. Ames: Iowa State University Press. $163 \mathrm{p}$.

Danskin S, Bettinger P, Jordan T. 2009. Multipath mitigation under forest canopies: a choke ring antenna solution. Forest Sci 55(2):109-116. 
D’Antonio, Monz C, Lawson S, Newman P, Pettebone D, Courtemanch A. 2010. GPSbased measurements of backcountry visitors in parks and protected areas: Examples of methods and applications from three case studies. J Park Recreat Admi 28(3):42-60.

Dechen-Quinn AC, Williams DM, Porter WF. 2012. Postcapture movement rates can inform data censoring protocols for GPS collared animals. J Mammal 93:456-463.

Deckert CJ, Bolstad PV. 1996. Global Positioning System (GPS) accuracies in eastern U.S. deciduous and conifer forests. Southern J Appl Forestry 20(2):81-84.

Dennis TE, Shah SF. 2012. Assessing acute effects of trapping, handling, and tagging on the behavior of wildlife using GPS telemetry: a case study of the common brushtail possum. J Appl Anim Welf Sci 15(3):189-207.

D’Eon RG. 2003. Effects of a stationary GPS fix-rate bias on habitat selection analyses. J Wildl Manage 67:858-863.

D'Eon RG, Delparte D. 2005. Effects of radio-collar position and orientation on GPS radio-collar performance, and the implications of PDOP in data screening. $J$ of Appl Ecol 42:383-388.

D’Eon RG, Serrouya R, Smith G, Kochanny CO. 2002. GPS radiotelemetry error and bias in mountainous terrain. Wildl Soc Bull 30(2):430-439.

De Passillé AM, Jensen MB, Chapinal N, Rushen J. 2010. Technical note: Use of accelerometers to describe gait patterns in dairy calves. J Dairy Sci 93:3287-3293.

De Silva, S Ranjeewa ADG, Kryazhimskiy S. 2011. The dynamics of social networks among female Asian elephants. BMC Ecology 11:17.

Dimeo-Ediger N. 2001. Results of a survey of elephant foot condition and care in North America. In: Csuti B, Sargent EL, Bechert US, editors. The elephant's foot: Prevention and care of foot conditions in captive Asian and African elephants. Ames: Iowa State University Press. p 153.

DOD. 2014. DOD announces start of civil navigation message broadcasting. U.S. Department of Defense. Release No: NR-209-14. 2014 Apr 25. <http://www.defense.gov/releases/release.aspx?releaseid=16666>. Accessed 2015 Jan 12.

Doherty P, Coster A, Murtagh M. 2004. Space weather effects of October - November 2003. GPS Solutions 8(4):267-271. 
DOT, FAA. 2008. Global Positioning System wide area augmentation system (WAAS) performance standard. 1st ed. 2008 Oct 31. Department of Transportation and Federal Aviation Administration. <http://www.gps.gov/technical/ps/2008-WAAS-performancestandard.pdf $>$. Accessed 2015 Jan 12.

Douglas-Hamilton I. 1998. Tracking African elephants with a global positioning system (GPS) radio collar. Pachyderm 25:81-92.

Dow TL, Brown JL. 2012. Evidence that hyperprolactinemia is associated with ovarian acyclicity in female zoo African elephants. Reprod Fertil Dev 24:1019-1027.

Dow TL, Holásková I, Brown JL. 2011. Results of the third reproductive assessment survey of north American Asian (Elephas maximus) and African (Loxodonta africana) female elephants. Zoo Biol 30(6):699-711.

Dussault C, Courtois R, Ouellet JP, Huot J. 1999. Evaluation of GPS telemetry collar performance for habitat studies in the boreal forest. Wildl Soc Bull 27:965-972.

Dussault C, Courtois R, Ouellet JP, Huot J. 2001. Influence of satellite geometry and differential correction on GPS location accuracy. Wildl Soc Bull 29:171-179.

EC. 2013. European Commission. Why Galileo? 2013 Apr 4.

<http://ec.europa.eu/enterprise/policies/satnav/galileo/why/index_en.htm>. Accessed 2015 Jan 12.

Edenius L. 1997. Field test of a GPS location system for moose (Alces alces) under Scandinavian boreal conditions. Wildl Biol 3:39-43.

Ekelund U, Ward HA, Norat T, Luan J, May AM, Weiderpass E, Sharp SS, et al. 2015. Physical activity and all-cause mortality across levels of overall and abdominal adiposity in European men and women: The European Prospective Investigation into Cancer and Nutrition Study (EPIC). Am J Clin Nutr doi: 10.3945/ajen.114.100065.

El-Rabbany A. 2006. Introduction to GPS: The Global Positioning System. $2^{\text {nd }}$ ed. Norwood (MA): Artech House Inc. 210 p.

Endres M I, Barberg AE. 2007. Behavior of dairy cows in an alternative bedded-pack housing systems. J Dairy Sci 90:4192-4200.

Everson CA, Bergmann BM, Rechtschaffen A. 1989. Sleep deprivation in the rat: III. Total sleep deprivation. Sleep 12:13-21. 
Everson CA. 1995. Functional consequences of sustained sleep deprivation in the rat. Behav Brain Res 69:43-54.

FAWC. 1992. Farm Animal Welfare Council updates the five freedoms. Vet Rec $131: 357$.

Feng L, Zhang L. 2005. Habitat selection by Asian elephant (Elephas maximus) in Xishuangbanna, Yunnan, China. Acta Theriologica Sinica 25:229-236. (in Chinese with English abstract).

Flower FC, Weary DM. 2009. Gait assessment in dairy cattle. Animal 3:87-95.

Foley CAH, Papageorge S, Wasser SK. 2001. Noninvasive stress and reproductive measures of social and ecological pressures in free-ranging African elephants. Cons Biol 15:1134-1142.

Fowler ME. 2001. An overview of foot conditions in Asian and African elephants. In: Csuti B, Sargent EL, Bechert US, editors. The elephant's foot: Prevention and care of foot conditions in captive Asian and African elephants. Ames: Iowa State University Press. pp 3-9.

Frair JL, Fieberg J, Hebblewhite M, Cagnacci F, DeCesare NJ, Pedrotti L. 2010. Resolving issues of imprecise and habitat-biased locations in ecological analyses using GPS telemetry data. Phil Trans R Soc B 365:2187-2200.

Freeman EW, Weiss E, Brown JL. 2004. Examination of the interrelationships of behavior, dominance status, and ovarian activity in captive Asian and African elephants. Zoo Biol 23(5):431-448.

Freeman EW, Guagnano G, Olson D, Keele M, Brown JL. 2009. Social factors influence ovarian acyclicity in captive African elephants (Loxodonta africana). Zoo Biol 28(1):115.

Fregonesi JA, Tucker CB, Weary DM. 2007. Overstocking reduces lying time in dairy cows. J Dairy Sci 90:3349-3354.

Gadd ME. 2002. The impact of elephants on the marula tree Sclerocarya birrea. Afr J Ecol 40:328-336.

Gage LJ. 2001. Treatment of osteomyelitis in elephant feet. In: Csuti B, Sargent EL, Bechert US, editors. The elephant's foot: Prevention and care of foot conditions in captive Asian and African elephants. Ames: Iowa State University Press. pp 117-118. 
Galindo F, Broom DM. 2000. The relationships between social behaviour of dairy cows and the occurrence of lameness in three herds. Res Vet Sci 69:75-79.

Ganskopp D. 2001. Manipulating cattle distribution with salt and water in large arid-land pastures: A GPS/GIS assessment. Appl Anim Behav Sci 73(4):251-262.

Ganskopp DC, Johnson DD. 2007. GPS error in studies addressing animal movements and activities. Rangeland Ecol Manag 60(4):350-358.

Glander KE. 1993. Capture and marking techniques for arboreal primates. In: Estrada A, Rodriguez-Luna E, Lopez-Wilchis R, Coates-Estrada R, editors. Estudios primatalogicos en Mexico. Veracruz: Universidad Veracruzana. pp 299-304.

Goodyear J. 2007. Integrated GPS systems and is GSM next? In: Kays RW, Wikelski M. Review of the NSF sponsored animal tracking and physiological monitoring workshop. <http://www.movebank.org/assets/ATPM_whitepaper.pdf>. Accessed 2014 Dec 16.

GPS.gov. 2014a. National Coordination Office for Space-Based Positioning, Navigation, and Timing. Space segment. 2014 Dec 12. < http://www.gps.gov/systems/gps/space/>. Accessed 2015 Jan 12.

GPS.gov. 2014b. National Coordination Office for Space-Based Positioning, Navigation, and Timing. New civil signals. 2014 Apr 28.

<http://www.gps.gov/systems/gps/modernization/civilsignals>. Accessed 2015 Jan 12.

GPS.gov. 2014c. National Coordination Office for Space-Based Positioning, Navigation, and Timing. Control segment. 2014 Sep 17. < http://www.gps.gov/systems/gps/control/> . Accessed 2015 Jan 12.

Graham MD, Douglas-Hamilton I, Adams WM, Lee P. 2009. The movement of African elephants in a human-dominated land-use mosaic. Animal Conservation 12(5):445-455.

Greco BJ, Meehan CL, Hogan JL, Leighty KL, Mellen J, Mason G, Mench JA. (in prep). The days and nights of zoo elephants: Using epidemiology to better understand stereotypic behavior of African savannah elephants (Loxodonta africana) and Asian elephants (Elephas maximus) in North American zoos.

Guy PR. 1976. Diurnal activity patterns of elephant in the Sengwa Area, Rhodesia. Afr J Ecol 14:285-295.

Hacker CE, Horback KM, Miller LJ. 2015. GPS technology as a proxy tool for determining relationships in social animals: An example with African elephants. Appl Anim Behav Sci 163:175-182. 
Haley DB, de Passillé AM, Rushen J. 2001. Assessing cow comfort: Effects of two floor types and two tie stall designs on the behaviour of lactating dairy cows. Appl Anim Behav Sci 71:105-117.

Hancocks D. 2008. Most zoos do not deserve elephants. In: Wemmer CM, Christen CA, editors. Elephants and ethics: Toward a morality of coexistence. Baltimore: Johns Hopkins University Press. pp 259-283.

Hansen MC, Riggs RA. 2008. Accuracy, precision, and observation rates of global positioning system telemetry collars. J Wildl Manage 72:518-526.

Harris M, Sherwin S, Harris S. 2008. The welfare, housing and husbandry of elephants in UK zoos: Final report, University of Bristol. DEFRA Science and Research Project WC05007. London: Department of Food, the Environment and Rural Affairs. 127 p.

Hartmann E, Bernstein J, Wilson C. 1968. Sleep and dreaming in the elephant. Abstract. Psychophysiology 4:389.

Hatt J-M, Clauss M. 2006. Feeding Asian and African elephants in captivity. Int Zoo Yb 40:88-95.

Hendrichs H, Hendrichs U. 1971. Dikdik und Elefanten: Ökologie und Soziologie zweier afrikanischer Huftiere. München: R. Piper. 172 p.

Hermes R, Göritz F, Streich W, Hildebrandt T. 2007. Assisted reproduction in female rhinoceros and elephants - current status and future perspective. Reprod Domest Anim 42:33-44.

Hittmair KM, Vielgrader HD. 2000. Radiographic diagnosis of lameness in African Elephants (Loxodonta africana). Vet Radiol Ultrasound 41(6):511-515.

Hokkanen AH, Hänninen L, Tiusanen J, Pastell M. 2011. Predicting sleep and lying time of calves with a support vector machine classifier using accelerometer data. Appl Anim Behav Sci 134:10-15.

Horback KM, Miller LJ, Andrews J, Kuczaj SA, Anderson M. 2012. The effects of GPS collars on African elephant (Loxodonta africana) behavior at the San Diego Zoo Safari Park. Appl Anim Behav Sci 142(1):76-81.

Hoque MM, Jakowski N. 2008. Estimate of higher order ionospheric errors in GNSS positioning. Radio Sci 43:RS5008. 
Hosey GR, Melfi V, Pankhurst S. 2013. Zoo animals: Behaviour, management and welfare. $2^{\text {nd }}$ ed. Oxford: Oxford University Press. 643 p.

Hughes BO, Duncan IJH. 1988. The notion of ethological 'need', models of motivation and animal welfare. Anim Behav 36:1696-1707.

Hulbert IAR, Wyllie JTB, Waterhouse A, French J, McNulty D. 1998. A note on the circadian rhythm and feeding activity of sheep fitted with a lightweight GPS collar. Appl Anim Behav Sci 60:359-364.

Hutchins M. 2003. Zoo and aquarium animal management and conservation: Current trends and future challenges. Int Zoo Yearb 38:14-28.

Hutchins M. 2006. Variation in nature: Its implications for zoo elephant management. Zoo Biol 25:161-171.

Hutchins M, Keele M. 2006. Elephant importation from range countries: Ethical and practical considerations for accredited zoos. Zoo Biol 25:219-233.

Hutchinson JR, Schwerda D, Famini D, Dale RHI, Fischer M, Kram R. 2006. The locomotor kinematics of African and Asian elephants: Changes with speed and size. J Exp Biol 209:3812-3827.

ICARUS. 2014. ICARUS initiative. < http://icarusinitiative.org/> . Accessed 2015-01-19.

Ito K, Weary DM, von Keyserlingk MAG. 2009. Lying behavior: Assessing within- and between-herd variation in free-stall-housed dairy cows. J Dairy Sci 92:4412-4420.

Jensen MB, Pedersen LJ, Munksgaard L. 2005. The effect of reward duration on demand functions for rest in dairy heifers and lying requirements as measured by demand functions. Appl Anim Behav Sci 90:207-217.

Jiang Z, Sugita M, Kitahara M, Takatsuki S, Goto T, Yoshida Y. 2008. Effects of habitat feature, antenna position, movement, and fix interval on GPS radio collar performance in Mount Fuji, central Japan. Ecol Res 23:581-588.

Jones EE. 1989. Hyperprolactinaemia and female infertility. J Reprod Med. 34:117-126.

Jones D, McGreevy JE. 2007. How much space does an elephant need? The impact of confinement on animal welfare. J Vet Behav 2:185-187.

Joubert D. 2006. Hunting behaviour of lions (Panthera leo) on elephants (Loxodonta africana) in the Chobe National Park, Botswana. Afr J Ecol 44(2):279-281. 
Kagan R, Veasey J. 2010. Challenges of zoo animal welfare. In: Kleiman DG., Thompson KV, Baer CK, editors. Wild mammals in captivity: Principles and techniques for zoo management. Chicago: The University of Chicago Press. pp 11-21.

Kandler C. 2010. Analyse des nächtlichen verhaltens von Afrikanischen elefanten (Loxodonta africana) in menschenobhut unter anwendung chronoethologischer methoden. Ph.D. Dissertation. Frankfurt: Goethe University Frankfurt.

Kaplan ED. 2006. Introduction. In: Kaplan ED, Hegarty CJ, editors. Understanding GPS: principles and applications. $2^{\text {nd }}$ ed. pp 1-20. Norwood (MA): Artech House Inc. 703 p.

Kaplan ED, Hegarty CJ. 2006. Understanding GPS: principles and applications. $2^{\text {nd }}$ ed. Norwood (MA): Artech House Inc. 703 p.

Kaplan ED, Leva JL. 2006. Fundamentals of satellite navigation. In: Kaplan ED, Hegarty CJ, editors. Understanding GPS: principles and applications. $2^{\text {nd }}$ ed. pp 21-65. Norwood (MA): Artech House Inc. 703 p.

Kleusberg A, Langley RB. 1990. The Limitations of GPS. GPS World 1(2):50-52.

Kuhar CW. 2006. In the deep end: pooling data and other statistical challenges of zoo and aquarium research. Zoo Biol 25:339-352.

Kühme W. 1963. Ethology of the African Elephant (Loxodonta africana Blumenbach 1797) in captivity. Int Zoo Yearb 4:113-121.

Kumar A, Mudappa D, Raman TRS. 2010. Asian elephant Elephas maximus habitat use and ranging in fragmented rainforest and plantations in the Anamalai Hills, India. Tropical Conservation Science 3(2):143-158.

Langley RB. 1999. Dilution of precision. GPS World 10(5):52-59.

Langley RB. 2000. GPS, the ionosphere, and the solar maximum. GPS World 11(7):4449.

Ledgerwood DN, Winckler C, Tucker CB. 2010. Evaluation of data loggers, sampling intervals, and editing techniques for measuring the lying behavior of dairy cattle. J Dairy Sci 93:5129-5139.

Lee C, Henshall JM, Wark TJ, Crossman CC, Reed MT, Brewer HG, O'Grady J, Fisher AD. 2009. Associative learning by cattle to enable effective and ethical virtual fences. Appl Anim Behav Sci 119:15-22. 
Leggett KEA. 2006. Home range and seasonal movement of elephants in the Kunene Region northwestern Namibia. Afr Zool 41:17-36.

Leighty KA, Soltis J, Wesolek CM, Savage A. 2008. Rumble vocalizations mediate interpartner distance in African elephants, Loxodonta africana. Anim Behav 76:16011608.

Leighty KA, Soltis J, Wesolek CM, Savage A, Mellen J, Lehnhardt J. 2009. GPS determination of walking rates in captive African elephants (Loxodonta africana). Zoo Biol 28(1):16-28.

Leighty KA, Soltis J, Savage A. 2010. GPS assessment of the use of exhibit space and resources by African elephants (Loxodonta africana). Zoo Biol 29(2):210-220.

Lesku JA, Roth TC, Amlaner CJ, Lima SL. 2006. A phylogenetic analysis of sleep architecture in mammals: The integration of anatomy, physiology and ecology. Am Nat 168:441-453.

Lewis JS, Rachlow JL, Garton EO, Vierling LA. 2007. Effects of habitat on GPS collar performance: Using data screening to reduce location error. J Appl Ecol 44(3):663-671.

Lewis KD, Shepherdson DJ, Owens TM, Keele M. 2010. A survey of elephant husbandry and foot health in North American zoos. Zoo Biol 29:221-236.

Loarie SR, van Aarde RJ, Pimm SL. 2009. Elephant seasonal vegetation preferences across dry and wet savannas. Biol Conserv 142(12):3099-3107.

Macdonald DW. 1978. Radio-tracking: some applications and limitations. In: Stenhouse GB, editor. Animal marking: recognition marking of animals in research. London: Macmillan. pp 192-204.

Maletzke BT, Koehler GM, Meyer WR. 2005. Identifying I-90 wildlife corridors using GIS \& GPS: spatial-temporal model of landscape use by GPS marked cougars. Washington State Department of Transportation: Technical Bulletin WA-RD 622.1. Maple TL, Perdue BM. 2013. Zoo animal welfare. Berlin Heidelberg: Springer. 209 p. Mason G. 1991. Stereotypies: A critical review. Anim Behav 41(6):1015-1037.

Mason G, Rushen J. 2006. Stereotypic animal behaviour: Fundamentals and applications to welfare. $2^{\text {nd }}$ ed. Wallingford, UK: CABI Pub. 384 p. 
Mason G, Clubb R, Latham N, Vickery S. 2007. Why and how should we use environmental enrichment to tackle stereotypic behaviour? Appl Anim Behav Sci 102:163-188.

Mason GJ, Veasey J. 2010. How should the psychological well-being of zoo elephants be objectively investigated? Zoo Biol 29:237-255.

McBeath JK. 2009. Navigation through the Desert Museum as determined by GPS tracking and exit survey. Honors Bachelor's thesis. <http://arizona.openrepository.com/arizona/bitstream/10150/192551/1/azu_etd_mr20090 176_sip1_m.pdf>. Accessed 2015-01-19.

McKay GM. 1973. Behavior and ecology of the Asiatic elephant in southeastern Ceylon. Smithsonian Contributions to Zoology (125). Washington DC: Smithsonian Institution Press. 113 p.

McKnight BL. 1995. Behavioural ecology of 'hand-reared' African elephants (Loxodonta africana [Blumenbach]) in Tsavo East National Park, Kenya. Afr J Ecol 33:242-256.

McMahon CR, Hindell MA, Harcourt RG. 2012. Publish or perish: Why it's important to publicize how, and if, research activities affect animals. Wildlife Research 39:375-377.

Mech LD, Barber SM. 2002. A critique of wildlife radio-tracking and its use in national parks: a report to the U.S. National Park Service. Jamestown (ND): U.S. Geological Survey, Northern Prairie Wildlife Research Center. <http://www.npwrc.usgs.gov/resource/wildlife/radiotrk/index.htm>. Accessed 2015 Jan 12.

Meehan CL, Hogan JN, Bonaparte-Saller M, Mench JA. (in prep). Standardized quantification of housing and social parameters for African (Loxodonta africana) and Asian (Elephas maximus) elephants in North American zoos.

Mellen J, Hayes M, Shepherdson D. 1998. Captive environments for small felids. In: Shepherdson D, Mellen J, Hutchins M, editors. Second nature: Environmental enrichment for captive animals. Washington: Smithsonian Institution Press. pp. 184-201.

Meller CL, Croney CC, Shepherdson D. 2007. Effects of rubberized flooring on Asian elephant behavior in captivity. Zoo Biol 26:51-61.

MELP. 2008. Ministry of Environment, Lands and Parks. British Columbia standards, specifications and guidelines for resource surveyors using global positioning systems (GPS) technology. Release 4.0. British Columbia MELP. Victoria, Canada. 
Merrill SB, Adams LG, Nelson ME, Mech LD. 1998. Testing releasable GPS radiocollars on wolves and white-tailed deer. Wildl Soc Bull 26(4):830-835.

Metz, JHM. 1985. The reaction of cows to short-term deprivation of lying. Appl Anim Behav Sci 13:301-307.

Mikota SK, Sargent EL, Ranglack GS. 1994. Medical management of the elephant. West Bloomfield, Michigan: Indira Publishing House. Pp 147-148.

Milbert D. 2009. Improving dilution of precision: A companion measure of systematic effects. GPS World 20(11):38-47.

Miller L, Andrews J, Anderson M. 2012. Validating methods to determine walking rates of elephants within a zoological institution. Anim Welf 21(4):577-582.

Miller MA, Hogan JN, Meehan CL. (in prep). Risk factors impacting joint and foot health in African savannah elephants (Loxodonta africana) and Asian elephants (Elephas maximus) in North American zoos.

Mills DS, Eckley S, Cooper JJ. 2000. Thoroughbred bedding preferences, associated behaviour differences and their implications for equine welfare. Anim Sci 70:95-106.

Misra P, Enge P. 2006. Global Positioning System: Signals, measurements, and performance. $2^{\text {nd }}$ ed. Lincoln (MA): Ganga-Jamuna Press. 569 p.

Moen R, Pastor J, Cohen Y, Schwartz CC. 1996. Effects of moose movement and habitat use on GPS collar performance. J Wildl Manage 60(3):659-668.

Moen R, Pastor J, Cohen Y. 1997. Accuracy of GPS telemetry collar locations with differential correction. J Wildl Manage 61(2):530-539.

Moreau M, Siebert S, Buerkert A, Schlecht E. 2009. Use of a tri-axial accelerometer for automated recording and classification of goats' grazing behaviour. Appl Anim Behav Sci 119:1581-70.

Morellet N, Verheyden H, Angibault JM, Cargnelutti B, Lourtet B, Hewison MAJ. 2009. The effect of capture on ranging behavior and activity of the European roe deer Capreolus capreolus. Wildlife Biol 15:278-287.

Morfeld KA, Brown JL. 2014. Ovarian acyclicity in zoo African elephants (Loxodonta africana) is associated with high body condition scores and elevated serum insulin and leptin. Reprod Fertil doi: 10.1071/RD14140 [Epub ahead of print]. 
Morfeld KA, Lehnhardt J, Alligood C, Bolling J, Brown JL. 2014a. Development of a body condition scoring index for female African elephants validated by ultrasound measurements of subcutaneous fat. PLoS One 9(4):e93802.

Morfeld KA, Ball RL, Brown JL. 2014b. Recurrence of hyperprolactinemia and continuation of ovarian acyclicity in captive African elephants (Loxodonta africana) treated with cabergoline. J Zoo Wildl Med 45(3):569-576.

Morfeld KA, Brown JL, Meehan CL, Hogan JN. (in prep). Assessment of body condition in African (Loxodonta africana) and Asian (Elephas maximus) elephants in North American zoos and evidence-based management practices associated with optimal body condition.

Moss C. 1975. Portraits in the wild: Behavior studies of East African mammals. Boston: Houghton Mifflin. 371 p.

Moss CJ. 2011. Female social dynamics: fidelity and flexibility. In: Moss CJ, Croze H, Lee PC, editors. The Amboseli elephants: A long-term perspective on a long-lived mammal. Chicago: University of Chicago Press. pp 205-223.

Munksgaard L, Løvendahl P. 1993. Effects of social and physical stressors on growth hormone levels in dairy cows. Can J Anim Sci 73:847-853.

Munksgaard L, Ingvartsen KL, Pedersen LJ, Nielsen VKM. 1999. Deprivation of lying down affects behaviour and pituitary-adrenal axis responses in young bulls. Acta Agric Scand A 49:172-178.

Munksgaard L, Jensen MB, Pedersen LJ, Hansen SW, Matthews L. 2005. Quantifying behavioural priorities: Effects of time constraints on behaviour of dairy cows, Bos taurus. Appl Anim Behav Sci 92:3-14.

Murray DL, Fuller MR. 2000. A critical review of the effects of marking on the biology of vertebrates. In: Boitani L, Fuller TK, editors. Research techniques in animal ecology: Controversies and consequences. New York: Columbia University Press. p 15-64.

Nathan R, Spiegel O, Fortmann-Roe S, Harel R, Wikelski M, Getz WM. 2012. Using triaxial acceleration data to identify behavioral modes of free-ranging animals: General concepts and tools illustrated for griffon vultures. J Exp Biol 215(6):986-996.

Nelson RJ. 2005. An introduction to behavioral endocrinology. Sunderland (MA): Sinauer Associates. 822 p. 
Ngene SM, Van Gils H, Van Wieren SE, Rasmussen H, Skidmore AK, Prins HHT, Toxopeus AG, Omondi P, Douglas-Hamilton I. 2010. The ranging patterns of elephants in Marsabit protected area, Kenya: The use of satellite-linked GPS collars. Afr J Ecol 48:386-400.

NOAA. 2011. Quality Controlled Local Climatological Data (QCLCD). National Oceanic and Atmospheric Administration . <http://cdo.ncdc.noaa.gov/qclcd/QCLCD>. Accessed 2015-01-15.

NOAA. 2014. Continuously Operating Reference Station (CORS). 2014 Dec 22. < http://geodesy.noaa.gov/CORS/>. Accessed 2015 Jan 12.

Northrup JM, Anderson CR, Wittemyer G. 2014. Effects of helicopter capture and handling on movement behavior of mule deer. J Wildl Manage 78:731-738.

Palmer MC. 2008. Calculation of distance traveled by fishing vessels using GPS positional data: A theoretical evaluation of the sources of error. Fish Res 89:57-64.

Pedersen GR, Søndergaard E, Ladewig J. 2004. The influence of bedding on the time horses spend recumbent. J Equine Vet Sci 24:153-158.

Phillips KA, Elvey CR, Abercrombie CL. 1998. Applying GPS to the study of primate ecology: A useful tool? Am J Primatol 46:167-172.

Plowman AB. 2008. BIAZA statistics guidelines: Toward a common application of statistical tests for zoo research. Zoo Biol 27:226-233.

Posta B, Huber R, Moore DE III. 2013. The effects of housing on zoo elephant behavior: A quantitative case study of diurnal and seasonal variation. Int J Comp Psychol 26:37-52.

Powell GVN, Bjork R. 1995. Implications of intratropical migration on reserve design: A case study using Pharomachrus mocinno. Conserv Biol 9(2):354-362.

Power RJ, Compion RXS. 2009. Lion predation on elephants in the Savuti, Chobe National Park, Botswana. Afr Zool 44(1):36-44.

Prado-Oviedo NA, Bonaparte-Saller MK, Malloy E, Meehan C, Mench J, Brown J. (in prep). Using studbooks to analyze the life event histories of African savannah elephants (Loxodonta africana) and Asian elephants (Elephas maximus) in North American zoos.

PRLog. 2012. Dallas Zoo tracks elephants uising CSL real time location system. Press Release. <http://www.prlog.org/11798605-dallas-zoo-tracks-elephants-using-csl-realtime-location-system.html $>$. Accessed 2015-01-19. 
Proctor CM, Freeman EW, Brown JL. 2010. Results of a second survey to assess the reproductive status of female Asian and African elephants in North America. Zoo Biol 29(2):127-139.

Raabymagle P, Ladewig J. 2006. Lying behavior in horses in relation to box size. J Equine Vet Sci 26(1):11-17.

Rechtschaffen A, Bergmann BM. 2002. Sleep deprivation in the rat: An update of the 1989 paper. Sleep 25:18-24.

Recio MR, Mathieu R, Denys P, Sirguey P, Seddon PJ. 2011. Lightweight GPS-tags, one giant leap for wildlife tracking? An assessment approach. PLoS ONE 6(12):e28225.

Rempel RS, Rodgers AR, Abraham KF. 1995. Performance of a GPS animal location system under a boreal forest canopy. J Wildl Manage 59:543-551.

Rempel RS, Rodgers AR. 1997. Effects of differential correction on accuracy of a GPS animal location system. J Wildl Manage 61:525-530.

Reynolds M. 2007. The present and future of animal tracking with RFID In: Kays RW, Wikelski M. Review of the NSF sponsored animal tracking and physiological monitoring workshop. <http://www.movebank.org/assets/ATPM_whitepaper.pdf>. Accessed 2014 Dec 16.

Rode KD, Pagano AM, Bromaghin JF, Atwood TC, Durner GM, Simac KS, Amstrup SC. 2014. Effects of capturing and collaring on polar bears: Findings from long-term research on the southern Beaufort Sea population. Wildlife Research 41:311-322.

Rodgers AR, Anson P. 1994. Animal-borne GPS: Tracking the habitat. GPS World 5:2032.

Rodgers AR, Rempel RS, Moen RA, Paczkowski J, Schwartz CC, Lawson EJ, Gluck M J. 1997. GPS collars for moose telemetry studies: A workshop. Alces 33:203-209.

Rodgers AR. 2001. Tracking Animals with GPS: The First 10 Years. In: Tracking Animals with GPS: An International Conference Held at the Macaulay Land Use Research Institute. p 1-10. Aberdeen UK. 2001 Mar 12-13.

<http://www.nrac.wvu.edu/classes/resm575/gps_abstract_2001.pdf>. Accessed 2015 Jan 12.

Roorcroft A, Oosterhuis J. 2001. Foot care for captive elephants. In: Csuti B, Sargent EL, Bechert US, editors. The elephant's foot: Prevention and care of foot conditions in captive Asian and African elephants. Ames: Iowa State University Press. pp 21-52. 
Rothwell ES, Bercovitch FB, Andrews JR, Anderson MJ. 2011. Estimating daily walking distance of captive African elephants using an accelerometer. Zoo Biol 30(5):579-591.

Rowell Z. 2014. Locomotion in captive Asian elephants (Elephas maximus). Journal of Zoo and Aquarium Research 2(4):130-135.

Rushen J, Haley D, de Passillé AM. 2007. Effect of softer flooring in tie stalls on resting behavior and leg injuries of lactating cows. J Dairy Sci 90:3647-3651.

Rushen, J, Chapinal N, De Passillé AM. 2012. Automated monitoring of behaviouralbased animal welfare indicators. Anim Welf 21:339-350.

Rutter SM, Beresford NA, Roberts G. 1997. Use of GPS to identify the grazing areas of hill sheep. Comput Electron Agric 17:177-188.

Ryan PG, Petersen SL, Peters G, Grémillet D. 2004. GPS tracking a marine predator: The effects of precision, resolution and sampling rate on foraging tracks of African Penguins. J Mar Biol 145:215-223.

Sager-Fradkin KA, Jenkins KJ, Hoffman RA, Happe PJ, Beecham JJ, Wright RG. 2007. Fix success and accuracy of global positioning system collars in old-growth temperate coniferous forests. J Wildl Manage 71:1298-1308.

Schofield G, Bishop CM, MacLean G, Brown P, Baker M, Katselidis KA, Dimopoulos P, Pantis JD, Hays GC. 2007. Novel GPS tracking of sea turtles as a tool for conservation management. J Exp Mar Biol Ecol 347:58-68.

Schulte BA, Feldman E, Lambert R, Oliver R, Hess DL. 2000. Temporary ovarian inactivity in elephants: Relationship to status and time outside. Physiol \& Behav 71(12):123-131.

Sellers WI, Crompton RH. 2004. Automatic monitoring of primate locomotor behaviour using accelerometers. Folia Primatol 75:279-293.

Shepherdson DJ. 1999. Environmental enrichment for elephants: current status and future directions. Journal of the Elephant Managers Association 10:68-77.

Shepherdson DJ, Carlstead K, Mellen JD, Seidensticker J. 1993. The influence of food presentation on the behavior of small cats in confined environments. Zoo Biol 12:203216. 
Shepherdson D, Lewis KD, Carlstead K, Bauman J, Perrin N. 2013. Individual and environmental factors associated with stereotypic behavior and fecal glucocorticoid metabolite levels in zoo housed polar bears. Appl Anim Behav Sci. 147(3-4):268-277.

Siegel, J M. 2009. Sleep viewed as a state of adaptive inactivity. Nat Rev Neurosci 10(10):747-753.

Sikes SK. 1971. The natural history of the African elephant. London: Weidenfeld and Nicolson. 397 p.

Soltis J, Wilson RP, Douglas-Hamilton I, Vollrath F, King L, Savage A. 2012. Accelerometers in collars identify behavioral states in captive African elephants Loxodonta africana. Endang Species Res 18:255-263.

Soulsby KS. 2013. Use of a tri-axial accelerometer, behavioral observation, and GPS to monitor the activity of female Asian elephants in a zoo. Master's thesis. Arlington (TX): The University of Texas at Arlington. 77 p.

Spinage CA. 1994. Elephants. London: T \& A D Poyser. 319 p.

Stokke S, du Toit JT. 2002. Sexual segregation in habitat use by elephants in Chobe National Park, Botswana. Afr J Ecol 40:360-371.

Sukumar R. 2003. The living elephants: evolutionary ecology, behavior, and conservation. New York: Oxford University Press. 496 p.

Swaisgood RR, Shepherdson DJ. 2005. Scientific approaches to enrichment and stereotypies in zoo animals: What's been done and where should we go next? Zoo Biol 24(6):499.

Takahashi M, Tobey JR, Pisacane CB, Andrus CH. 2009. Evaluating the utility of an accelerometer and urinary hormone analysis as indicators of estrus in a Zoo-housed koala (Phascolarctos cinereus). Zoo Biol 28:59-68.

Thomas B, Holland JD, Minot EO. 2008. Elephant (Loxodonta africana) home ranges in Sabi Sand Reserve and Kruger National Park: A five-year satellite tracking study. PLoS ONE 3(12): e3902.

Tobler I. 1992. Behavioral sleep in the Asian elephant in captivity. Sleep 15:1-12.

Tobler I. 1995. Is sleep fundamentally different between mammalian species? Behav Brain Res 69:35-41. 
Toth LA. 1995. Sleep, sleep deprivation and infectious disease: Studies in animals. Adv Neuroimmunol 5:79-92.

Townsend B, Fenton P. 1994. A practical approach to the reduction of pseudorange multipath errors in a L1 GPS receiver. In: Proceedings of the 7th International Technical Meeting of the Satellite Division of the Institute of Navigation (ION GPS-94). Salt Lake City. p 143-148.

Tucker CB, Weary DM, Fraser D. 2004. Free-stall dimensions: Effects on preference and stall usage. J Dairy Sci 87:1208-1216.

Turner LW, Udal MC, Larson BT, Shearer SA. 2000. Monitoring cattle behavior and pasture use with GPS and GIS. Can J Anim Sci 80(3):405-413.

Uno H, Tamada K, Hirakawa H, Akamatsu R. 2002. Evaluation of observation rate and positional accuracy for GPS telemetry systems. Honyurui Kagaku (Mammalian Science) 42:129-137 (Japanese with English abstract).

USNO. 2015. U.S. Naval Observatory: NAVSTAR Global Positioning System information. <http://www.usno.navy.mil/USNO/time/gps/gps-info>. Accessed 2015 Jan 06.

van Gils JA, Munster VJ, Radersma R, Liefhebber D, Fouchier RAM, Klaassen M. 2007. Hampered foraging and migratory performance in swans infected with low-pathogenic avian influenza A virus. PLoS ONE 2(1):e184.

Veasey JS, Waran NK, Young RJ. 1996. On comparing the behaviour of zoo housed animal with wild conspecifics as a welfare indicator. Anim Welf 5:13-24.

Veasey J. 2006. Concepts in the care and welfare of captive elephants. Int Zoo Yearb 40:63-79.

Viljoen JJ, Ganswindt A, du Toit JT, LangbauerWR. 2008. Tranlocation stress and faecal glucocorticoid metabolite levels in free-ranging African savannah elephants. S Afr J Wild Res 38:146-152.

Wall J, Douglas-Hamilton I, Vollrath F. 2006. Elephants avoid costly mountaineering. Current Biology 16:527-529.

Weill LR. 1997. Conquering multipath: The GPS accuracy battle. GPS World 8(4):59-66.

Weill LR. 2002. Multipath mitigation using modernized GPS signals: how good can it get? In: Proceedings of the 15th International Technical Meeting of the Satellite Division 
of The Institute of Navigation (ION GPS 2002). Portland (OR). 2002 Sep 24-27. p 493505.

Weir JS. 1969. Chemical properties and occurrence on Kalahari sand of salt licks created by elephants. J Zool 158:293-310.

Weir JS. 1972. Spatial distribution of elephants in an African National Park in relation to environmental sodium. Oikos 23:1-13.

Weisz I, Wuestenhagen A, Schwammer H. 2000. Research on nocturnal behaviour of African elephants at Schönbrunn Zoo. International Zoo News 47:228-233. <http://www.izn.org.uk/Archive/301/IZN-301.htm>. Accessed 2014-08-12.

West G. 2001. Occurrence and treatement of nail/foot abscesses, nail cracks, and sole abscesses in captive elephants. In: Csuti B, Sargent EL, Bechert US, editors. The elephant's foot: Prevention and care of foot conditions in captive Asian and African elephants. Ames: Iowa State University Press. pp 93-98.

Whitham JC, Wielebnowski N. 2013. New directions for zoo animal welfare science. Appl Anim Behav Sci 147:247-260.

Wielebnowski NC, Fletchall N, Carlstead K, Busso JM, Brown JL. 2002. Noninvasive assessment of adrenal activity associated with husbandry and behavioral factors in the North American clouded leopard population. Zoo Biol 21(1):77-98.

Wilson ML, Bashaw MJ, Fountain K, Kieschnick S, Maple TL. 2006. Nocturnal behavior in a group of female African elephants. Zoo Biol 25:173-186.

Wilson RP, Wilson M-PT. 1989. A peck activity record for birds fitted with devices. J Field Ornithol 60(1):104-108.

Wilson RP, McMahon CR. 2006. Measuring devices on wild animals: What constitutes acceptable practice? Front Ecol Environ 4:147-154.

Witte TH, Wilson AM. 2005. Accuracy of WAAS-enabled GPS for the determination of position and speed over ground. Journal of Biomechanics 38(8):1717-1722.

Wittemyer G, Douglas-Hamilton I, Getz WM. 2005. The socioecology of elephants: analysis of the processes creating multitiered social structures. Anim Behav 69:13571371.

Wyatt JR, Eltringham SK. 1974. The daily activity of the elephant in the Rwenzori National Park, Uganda. Afr J Ecol 12:273-289. 
Yeates JW, Main DCJ. 2008. Assessment of positive welfare: A review. The Veterinary Journal 175 (3):293-300.

Young RJ. 2003. Environmental Enrichment for Captive Animals. Oxford: Blackwell Science. 228 p. 